\title{
评述
}

\section{海基合成燃油系统关键单元的热力学分析与优化 研究进展}

陈林根 ${ }^{1,2^{*}}$, 王超 ${ }^{3}, 弓$ 否 $^{4}$, 夏少军 $^{3 *}$

1. 武汉工程大学热科学与动力工程研究所, 武汉 430205;

2. 武汉工程大学机电工程学院, 武汉 430205;

3. 海军工程大学动力工程学院, 武汉 430033;

4. 91388 部队, 湛江 524022

*E-mail: lgchenna@yahoo.com; lingenchen@hotmail.com; 398843013@qq.com

收稿日期: 2020-03-01; 接受日期: 2020-04-30; 网络版发表日期: 2020-07-27

国家自然科学基金(批准号: 51976235, 51576207, 51606218)资助项目

摘要本文在简要回顾化学反应过程有限时间热力学研究的基础上, 从海基合成燃油系统的碳、氢源捕获子系 统各单元(包括电化学海水酸化单元, 酸化海水 $\mathrm{CO}_{2}$ 捕集单元, 氢气 $\left(\mathrm{H}_{2}\right)$ 获取单元)、燃料催化合成子系统各单元 (包括“长链烃裂解”合成燃油技术路径中逆水气变换单元反应器、费托合成单元反应器, “短链烃聚合”合成燃油 技术路径中 $\mathrm{CO}_{2}$ 氢化合成低碳烯烃单元反应器、烯烃齐聚单元反应器)性能研究方面介绍了其热力学分析与优化 研究进展. 研究工作结合热力学、传热学、流体力学、化学反应动力学、最优控制理论和多目标优化方法, 建立 模型, 优化性能, 探索海基合成燃油系统关键单元的热设计与优化问题. 由浅入深, 从建立热源温度完全可控的一 维活塞流反应器模型到建立考虑真实热源载热工质的二维拟均相反应器模型; 由可逆模型到不可逆模型, 从建立 经典平衡态热力学模型到建立考虑多种不可逆因素的有限时间热力学模型; 由单目标优化到多目标优化, 从熵产 生率最小和比摘产生率(对目标产物产率平均的熵产生率) 最小的单目标优化到综合考虑目标产物产率最大和熵 产生率最小、出口平均转化率最高和最大径向温差最小的多目标优化. 本文取得了一些具有重要理论意义和实 用价值的研究成果, 可为海基合成燃油系统的设计与优化提供科学依据和理论指导. 下一步的发展方向是实现两 个子系统和全系统与关键单元集成的构形热力学优化.

关键词 有限时间热力学, 广义热力学优化理论, 最优控制, 海基合成燃油系统, 化学反应过程, 熵产率, 产率, 多 目标优化

1 引言

海基合成燃油技术，是指首先利用电化学技术从
海水中获取碳源 $\left(\mathrm{CO}_{2}\right)$ 和氢源 $\left(\mathrm{H}_{2}\right)$, 随后将其通过催化 反应过程合成燃油的新技术 ${ }^{[1 \sim 5]}$. 海基合成燃油技术在 实现工程化应用后，将从根本上提升海军的远洋作战

引用格式: 陈林根, 王超, 张否, 等. 海基合成燃油系统关键单元的热力学分析与优化研究进展. 中国科学: 技术科学, 2021, 51: 137-175

Chen L G, Wang C, Zhang L, et al. Progress in thermodynamic analyses and optimizations for key component units in sea-based fuel synthesis systems (in Chinese). Sci Sin Tech, 2021, 51: 137-175, doi: 10.1360/SST-2020-0067 
能力, 是一项改变未来战争规则的前沿颠覆性技术. 另 一方面，该项技术在民用领域为燃油和化工产品的合 成提供了一条非石油合成路径 ${ }^{[6]}$, 可将温室气体 $\mathrm{CO}_{2}$ 转化为无硫、无氮的清洁燃料和高附加值的化学产 品, 是一种重要的热化学储能方式. 该技术若能在民用 储能和可再生能源领域得到转化，不仅能够缓解海水 酸化和气候变化等环境危机，还能拓展我国可再生能 源的供应渠道, 符合“军民融合”的战略思想.

海基合成燃油系统主要包括碳、氢源捕获子系统 和燃料催化合成子系统两大模块, 如图1所示. 碳、氢 源捕获子系统可分为碳源捕获子系统和氢源捕获子系 统两部分, 其中, 碳源捕获子系统还可进一步细分为电 化学海水酸化单元模块和酸化海水 $\mathrm{CO}_{2}$ 捕集单元模块. 电化学海水酸化单元模块主要是通过电化学的方法使 海水的 $\mathrm{pH}$ 降低到 6.0 以下, 这样海水中的碳元素将主要 以碳酸 $\left(\mathrm{H}_{2} \mathrm{CO}_{3}\right)$ 形式存在, 为后续环节从酸化海水中高 效提取 $\mathrm{CO}_{2}$ 创造必要的前提条件, 同时还可得到部分 $\mathrm{H}_{2}$; 酸化海水 $\mathrm{CO}_{2}$ 捕集单元模块主要通过膜分离方法 脱出酸化海水中溶解的 $\mathrm{CO}_{2}$, 为后续催化合成燃油过 程直接提供碳源. 氢源捕获子系统主要目的是制取 $\mathrm{H}_{2}$, 为后续催化合成燃油过程提供氢源, 前述电化学海水 酸化单元模块所得 $\mathrm{H}_{2}$ 不足以支撑后续燃油合成需要.
由于海基燃油合成系统目标使用场景多为核能场景, 故相比于传统水电解制氢，使用热化学硫碘循环制 氢 $^{[7 \sim 10]}$ 可以直接将核能废热转换为氢能，在能量转换 环节上更有优势，同时具有高效无污染的优点，使燃 油合成所需氢源得到充分保障，故海基燃油合成系统 氢源捕获子系统选取热化学硫碘循环制氢. 而燃料催 化合成子系统根据催化体系、中间产物和反应工艺的 不同，主要可通过“长链烃裂解”和“短链烃聚合”两种 技术路径实现催化合成燃油. “长链烃裂解”技术路径, 即 $\mathrm{CO}_{2}$ 和 $\mathrm{H}_{2}$ 首先经逆水气变换(reverse water gas shift, RWGS $)$ 反应制取合成气 $\left(\mathrm{CO}+\mathrm{H}_{2}\right)$ ，随后合成气通过选 择性费托(Fischer-Tropsch，FT) 合成反应合成 $\mathrm{C}_{9} \sim \mathrm{C}_{16}$ 的 目标燃油; “短链烃聚合”技术路径，即 $\mathrm{CO}_{2}$ 和 $\mathrm{H}_{2}$ 首先在 铁基催化剂的作用下转化为以短链烃等为主的不饱和 烃类, 然后在镍基催化剂的作用下进行齐聚反应合成目 标燃油. 两种合成燃油技术路径都包含两个基本单元反 应, 均是以 $\mathrm{CO}_{2}$ 和 $\mathrm{H}_{2}$ 为原料, 以高收率、低能耗地合成 $\mathrm{C}_{9} \sim \mathrm{C}_{16}$ 燃油为目标. 两条技术路径中的基本单元反应在 反应特性、热力学性能和优化潜力上存在较大差异, 且均面临着目标产物产率低和能耗高的瓶颈问题 ${ }^{[5,11]}$.

海基合成燃油系统在物理本质上是由传热、传 质、流体流动和电荷传输等各类能量传递与转换过程

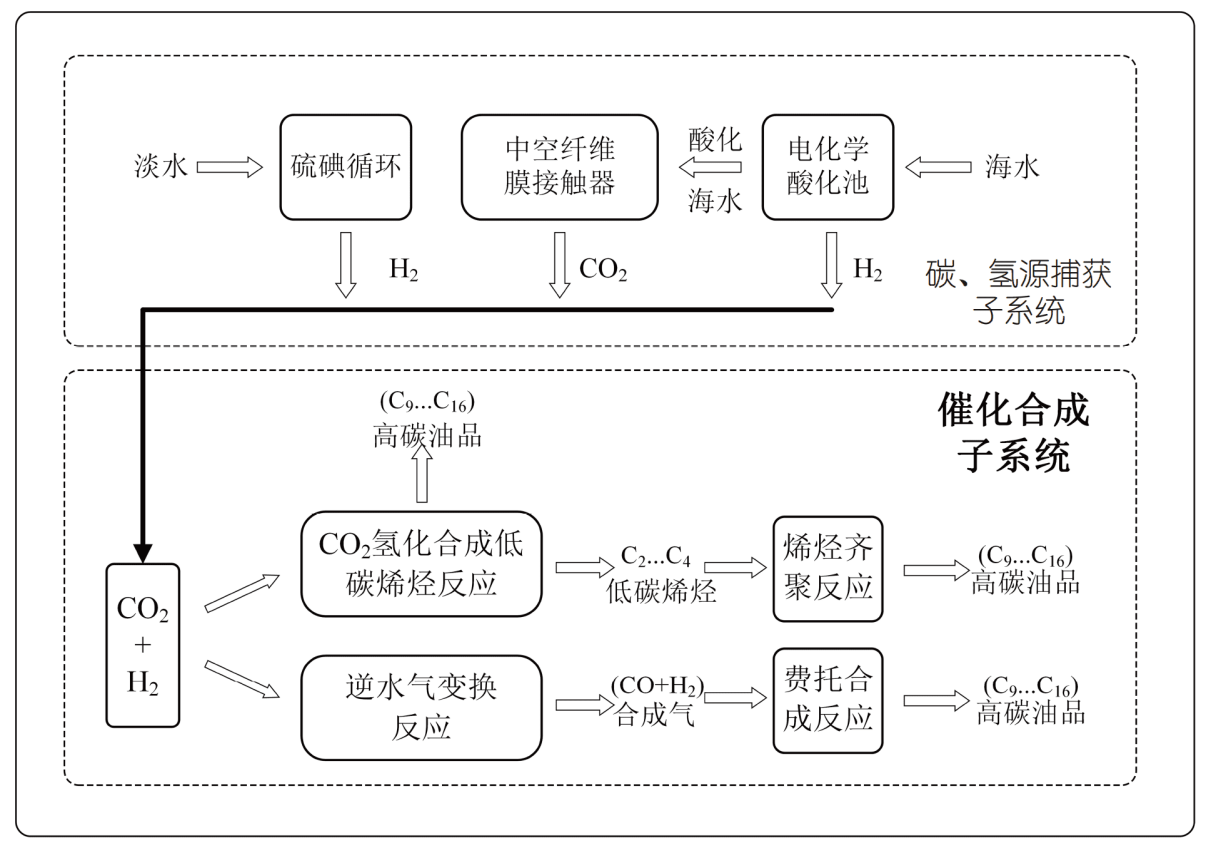

图 1 海基合成燃油系统示意图

Figure 1 Schematic diagram of the sea-based fuel synthesis system. 
相互耦合、相互影响的复杂生产流程. 因此, 如何基于 系统中各单元过程的主要特征, 建立起描述过程物理 化学机理的合适数学模型, 以提高燃油产率和降低系 统能耗为目标, 获得各单元反应过程路径和两个子系 统在不同性能目标下的热设计和运行方案，是迫切需 要解决的关键科技问题之一, 亟需开展相关应用基础 研究以提供理论支撑.

“有限时间热力学”(finite time thermodynamics, FTT)或“熵产生最小化”理论是20世纪70年代中期诞生 并兴起的一个现代热力学分支，它将热力学、传热 学、流体力学和化学反应动力学等基础学科相结合, 考虑被经典平衡态热力学所忽略的“时间”或“速率”因 素, 在“有限时间”或“有限尺寸”的约束下, 求解存在有 限温差传热、有限压差流体流动和有限速率化学反应 等不可逆性的过程、循环和装置在不同优化目标时的 目标极值(最优性能)或所取目标为极值时的最优热力 过程(最优构型), 所得到的理论结果对指导相应实际 过程和工程装置的最优设计具有重要意义. 显然, 将 FTT理论应用于海基合成燃油系统和各单元部件的热 力学分析与优化, 对提高系统燃油产率、降低过程能 耗具有重要意义. 本文首先将对海基合成燃油技术中 涉及的主要单元反应的相关研究现状作简要回顾，然 后对化学反应过程FTT研究现状作简要回顾, 接着对 海基合成燃油技术的FTT优化研究现状进行系统介绍, 最后指出下一步的研究发展方向.

\section{2 海基合成燃油技术总体研究现状}

在国外, 海基合成燃油技术主要是由美国海军投 资 $^{[1,12]}$, 美国海军研究实验室(Naval Research Laboratory, NRL)的Willauer领导的研究团队承研. 该团队对 海基合成燃油系统及其子系统进行了技术攻关，经过 十多年的研究, NRL分别对电化学海水酸化过 程 ${ }^{[13 \sim 22]}$ 、酸化海水 $\mathrm{CO}_{2}$ 捕集过程 ${ }^{[23 \sim 25]}$ 和催化合成过 程 ${ }^{[26-36]}$ 开展了研究, 并从能量平衡和经济成本方面对 该技术进行了可行性分析 ${ }^{[37-40]}$. 根据前期的研究成果, NRL在现有工程技术的基础上成功研制了一套海基合 成燃油系统原理样机, 在实验室状态下合成了与舰载 机燃油成分类似的液态燃油，并在2014年4月利用该 燃油开展了P-51野马战斗机航模飞行试验，在实验室 条件下证明了该技术的可行性. 其他研究团队有Pat- terson等人 ${ }^{[41]}$ 和de Lannoy等人 ${ }^{[42]}$ 研究了以纯气体和固 体矿物等不同形式捕获海水中 $\mathrm{CO}_{2}$, 分析了降低合成 燃料总体成本的技术创新和优化研究方向. 但目前的 技术手段还不具备工业规模生产燃油的能力，氢、碳 源捕获子系统和催化合成子系统也未真正意义上实现 高度集成, 还需要进一步进行过程优化和升级.

在国内, 相关单位针对海基合成燃油技术开展了 专门研究, 中国科学院大连化学物理研究所 ${ }^{[43-46]}$ 和中 国船舶重工集团公司第七一八研究所 ${ }^{[47 ~ 50]}$ 分别基于 “短链烃聚合”和“长链烃裂解”两条不同技术路径开展 了各子系统原理技术研究, 并致力于开发出各单元功 能原理样机.

上述海基合成燃油技术研究内容主要是从工程角 度利用经典平衡态热力学和经济学原理证明技术研发 的可行性, 对反应过程性能及其影响因素分析也主要 是在实验室条件下通过纯动力学实验方法加以研究, 侧重于开发出合适的催化剂体系和各模块单元的原理 样机, 对海基合成燃油技术的发展具有十分重要的意 义. 然而，在海基合成燃油技术未来实现工程应用前， 仍然会面临系统能耗高和燃油产率低的技术瓶颈. 由 于前述对海基燃油合成系统及其子系统性能与影响因 素的分析只是通过实验方法加以研究, 公开文献中未 见从过程进行的物理化学机理上进行理论研究的报 道, 无法探索系统性能界限、寻求最佳工作参数. 因 此, 为解决该瓶颈问题, 需要从过程进行的物理化学 机理上解决“海基合成燃油系统性能特性及其影响参 数规律的定量化表征”这一关键问题, 对各模块关键过 程进行定量阐述, 得到其最优性能, 在此基础上对系统 流程进行优化, 以得到降低系统能耗、提高产率的有 效途径. 本文作者所在研究团队 ${ }^{[51 ~ 75]}$ 从过程进行的物 理化学机理角度对海基合成燃油系统各单元模块的关 键过程环节和子系统整体进行了热力学建模分析和综 合优化研究, 详见本文第4节和第5节.

\section{3 化学反应过程有限时间热力学相关研究 现状简介}

\section{1 有限时间热力学研究概述}

以寻求热机热功转换最高效率为目标, 法国工程 师Carnot ${ }^{[76]}$ 于 1824 年导出了著名的卡诺效率 $\left(\eta_{\mathrm{C}}=\right.$ $1-T_{\mathrm{L}} / T_{\mathrm{H}}, T_{\mathrm{H}}$ 和 $T_{\mathrm{L}}$ 分别为高温热源和低温热源温度), 但 
为达到这一效率界限, 热机必须以可逆的方式运行, 即 运行周期无限长, 功率输出为零. 而实际的热力循环和 工程装置运行过程均是在有限时间约束下的不可逆过 程, 因此, 考虑过程有限时间或装置有限尺寸约束的性 能界限更适于为实际过程和装置提供理论指导.

为解决考虑不可逆热阻损失条件下热机在最大功 率输出时的效率界限问题, Reitlinger (1929) ${ }^{[77,78]}$, Yvon $(1955)^{[79]}$, Novikov $(1957)^{[80]}$, Chambadal $(1957)^{[81]}$, Curzon和Alborn (1975) ${ }^{[82]}$ 相继于不同时期导出了著名 的 $\mathrm{CA}$ 效率 $\eta_{\mathrm{CA}}=1-\sqrt{T_{\mathrm{L}} / T_{\mathrm{H}}}, \mathrm{CA}$ 效率的诞生激励着一 大批物理学家和工程学家对考虑各种不可逆因素的实 际热力系统和装置开展热力学优化研究, 由此诞生了 “有限时间热力学”, 它以降低系统不可逆性为目标, 将热力学、传热学、流体力学和化学反应动力学等基 础学科相结合, 考虑了实际不可逆过程的“时间”或“速 率”概念，侧重从过程“机理”角度对各类热力过程和工 程装置进行优化研究 ${ }^{[83-98]}$. 随着理论的发展, FTT的内 涵得到了进一步的深化，任何在有限势差或有限尺寸 约束下发生的不可逆输运过程、装置和系统，均可使 用FTT理论进行优化; 在优化目标上不限于功率最大 和熵产生率最小, 任何有实际物理意义的函数均可作 为优化目标加以研究. 根据待优化问题的具体数学形 式和优化方法, 可将FTT的主要研究内容分为求解给 定过程的目标极值(简称为最优性能, 在数学上属于静 态优化问题)和所取目标为极值时的最优路径(简称为 最优构型, 在数学上属于动态优化问题)两类. 经过 40 多年的不断革新和发展, FTT在研究方法上, 可将其与 场协同理论、积理论和广义热力学优化理论等现代热 学优化理论进行有机结合; 在研究对象上, 从传统的热 机、热洜、制冷机和传热、传质过程拓展到了布朗马 达、量子热机、电子机、热离子装置等微观能量转换 系统和化学反应过程、燃料电池、钢铁生产工序和流 程等复杂实际过程和系统, 得到了大量既具有理论意义 又具有工程应用价值的新结论、新规律。近年来该理 论的主要进展详见最近发表的一些综述文献 ${ }^{[99 ~ 107]}$.

化学反应是工业上进行能量储存、转换与利用的 重要环节, 应用FTT理论开展化学反应过程优化对提 高工业设备的能源利用率具有重要意义. 按研究对象, 化学反应过程的FTT研究分为理论化学反应过程优化 和工业反应器优化.

\section{2 理论化学反应过程优化}

理论化学反应并不特指某一个具体化学反应，而 是对工业上具有共性的真实化学反应进行抽象而得到 的理论模型. 对理论化学反应过程的优化研究是理解 和研究真实化学反应过程的基础.

Ondrechen等人 ${ }^{[108,109]}$ 和陈林根等人 ${ }^{[110]}$ 考虑了化 学反应和耦合热机的有限时间特性, 对化学反应驱动 热机进行了功率最大优化. 张否等人 ${ }^{[111,112]}$ 在文献 [108 110]的基础上, 结合概率理论 ${ }^{[113,114]}$ 对化学反应 驱动双卡诺热机模型进行了功率最大化研究, 得到了 工作在有限高温热源条件下耦合热机的最优功率及其 概率分布. De $\operatorname{Vos}^{[115]}$ 首先将内可逆热机的研究思路拓 展到对化学反应过程的有限时间热力学研究中, 考虑 库与工质间的传热与传质损失, 建立了一类内可逆化 学机模型. Gordon ${ }^{[116]}$ 建立了等温内可逆化学机模型, 研究了无限和有限化学势库传质条件下的化学机最大 功率输出问题. 陈林根等人 ${ }^{[117 ~ 120]}$ 建立了单级 ${ }^{[117,119]}$ 和 联合循环等温化学机 ${ }^{[118,119]}$ 的不可逆模型, 得到了功率 和效率的基本优化关系，并分析了质漏对系统最优性 能的影响 ${ }^{[119,120]}$. 夏丹等人 ${ }^{[121 ~ 124]}$ 系统地研究了扩散和 线性两类传质规律下的内可逆、不可逆和广义不可逆 等温化学机的最优性能问题, 并以生态学函数为目标 对系统进行了优化 ${ }^{[122 ~ 124]}$. 夏少军等人 ${ }^{[125 ~ 127]}$ 进一步 对化学机的功率输出最大化最优构型问题进行了研 究, 包括多库单级等温化学机 ${ }^{[125]}$ 、有限势库单级等温 化学机 ${ }^{[126]}$ 、有限势库多级等温化学机系统 ${ }^{[127]}$ 模型. Ocampo-García等人 ${ }^{[128]}$ 对内可逆等温化学机进行了热 经济性分析, 得到了内可逆等温化学机在最大功率、 最大生态学函数和最大效率功率运行状态下的热经济 性能. Watowich和Berry ${ }^{[129]}$ 将FTT理论和最优控制理论 相结合, 导出了一类简单电化学系统 $\mathrm{A}+\mathrm{B} \Leftrightarrow \mathrm{X}+\mathrm{Y}$ 最大 输出功和最大利润时的电流最优路径. Schön和Andre$\operatorname{sen}^{[130]}$ 在给定时间约束下, 对间歇反应器中的 $n \mathrm{~A} \Leftrightarrow m \mathrm{~B}$ 型化学反应进行了产率最大化研究, 得到了最优的反 应体积和温度最优构型. Bak等人 ${ }^{[131]}$ 和陈林根等人 ${ }^{[132]}$ 以反应温度为控制变量, 分别对简单的连续化学反应 $\mathrm{A} \Leftrightarrow \mathrm{B} \Leftrightarrow \mathrm{C}^{[131]}$ 和考虑反应级数影响的一般连续化学反 应 $x \mathrm{~A} \Leftrightarrow y \mathrm{~B} \Leftrightarrow z \mathrm{C}^{[132]}$ 进行了动态优化, 得到了中间产物 $\mathrm{B}$ 产率最大时对应的最优反应过程路径. 熵产生(率)是 过程不可逆性的直接度量 ${ }^{[133,134]}$. 王超等人 ${ }^{[135]}$ 使用非 
线性规划数值方法对连续化学反应过程 $\mathrm{A} \Leftrightarrow \mathrm{B} \Leftrightarrow \mathrm{C}$ 进行 了熵产生最小优化, 得到了过程摘产生最小时的最优 浓度构型. Lems等人 ${ }^{[136]}$ 和Sánchez-Salas等人 ${ }^{[137]}$ 类比 热机、热百的有限时间热力学研究思路, 对(生物)化 学反应系统的能量传递过程进行了研究, 得到了系统 最大输出功率、最小熵产生率的热力学性能最优运行 区间. Tsirlin等人 ${ }^{[138,139]}$ 分别对间歇式反应器(等温等容 条件 $)^{[138]}$ 和管式反应器 (均相变温条件) 中的 $\sum_{i=1}^{j} \alpha_{i} N_{i} \rightleftharpoons \sum_{i=j+1}^{m} \alpha_{i} N_{i}$ 型反应 $^{[139]}$ 进行了熵产生最小 优化, 得到了反应器的热力学可行域. 夏少军等人 ${ }^{[140]}$ 得到了一类普适电化学反应系统的最优电流路径.

\section{3 工业反应器优化}

工业反应器是化工流程和系统中的基本反应单 元, 对化工流程的设计和运行有直接的影响, 也是整个 工艺流程性质的决定性因素. 因此, 在对化工流程进行 设计与优化前, 可首先对其中的关键反应器单元开展 综合优化研究.

工业反应器在物理本质上是一类耦合了多种传输 现象的复杂能量转换系统, 不同的工业反应器在反应 器构型、反应条件和优化策略上均有所不同, 需要根 据给定的技术、经济指标开展特定研究. 对单独的传 热、传质和化学反应过程进行优化得到的最优热力学 优化准则是否适用于复杂的工业化学反应过程? 各种 优化目标下的最优反应路径是否具有共性? 最优反应 路径在工业上如何实现? 一些学者对多种工业反应器 进行了优化研究.

在产率最大化研究方面, Måansson和Andresen ${ }^{[141]}$ 首次使用FTT理论对工业管式活塞流反应器中的合成 氨反应进行了产率最大优化，得到了管内混合物温度 的最优构型，在优化过程中使用了贝蒂-布里奇曼 (Beattie-Brudgeman)真实气体状态方程对反应混合物 状态进行描述. Piña等人 ${ }^{[142]}$ 在给定总传热流率、最大 管壁温度的约束下，求解了甲烷水蒸气重整(steam methane reforming, SMR)反应器在转化率最大时所对 应的管壁热源温度分布, 并分析了析碳反应 ${ }^{[143]}$ 对反应 器性能的影响. Pantoleontos等人 ${ }^{[144]}$ 对SMR反应进行 了研究, 以 $\mathrm{H}_{2}$ 产率最大为优化目标, 对随反应器轴向 位置呈二次变化的管外热源温度曲线 $\left(T_{\mathrm{a}}=A+B z+C z^{2}\right)$ 进行了优化. 李鹏蕾等人 ${ }^{[145 \sim 148]}$ 假设管外热源温度完
全可控，以管外热源温度为控制变量分别对SMR反应 器 ${ }^{[145,146]}$ 和 $\mathrm{CO}_{2}$ 加氢合成甲醇反应器 ${ }^{[147,148]}$ 进行了 $\mathrm{H}_{2}$ 产 率和甲醇收率最大化研究, 并分析了反应混合物进口 温度、进口压力等因素对管外热源温度最优构型的影 响规律 ${ }^{[145,146]}$.

在熵产生率最小化研究方面, Kjelstrup等人 ${ }^{[149]}$ 以 化学反应过程熵产生率最小为优化目标，在甲醇产率 一定的约束条件下对 $\mathrm{CO}_{2}$ 加氢合成甲醇反应进行了优 化，但在优化过程中未考虑动量、质量和能量守恒方 程约束. 李鹏蕾等人 ${ }^{[150 ~ 152]}$ 在文献[149]的基础上，考 虑以传热、黏性流动和化学反应过程总熵产生率最小 为优化目标对 $\mathrm{CO}_{2}$ 合成甲醇反应器进行了动态优化, 结果表明优化后可使总熵产生率降低了 $20.5 \%$. Nummedal等人 ${ }^{[153,154]}$ 改进了文献[149]的数值优化方法，在 考虑守恒方程约束的条件下，使用非线性规划方法分 别对管式活塞流反应器中的合成氨反应 ${ }^{[153]}$ 和SMR反 应 $^{[154]}$ 进行了熵产生率最小优化, 得到了管外热源温度 的最优分布曲线 (传热过程符合牛顿传热规律 $[q \propto(\Delta T)])$, 数值优化结果表明: 最优反应器存在恒定 的热驱动力或恒定的化学反应驱动力中间段区域. Johannessen和Kjelstrup ${ }^{[155]}$ 建立了管式活塞流反应器商 产生率最小优化问题的最优控制数学模型, 并以 $\mathrm{SO}_{2}$ 氧化反应为例进行了数值计算, 通过大量的数值算例 总结出反应器在熵产生率最小时的共性特征：反应器 最优构型存在符合驱动力均分和摘产生均分原则的子 区间，子区间的范围随优化自由度的增大而增大 ${ }^{[156]}$. 基于文献[155]的最优控制数学模型，van der Ham等

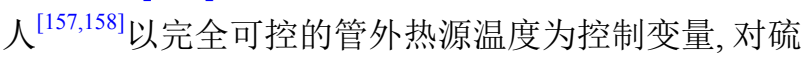
酸分解反应器进行了熵产生率最小优化，得到了匹配 假想高温热源最优分布的氦气流率分布规律，并根据 熵产生率最小的优化结果提出了一种全新的硫酸分解 流程和两种评判反应器性能优劣的指标. Wilhelmsen 等人 ${ }^{[159]}$ 考虑传热规律符合对流-辐射传热规律 $\left[q \propto(\Delta T)+\Delta\left(T^{4}\right)\right]$, 对SMR反应器进行了熵产生率最小 化研究, 根据反应最优构型提出了两种提高反应器效 率的最优设计方案, 并分析了反应器结构参数对比熵 产生率的影响规律. 敖晨阳等人 ${ }^{[160]}$ 和陈庆晓等人 ${ }^{[161]}$ 考虑了传热规律的影响，分别基于线性唯象传热规律 $\left[q \propto\left(\Delta T^{-1}\right)\right]^{[160]}$ 和Dulong-Peitit传热规律 $\left[q \propto\left(\Delta T^{1.25}\right)\right]^{[161]}$, 研究了管式反应器中的SMR反应制氢过程熵产生率 最小化，并与文献[153]的优化结果进行了对比分析. 
Kingston和Razzitte ${ }^{[162,163]}$ 以总熵产生率最小为优化目 标, 对包含反应器单元、压缩机单元和换热器单元的 反应系统进行了优化研究, 得到了最佳的单元布置方 案 ${ }^{[162]}$, 并对甲醇合成二甲醚反应进行了最优性能研 究 ${ }^{[163]}$. 曹刚等人 ${ }^{[164]}$ 以熵产生率和比摘产生率为目标, 分析了运行条件对光生物反应器性能的影响规律. 曹 雪普等人 ${ }^{[165]}$ 以一级不可逆反应为对象, 研究了不同传 输过程熵产生率在不同权重配比条件下的多目标优化 问题, 得到了强化化学反应条件下的最优速度场分布.

除了考察装置是否高产和节能以外，如何获取最 大的经济利润也是研究人员关心的重点因素之一. Szwast和Sieniutycz ${ }^{[166 \sim 168]}$ 以利润输出率最大为优化目 标, 考虑催化剂失活 ${ }^{[166]}$ 和再生效应 ${ }^{[166,167]}$ 的影响, 分别 在稳态运行 ${ }^{[166,167]}$ 和非稳态运行 ${ }^{[168]}$ 条件下对管式循环 床反应器中的平行串联反应 $(A+B \rightarrow R, R+B \rightarrow S, R$ 为目 标产物)进行了优化, 得到了反应温度的最优构型. Frolov等人 ${ }^{[169]}$ 建立了管式反应器催化合成一甲基苯胺的 数学模型, 以产品成本最小为优化目标, 得到了反应温 度的最优构型.

\section{4 碳、氢源捕获子系统关键单元热力学分 析与优化研究进展}

海基合成燃油技术在物理本质上是一类传热、传 质、流体流动和化学反应相互耦合的复杂传输过程, 使用FTT理论的研究思路对海基合成燃油系统中主要 的单元模块和子系统整体过程进行热力学分析与优 化, 能得到一些不同于经典热力学、纯反应动力学实 验研究的新结果和新现象.

在氢、碳源捕获子系统模块研究方面，王超等 人 $^{[61,66]}$ 基于灰色系统理论对电化学酸化池中降低海水 $\mathrm{pH}$ 的非稳态过程进行了建模和性能分析研究, 在NRL 公开的实验数据基础上对半经验模型公式参数进行了 拟合，并分析了恒定电流和恒定电压工况下电化学酸 化池的耗功特性. 陈林根等人 ${ }^{[62]}$ 和王超等人 ${ }^{[52,56,66]}$ 建 立了使用中空纤维膜接触器脱除酸化海水中 $\mathrm{CO}_{2}$ 过程 的有限时间热力学模型, 分别研究了操作和结构参数 对 $\mathrm{H}_{2}$ 在膜丝外部吹扫和真空吹扫两种不同条件下装 置的 $\mathrm{CO}_{2}$ 脱出率、熵产生率和耗功率的影响规律, 并 以纯传质过程熵产生率、传质与流动总摘产生率最小 为优化目标对过程进行了优化, 得到了熵产生率最小
时的 $\mathrm{CO}_{2}$ 浓度分布最优构型 ${ }^{[52,56,62,66]}$. 王超等人 ${ }^{[70,72,73]}$ 分别以产率最大 ${ }^{[72]}$ 和比摘产生率最小 ${ }^{[70,73]}$ 为优化目标 对管式活塞流反应器中的硫酸分解过程进行了研究. 孙铭等人 ${ }^{[74]}$ 运用第二代非支配解排序遗传算法 (NSGA-II), 以总熵产生率最小和 $\mathrm{SO}_{2}$ 产率最大为目标, 对硫酸分解过程进行了多目标优化. 孔锐等人 ${ }^{[71]}$ 研究 了碘化氢分解反应器摘产生率最小化问题. 王超 ${ }^{[6]}$ 以 满足催化合成子系统所需的氢碳比例为前提, 将氢、 碳源捕获子系统中的电化学海水酸化单元模块、酸化 海水 $\mathrm{CO}_{2}$ 捕集单元模块、硫碘循环制氢单元模块相串 联, 分析了各单元模块的工作和结构参数对氢、碳源 产量和流程总耗功的影响规律.

\section{1 电化学酸化池降低海水pH过程建模与分析}

电化学海水酸化过程是海基燃油合成系统碳源捕 获子系统的核心环节, 为后续环节从酸化海水中高效 提取 $\mathrm{CO}_{2}$ 创造必要的前提条件, 其工作性能的优劣直 接影响到整个系统的燃油收率和能耗. 电化学海水酸 化单元模块使用电化学酸化池降低海水 $\mathrm{pH}$.

Willauer等人 ${ }^{[17,19]}$ 对Ionpure型电化学酸化池进行 了放大和集成实验，报道了在 4 个独立的评价时间内酸 化池性能的评价结果 ${ }^{[17]}$, 并对降低电极组件的离子交换 容量性能进行了实验研究 ${ }^{[19]}$. 酸化池降低海水 $\mathrm{pH}$ 过程中 氢离子通过离子交换膜从阳极室进入中间腔的传输过 程涉及复杂的电化学和反应动力学, 在缺乏相关信息情 况下, 电化学酸化池可视为信息不完全的灰色系统 ${ }^{[170]}$.

\subsection{1电化学酸化池 $\mathrm{pH}$ 特性}

对文献[19]中使用的改进Ionpure型电化学酸化池 建立其灰色 $\mathrm{GM}(1, N)$ 幕模型及派生模型 $\mathrm{GM}(1, N$, $\left.x^{(1)}\right)^{[171]}$. 研究表明 ${ }^{[61,65,66]}, \operatorname{GM}\left(1, N, x^{(1)}\right)$ 相比 $\operatorname{GM}(1, N)$ 幂模型更适于电化学酸化池降低海水 $\mathrm{pH}$ 过程的模拟, 相应的 $\operatorname{GM}\left(1, N, x^{(1)}\right)$ 幂模型为

$$
\begin{aligned}
\widehat{x}_{1}^{(0)}(k)= & -0.986 \times 10^{4} \times\left(x_{2}^{(1)}(k)\right)^{-0.966} \\
& -0.785 \times 10^{8} \times\left(x_{3}^{(1)}(k)\right)^{-4.001} \\
& +0.581 \times\left(x_{4}^{(1)}(k)\right)^{0.837} \\
& +1.147 \times 10^{4} \times\left(x_{5}^{(1)}(k)\right)^{-2.069} \\
& -1.314 x_{1}^{(1)}(k-1) .
\end{aligned}
$$


两种模型模拟曲线与原始曲线对比 ${ }^{[5]}$ 表明, $\operatorname{GM}(1$, $\left.N, x^{(1)}\right)$ 幂模型模拟曲线与原始曲线基本重合.

经理论推导, 可得电化学酸化池出口海水 $\mathrm{H}^{+}$浓度 变化率为 ${ }^{[66]}$

$$
\begin{aligned}
V_{\mathrm{m}} \eta_{\mathrm{v}} \gamma_{\mathrm{c}} \frac{\mathrm{d} C_{\mathrm{H}^{+}, \text {out }}}{\mathrm{d} t}= & \frac{60 I t^{2}}{F\left(t^{2}-44.34 t+2696.69\right)} \\
& +Q_{\mathrm{m}}\left(C_{\mathrm{H}^{+}, \text {in }}-C_{\mathrm{H}^{+}, \text {out }}\right) \\
& -Q_{\mathrm{m}} C_{\mathrm{T}_{\left[\mathrm{CO}_{2}\right.}{ }} \alpha_{\mathrm{H}_{2} \mathrm{CO}_{3},}
\end{aligned}
$$

式中, $V_{\mathrm{m}}$ 为中间腔的总体积, $\eta_{\mathrm{V}}$ 为中间腔体积效率, $\eta_{\mathrm{V}}<1, \gamma_{\mathrm{c}}=\overline{C_{\mathrm{H}^{+}, V_{\mathrm{m}}}} / \overline{C_{\mathrm{H}^{+}, \text {out }}}$ 为浓度接近系数, $C_{\mathrm{H}^{+}, \text {out }}$ 为出口海水 $\mathrm{H}^{+}$浓度, $C_{\mathrm{H}^{+}, V_{\mathrm{m}}}$ 为中间腔中 $\mathrm{H}^{+}$的平均浓 度, $I$ 为酸化池的工作电流, $F$ 为法拉第常数, $Q_{\mathrm{m}}$ 为海水 体积流率, $C_{\mathrm{H}^{+}, \mathrm{in}}$ 为入口海水中 $\mathrm{H}^{+}$浓度; $C_{\mathrm{T}\left[\mathrm{CO}_{2}\right]}$ 为海水中 总 $\mathrm{CO}_{2}$ 浓度, $\alpha_{\mathrm{H}_{2} \mathrm{CO}_{3}}$ 为海水中碳酸的摩尔分数.

\subsection{2 电化学酸化池电压特性}

电化学酸化池槽电压由理论分解电压、极化过电 位、导体电压降、隔膜电压降和接触电压降 5 个部分 组成. 经理论推导, 可得电化学酸化池槽电压 $V_{\text {cell }}$ 为 ${ }^{[66]}$

$$
\begin{aligned}
V_{\text {cell }}= & V_{\mathrm{de}}+I R_{\mathrm{i}}+\frac{R T}{z_{\mathrm{c}} F} \ln \left(\frac{i_{\mathrm{d}, \mathrm{c}}}{i_{\mathrm{d}, \mathrm{c}}-i}\right)+\frac{R T}{z_{\mathrm{a}} F} \ln \left(\frac{i_{\mathrm{d}, \mathrm{a}}}{i_{\mathrm{d}, \mathrm{a}}-i}\right) \\
& +\frac{R T}{\alpha_{\mathrm{c}} z_{\mathrm{c}} F} \ln \left(\frac{i}{i_{0, \mathrm{c}}}\right)+\frac{R T}{\alpha_{\mathrm{a}} z_{\mathrm{a}} F} \ln \left(\frac{i}{i_{0, \mathrm{a}}}\right),
\end{aligned}
$$

式中, $V_{\mathrm{de}}$ 为理论分解电压, $R_{\mathrm{i}}$ 为等效内电阻, $i_{\mathrm{d}}$ 为极限 电流密度, $z$ 为反应电子数, $i=I / A$ 为实际电流密度, $A$ 为 电极面积, $i_{0}$ 为电极的交换电流密度, $\alpha$ 为电极反应的 电子传输系数, 下标c和a指阴极和阳极.

\subsection{3 电化学酸化池耗功特性}

恒定电流条件下电化学酸化池瞬时耗功率和总耗 功分别为 ${ }^{[66]}$

$$
\begin{aligned}
P(I, t) & =I V_{\text {cell }}(I, t) \\
& =I\left\{\begin{array}{l}
4.75+I\left[0.85-\frac{t^{2}}{(0.46 I+16.8) t^{2}+(-12.3 I-947) t-50 I+2.02 \times 10^{4}}\right] \\
+0.013 \ln \left(\frac{0.15}{0.15-I / 497}\right)+0.026 \ln (2012 I)
\end{array}\right\},
\end{aligned}
$$

$W(I, \tau)=\int_{0}^{\tau} I V_{\text {cell }}(I, t) \mathrm{d} t$.

平均耗功率为

$$
\bar{P}(I)=\frac{W(I, \tau)}{\tau} \text {. }
$$

恒定电压条件下电化学酸化池瞬时耗功率、总耗 功和平均耗功率分别为 ${ }^{[66]}$

$$
\begin{aligned}
& P\left(V_{\text {cell }}, t\right)=V_{\text {cell }} I\left(V_{\text {cell }}, t\right), \\
& W\left(V_{\text {cell }}, \tau^{\prime}\right)=\int_{0}^{\tau_{\prime}} V_{\text {cell }} I\left(V_{\text {cell }}, t\right) \mathrm{d} t, \\
& \bar{P}\left(V_{\text {cell }}\right)=\frac{W\left(V_{\text {cell }}, \tau^{\prime}\right)}{\tau^{\prime}} .
\end{aligned}
$$

电化学酸化池的FTT研究是目前的重点难点问题, 函需建立其FTT模型, 揭示性能界限, 得到耗功率最 小、熵产率最小等目标下的最优设计和运行参数.

\section{2 中空纤维膜接触器脱出酸化海水中 $\mathrm{CO}_{2}$ 过程 分析与优化}

使用中空纤维膜接触器脱出酸化海水中溶解的 $\mathrm{CO}_{2}$ 具有分离效果好、能耗低的优点. DiMascio等 人 $^{[14]}$ 使用中空纤维膜接触器进行了实验, 成功从 $\mathrm{pH}$ 低 于 6.0 的酸化海水中脱出了溶解的 $\mathrm{CO}_{2}$, 且脱出率达到 了 $92 \%$ 以上. 陈林根等人 ${ }^{[62]}$ 和王超等人 ${ }^{[56,66]}$ 建立了该 过程的有限时间热力学模型, 获得了最优结果. 考虑 $\mathrm{H}_{2}$ 吹扫条件下 $\mathrm{CO}_{2}$ 分离装置. 以LiquiCel ${ }^{\circledR}$ 中空纤维膜 接触器 ${ }^{[172]}$ 为例, 其内中空纤维膜选用疏水聚丙烯 材料.

\subsection{1 恒温恒压流动 $\mathrm{H}_{2}$ 吹扫条件下 $\mathrm{CO}_{2}$ 脱出传质过程} 熵产生率最小化

只有溶解于酸化海水中的 $\mathrm{CO}_{2}$ 气体参与传质过程, 
其余各离子均为不参与传质的惰性成分. 依据文献 [14], $\mathrm{pH}$ 低于 4.5 的酸化海水中 $99 \%$ 的碳元素以 $\mathrm{H}_{2} \mathrm{CO}_{3}$ 形式存在, 故将酸化海水简化为 $\mathrm{H}_{2} \mathrm{CO}_{3}$ 水溶液, 并假设 全部 $\mathrm{CO}_{2}$ 能直接析出. 两种流体逆流流动以提高 $\mathrm{CO}_{2}$ 脱 出率．海水在管程(膜丝内部)流动, $\mathrm{H}_{2}$ 在壳程(膜丝外 部)吹扫时 $\mathrm{CO}_{2}$ 通过纤维膜传递过程如图2所示. 酸化
海水从中空纤维膜接触器 $z=L$ 处流入, $\mathrm{H}_{2}$ 从中空纤维 膜接触器 $z=0$ 处流入. 在分析该过程 $\mathrm{CO}_{2}$ 脱出率和传质 熵产率 ${ }^{[52]}$ 的基础上，可以假设气相中 $\mathrm{CO}_{2}$ 浓度完全可 控, 对其进行优化, 在 $\mathrm{CO}_{2}$ 脱出率不变的条件下求解最 小传质过程摘产生率 ${ }^{[56]}$. 现在的问题为在式(10)的约 束下求解式(11)的最小值:

$\int_{C_{\mathrm{CO}_{2}, 1, \text { out }}}^{C_{\mathrm{CO}_{2}, \text { in }}} \frac{Q_{1}}{2 \pi r_{\mathrm{f}} N_{\mathrm{f}} K_{\mathrm{l}_{1, \mathrm{CO}_{2}}}\left[C_{\mathrm{CO}_{2}, 1}-\frac{p_{\mathrm{g}} C_{\mathrm{CO}_{2}, \mathrm{~g}}}{H_{\mathrm{CO}_{2}}\left(C_{\mathrm{CO}_{2}, \mathrm{~g}}+C_{\mathrm{H}_{2}}\right)}\right]} \mathrm{d}_{\mathrm{CO}_{2}, \mathrm{l}}=L$,
$(\mathrm{d} S / \mathrm{d} t)_{\mathrm{mt}}=\frac{1}{L} \int_{C_{\mathrm{CO}_{2}, 1, \text { out }}}^{C_{\mathrm{CO}_{2}, \text { lin }}} R Q_{1} \ln \frac{H_{\mathrm{CO}_{2}} C_{\mathrm{CO}_{2}, 1}\left(C_{\mathrm{CO}_{2}, \mathrm{~g}}+C_{\mathrm{H}_{2}}\right)}{p_{\mathrm{g}} C_{\mathrm{CO}_{2}, \mathrm{~g}}} \mathrm{~d}_{\mathrm{CO}_{2}, \mathrm{l}}$,

式中, $C_{\mathrm{CO}_{2}, 1}$ 为 $\mathrm{CO}_{2}$ 在液相中的浓度, $Q_{1}$ 为液相体积流 率, $N_{\mathrm{f}}$ 为膜丝根数, $r_{\mathrm{f}}$ 为膜丝外半径, $K_{\mathrm{l}, \mathrm{CO}}$ 为液相传质 $p_{\mathrm{g}}$ 为气相总压力, $H_{\mathrm{CO}_{2}}$ 为亨利常数, $R$ 为摩尔气体常数. 由拉格朗日函数求极值法, 可得 ${ }^{[56]}$

系数, $C_{\mathrm{CO}_{2}, \mathrm{~g}}$ 为 $\mathrm{CO}_{2}$ 在气相中的浓度, $C_{\mathrm{H}_{2}}$ 为吹扫 $\mathrm{H}_{2}$ 浓度,

$\frac{\mathrm{d} C_{\mathrm{CO}_{2}, \mathrm{~g}}}{\mathrm{~d} z}=\frac{2 \pi r_{\mathrm{f}} N_{\mathrm{f}} K_{\mathrm{t}, \mathrm{CO}_{2}}}{Q_{1}} \times \frac{2 H_{\mathrm{CO}_{2}} C_{\mathrm{CO}_{2}, \mathrm{~g}}\left(C_{\mathrm{CO}_{2}, \mathrm{~g}}+C_{\mathrm{H}_{2}}\right)^{2}\left[C_{\mathrm{CO}_{2}, \mathrm{l}}-\frac{p_{\mathrm{g}} C_{\mathrm{CO}_{2}, \mathrm{~g}}}{H_{\mathrm{CO}_{2}}\left(C_{\mathrm{CO}_{2}, \mathrm{~g}}+C_{\mathrm{H}_{2}}\right)}\right]}{H_{\mathrm{CO}_{2}} C_{\mathrm{H}_{2}} C_{\mathrm{CO}_{2}, \mathrm{l}} C_{\mathrm{CO}_{2}, \mathrm{~g}}+H_{\mathrm{CO}_{2}} C_{\mathrm{H}_{2}}{ }^{2} C_{\mathrm{CO}_{2}, \mathrm{l}}+p_{\mathrm{g}} C_{\mathrm{H}_{2}} C_{\mathrm{CO}_{2}, \mathrm{~g}}}$.

由式(10)和(12)和边界条件 $C_{\mathrm{CO}_{2}, 1}(0)=C_{\mathrm{CO}_{2}, \mathrm{l}, \text { out }}$ 和 $C_{\mathrm{CO}_{2}, \mathrm{l}}(L)=C_{\mathrm{CO}_{2}, \text {, in }}$ 可求解得到最佳液相和气相 $\mathrm{CO}_{2}$ 浓度分布 $C_{\mathrm{CO}_{2}, 1}(z)$ 和 $C_{\mathrm{CO}_{2}, \mathrm{~g}}(z)$. 将 $C_{\mathrm{CO}_{2}, 1}(z)$ 和 $C_{\mathrm{CO}_{2}, \mathrm{~g}}(z)$ 代 入式(11)可得到传质过程最小熵产生率 $\left[(\mathrm{d} S / \mathrm{d} t)_{\mathrm{mt}}\right]_{\mathrm{min}}$. 此传质策略定义为 $\left[(\mathrm{d} S / \mathrm{d} t)_{\mathrm{m} t}\right]_{\min }$ 传质策略. 参考反应器 选用气相 $\mathrm{H}_{2}$ 吹扫策略, 将其定义为 $C_{\mathrm{CO}_{2}, \mathrm{~g}}(0)=0$ 传质策 略. 参考反应器的 $\mathrm{CO}_{2}$ 脱出率为 $51.93 \%$, 即出口液相中 $\mathrm{CO}_{2}$ 浓度为 $C_{\mathrm{CO}_{2}, \mathrm{lout}}=1.12 \mathrm{~mol} / \mathrm{m}^{3}$.

图3(a)为 $\left[(\mathrm{d} S / \mathrm{d} t)_{\mathrm{mt}}\right]_{\min }$ 传质策略的液相和气相中 $\mathrm{CO}_{2}$ 浓度沿程变化规律. 图3(b)为 $\left[(\mathrm{d} S / \mathrm{d} t)_{\mathrm{m} t}\right]_{\min }$ 传质策略 和 $C_{\mathrm{CO}_{2}, \mathrm{~g}}(0)=0$ 传质策略的传质摘产生率比较. 两种传

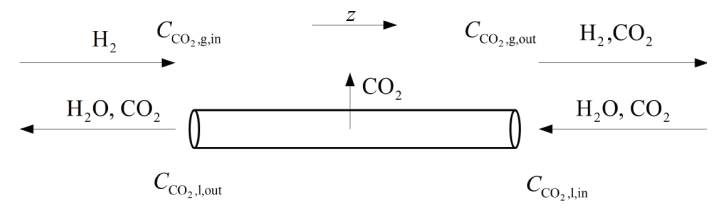

图 $2 \mathrm{CO}_{2}$ 通过中空纤维膜传递过程

Figure 2 The mass transfer process of $\mathrm{CO}_{2}$ through the hollow fiber membrane.
质策略下传质熵产生率均近似线性增加, $C_{\mathrm{CO}_{2}, \mathrm{~g}}(0)=0$ 传质策略下传质熵产生率的增加速率高 于 $\left[(\mathrm{d} S / \mathrm{d} t)_{\mathrm{mt}}\right]_{\mathrm{min}}$ 传质策略下．计算表明，传质熵产生率 最小传质策略下，液相气相在膜接触器内逆流流动, 优化后的熵产生率比壳程采用 $\mathrm{H}_{2}$ 吹扫传质策略的熵 产生率减小 $76.55 \%$; 通过优化气相 $\mathrm{CO}_{2}$ 浓度分布, 使液 相气相 $\mathrm{CO}_{2}$ 化学势差沿程分布更加均匀, 可大量降低 传质过程熵产生率.

4.2.2 考虑流动压降 $\mathrm{H}_{2}$ 吹扫条件下 $\mathrm{CO}_{2}$ 脱出过程传质 与流动总摘产生率最小化

现在的问题为在式(13) (15)的约束下求解式(16) 的最小值 ${ }^{[62]}$ :

$\frac{\mathrm{d} C_{\mathrm{CO}_{2}, \mathrm{l}}}{\mathrm{d} z}=\frac{g_{\mathrm{CO}_{2}}}{Q_{1}}$,

$\frac{\mathrm{d} p_{1}}{\mathrm{~d}(-z)}=-\frac{8 u_{1} v_{1}}{r_{\mathrm{i}}{ }^{2}}$,

$\frac{\mathrm{d} p_{\mathrm{g}}}{\mathrm{d} z}=-\frac{0.158 u_{\mathrm{g}}{ }^{0.25} \rho_{\mathrm{g}}{ }^{0.75} v_{\mathrm{g}}{ }^{1.75}}{d_{\mathrm{g}}{ }^{1.25}}$, 

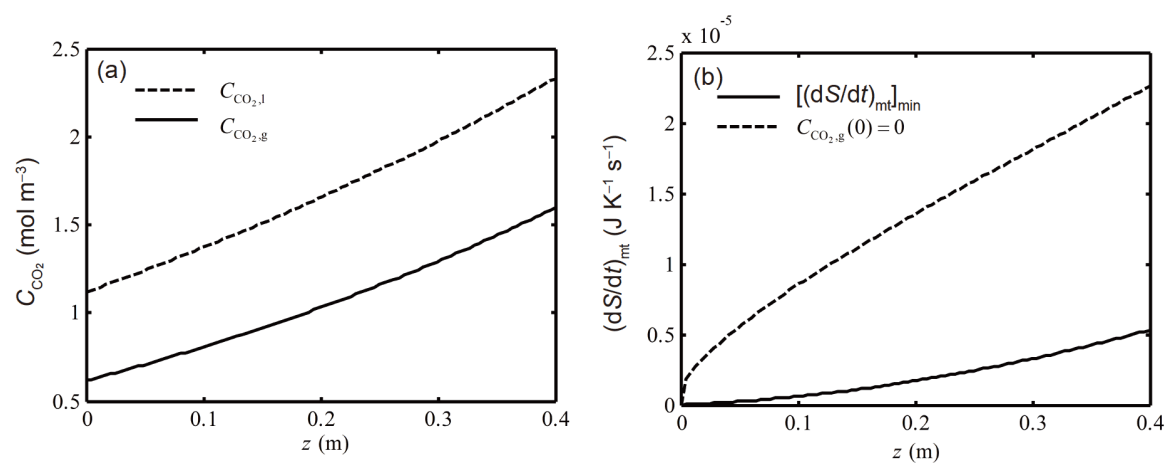

图 3 纯传质过程熵产生率最小化 ${ }^{[66]}$. (a) $\left[(\mathrm{d} S / \mathrm{d} t)_{\mathrm{mt}}\right]_{\min }$ 传质策略的液相和气相 $\mathrm{CO}_{2}$ 浓度沿程变化规律; (b) 两种传质策略的传质 熵产生率比较

Figure 3 Entropy generation rate minimization for pure mass transfer process [66]. (a) The concentration configurations of $\mathrm{CO}_{2}$ in the liquid and gaseous phases along the contactor length of the $\left[(\mathrm{d} S / \mathrm{d} t)_{\mathrm{mt}}\right]_{\min }$ mass transfer strategy; (b) comparison of the entropy generation rates caused by mass transfer of the two mass transfer strategies.

$$
\begin{aligned}
\mathrm{d} S / \mathrm{d} t & =\int_{0}^{L} \sigma_{\mathrm{tot}} \mathrm{d} z=(\mathrm{d} S / \mathrm{d} t)_{\mathrm{mt}}+(\mathrm{d} S / \mathrm{d} t)_{\mathrm{f}}=\int_{0}^{L}\left(\sigma_{\mathrm{mt}}+\sigma_{\mathrm{f}}\right) \mathrm{d} z \\
& =\int_{0}^{L}\left(\frac{g_{\mathrm{CO}_{2}} \Delta \mu}{T}+A_{1} v_{1}\left[-\frac{1}{T} \frac{\mathrm{d} p_{1}}{\mathrm{~d}(-z)}\right]+A_{\mathrm{g}} v_{\mathrm{g}}\left(-\frac{1}{T} \frac{\mathrm{d} p_{\mathrm{g}}}{\mathrm{d} z}\right)\right) \mathrm{d} z,
\end{aligned}
$$

式中, $g$ 为传质流率, $r_{\mathrm{i}}$ 为膜丝内半径, $u$ 为动力黏度, $v$ 为 流速, $p$ 为压力, $\rho$ 为密度, $\mu$ 为化学势, $T$ 为温度, $A$ 为面 积, 下标 1 和 $\mathrm{g}$ 分别为液相和气相.

为了对该优化问题进行数值求解, 将系统离散为 $n=1, \ldots, N$ 控制体, 约束条件和目标函数从连续的微分 方程转化为离散的差分方程形式:

$$
\begin{aligned}
& \frac{C_{\mathrm{CO}_{2}, 1}(j+1)-C_{\mathrm{CO}_{2}, 1}(j)}{z(j+1)-z(j)}=\frac{2 \pi r_{\mathrm{f}} N_{\mathrm{f}} K_{1, \mathrm{CO}_{2}}}{Q_{1}} \\
& \times\left[C_{\mathrm{CO}_{2}, 1}(j)-\frac{p_{\mathrm{g}}(j) C_{\mathrm{CO}_{2} \mathrm{~g}}(j)}{H_{\mathrm{CO}_{2}}\left(C_{\mathrm{CO}_{2}, \mathrm{~g}}(j)+C_{\left.\mathrm{H}_{2}\right)}\right)}\right], \\
& \frac{p_{1}(j+1)-p_{1}(j)}{z(j+1)-z(j)}=\frac{8 u_{1} v_{1}}{r_{\mathrm{i}}^{2}}, \\
& \frac{p_{\mathrm{g}}(j+1)-p_{\mathrm{g}}(j)}{z(j+1)-z(j)}=\frac{0.158 u_{\mathrm{g}}(j)^{0.25} \rho_{\mathrm{g}}(j)^{0.75} v_{\mathrm{g}}(j)^{1.75}}{d_{\mathrm{g}} 1.25}, \\
& \frac{\mathrm{d} S / \mathrm{d} t(j+1)-\mathrm{d} S / \mathrm{d} t(j)}{z(j+1)-z(j)} \\
& =2 \pi r_{\mathrm{f}} N_{\mathrm{f}} K_{1, \mathrm{CO}_{2}} R\left[C_{\mathrm{CO}_{2}, 1}(j)-\frac{p_{\mathrm{g}} C_{\mathrm{CO}_{2}, \mathrm{~g}}(j)}{H_{\mathrm{CO}_{2}}\left(C_{\mathrm{CO}_{2}, \mathrm{~g}}(j)+C_{\mathrm{H}_{2}}\right)}\right] \\
& \times \ln \frac{H_{\mathrm{CO}_{2}} C_{\mathrm{CO}_{2}, \mathrm{l}}(j)\left(C_{\mathrm{CO}_{2}, \mathrm{~g}}(j)+C_{\mathrm{H}_{2}}\right)}{p_{\mathrm{g}} C_{\mathrm{CO}_{2}, \mathrm{~g}}(j)}+\frac{8 N_{\mathrm{f}} \pi u_{1} v_{1}^{2}}{T} \\
& +\frac{0.158 \pi u_{\mathrm{g}}(j)^{0.25} \rho(j)^{0.75} v_{\mathrm{g}}(j)^{2.75}\left(R_{\mathrm{i}}^{2}-N_{\mathrm{f}} r_{\mathrm{i}}^{2}\right)}{T d_{\mathrm{g}}(j)^{1.25}},
\end{aligned}
$$

式中, $j=1, \ldots, N$.

以壳程采用 $\mathrm{H}_{2}$ 吹扫传质策略的 $\mathrm{CO}_{2}$ 脱出率为约束:

$\frac{C_{\mathrm{CO}_{2}, 1}(N)-C_{\mathrm{CO}_{2}, 1}(1)}{C_{\mathrm{CO}_{2}, 1}(N)}=\eta^{\text {ref }}$,

式中, $\eta^{\mathrm{ref}}$ 为壳程采用 $\mathrm{H}_{2}$ 吹扫传质策略的 $\mathrm{CO}_{2}$ 脱出率, $C_{\mathrm{CO}_{2}, 1}(N)$ 为液相进口处 $\mathrm{CO}_{2}$ 浓度, 即酸化海水中 $\mathrm{CO}_{2}$ 总 浓度, 则有 $C_{\mathrm{CO}_{2}, 1}(N)=C_{\mathrm{CO}_{2}, 1, \mathrm{in}}^{\mathrm{ref}}$. 故式(21) 可以改写为

$C_{\mathrm{CO}_{2}, 1}(1)=C_{\mathrm{CO}_{2,1, \text { out }}}^{\text {ref }}$,

式中, $C_{\mathrm{CO}_{2}, \mathrm{l}, \text { out }}^{\text {ref }}$ 和 $C_{\mathrm{CO}_{2}, \text {,in }}^{\text {ref }}$ 分别为壳程采用 $\mathrm{H}_{2}$ 吹扫传质策 略下膜接触器 $z=0$ 和 $z=L$ 处酸化海水中 $\mathrm{CO}_{2}$ 浓度.

优化问题的目标函数为

$\mathrm{d} S / \mathrm{d} t_{\min }=\min [\mathrm{d} S / \mathrm{d} t(N)]$.

现在问题变为在代数约束式(22)和离散约束式(17) (19)的约束下求解式(23)中的 $\min [\mathrm{d} S / \mathrm{d} t(N)]$ 值. 将总摘 产生率最小传质策略定义为 $(\mathrm{d} S / \mathrm{d} t)_{\min }$ 传质策略.

参考反应器选用气相使用 $\mathrm{H}_{2}$ 吹扫策略, 将其定义 为 $\mathrm{C}_{\mathrm{CO}_{2}, \mathrm{~g}, \mathrm{in}}=0$ 传质策略. 参考反应器 $\mathrm{CO}_{2}$ 脱出率为 $81.11 \%$, 即出口液相中 $\mathrm{CO}_{2}$ 浓度为 $C_{\mathrm{CO}_{2}, 1, \text { out }}=0.44 \mathrm{~mol} / \mathrm{m}^{3}$.

图 $4(\mathrm{a})$ 为 $(\mathrm{d} S / \mathrm{d} t)_{\min }$ 传质策略的液相和气相 $\mathrm{CO}_{2}$ 浓 度沿程变化规律. 图4(b)为 $(\mathrm{d} S / \mathrm{d} t)_{\min }$ 传质策略的局部熵 

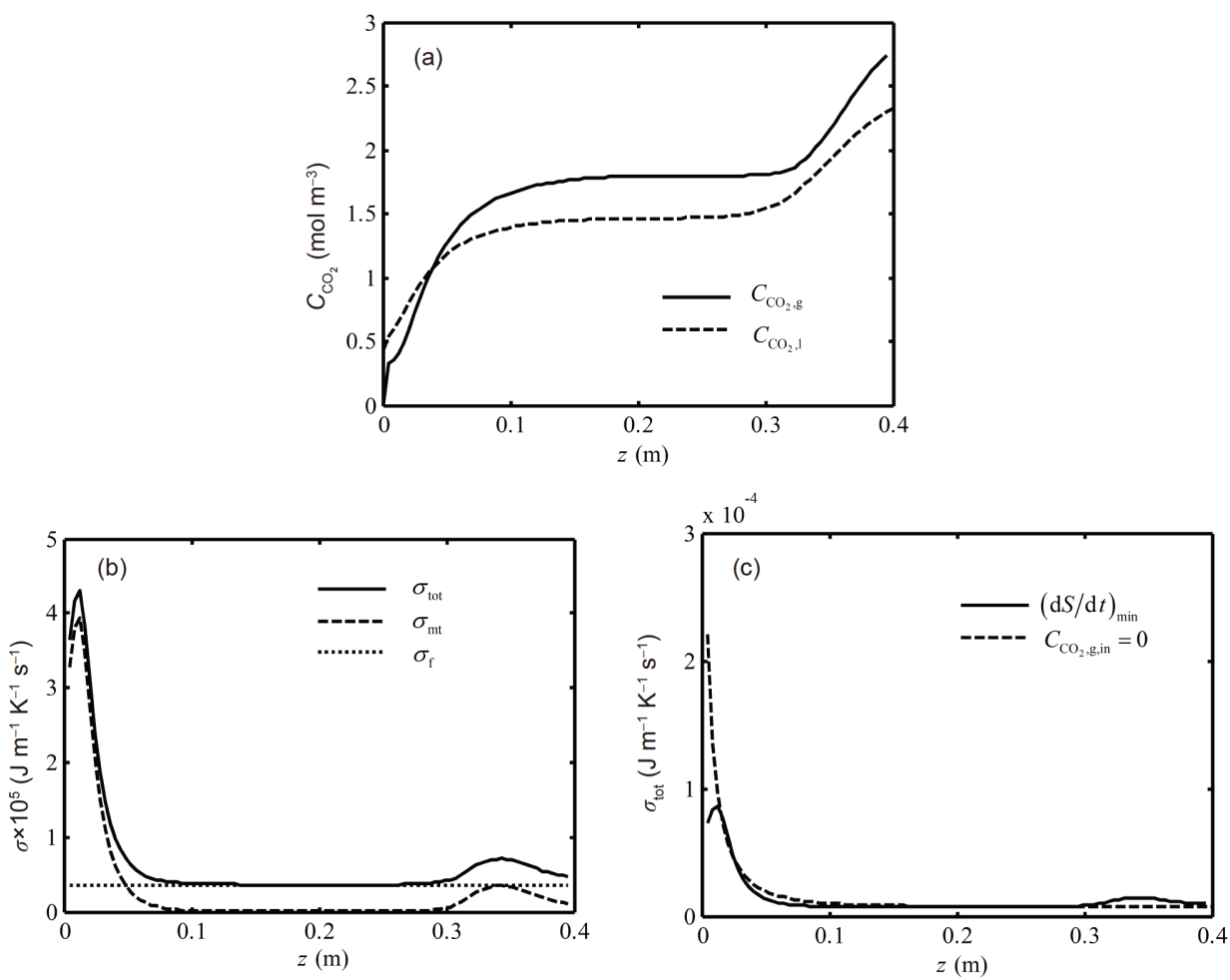

图 4 考虑传质与流动的过程熵产生率最小化 ${ }^{[62]}$. (a) $(\mathrm{d} S / \mathrm{d} t)_{\min }$ 传质策略的液相和气相 $\mathrm{CO}_{2}$ 浓度沿程变化规律; (b) $(\mathrm{d} S / \mathrm{d} t)_{\min }$ 传 质策略的局部熵产生率沿程变化规律; (c) 两种传质策略总局部熵产生率比较

Figure 4 Entropy generation rate minimization for process with mass transfer and fluid flow [62]. (a) The concentration configurations of $\mathrm{CO}_{2}$ in the liquid and gaseous phases along the contactor length of the $(\mathrm{d} S / \mathrm{d} t)_{\min }$ mass transfer strategy; (b) the configurations of local entropy generation rate along the contactor length of the $(\mathrm{d} S / \mathrm{d} t)_{\min }$ mass transfer strategy; (c) comparison of the local entropy generation rates of the two mass transfer strategies.

产生率沿程变化规律. 图4 $(\mathrm{c})$ 为 $(\mathrm{d} S / \mathrm{d} t)_{\min }$ 传质策略 与 $C_{\mathrm{CO}_{2, \mathrm{~g}, \mathrm{in}}}=0$ 传质策略总局部熵产生率比较.

计算表明，传质、流动总熵产生率最小传质策略 下, 液相气相在膜接触器内逆流流动, 优化后的传质 熵产生率比壳程采用 $\mathrm{H}_{2}$ 吹扫传质策略的传质摘产生 率降低了 $42.52 \%$ ，总熵产生率降低了 $36.57 \%$; 在只优 化气相中 $\mathrm{CO}_{2}$ 浓度分布, 液相和气相进口流率不变的 条件下，优化前后流动熵产生率基本相同。体现了显 著的性能改进潜力.

\section{3 热化学硫碘循环关键单元反应过程分析与 优化}

由于海基燃油合成系统燃油合成子系统所需碳、 氢配比为 $1: 3$, 而电化学酸化海水过程生成的碳、氢配 比为 $2: 1$, 该碳氢比不足以直接支撑后续燃油合成过程, 故海基燃油合成系统碳、氢源捕获子系统需另增加
$\mathrm{H}_{2}$ 补给单元模块以保证后续燃油合成所需物料. 在多 种工业制氢工艺中, 热化学循环制氢能直接将热能转 化为氢能，具有高效无污染的优点，其与核能相结合 可使制氢能源得到充分保证，是适用于海基燃油合成 系统氢源捕获子系统的制氢工艺. 热化学循环中硫碘 循环制氢被认为是最有前景的核能制氢工艺. 硫碘循 环制氢由 3 个反应组成，分别为气相HI吸热分解反 应、液相中自发进行的 $\mathrm{SO}_{2}$ 气体吸收反应和气相 $\mathrm{H}_{2} \mathrm{SO}_{4}$ 分解反应. 对硫碘循环中的 $\mathrm{H}_{2} \mathrm{SO}_{4}$ 分解反应和气 相HI吸热分解反应过程进行分析优化, 提高其效率, 是

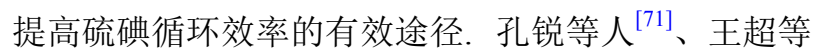
人 $^{[72,73]}$ 和孙铭等人 ${ }^{[74]}$ 分别建立了硫酸分解过程 ${ }^{[72 ~ 74]}$ 和碘化氢分解过程 ${ }^{[73]}$ 的有限时间热力学模型, 获得了 最优结果.

\subsection{1 $\mathrm{H}_{2} \mathrm{SO}_{4}$ 分解过程物理和数学模型}

管式活塞流反应器中 $\mathrm{H}_{2} \mathrm{SO}_{4}$ 的分解过程 
$\mathrm{H}_{2} \mathrm{SO}_{4} \rightarrow \mathrm{H}_{2} \mathrm{O}+\mathrm{SO}_{2}+\frac{1}{2} \mathrm{O}_{2}$ 分为两步进行:

$\mathrm{H}_{2} \mathrm{SO}_{4} \rightarrow \mathrm{SO}_{3}+\mathrm{H}_{2} \mathrm{O}$

$\mathrm{SO}_{3} \rightarrow \mathrm{SO}_{2}+\frac{1}{2} \mathrm{O}_{2}$

其中, 第一步即反应 $(24)$ 为温度在 $400^{\circ} \mathrm{C} \sim 500^{\circ} \mathrm{C}$ 时气相 的 $\mathrm{H}_{2} \mathrm{SO}_{4}$ 自发地分解成 $\mathrm{SO}_{3}$ 和 $\mathrm{H}_{2} \mathrm{O}$; 第二步即反应 $(25)$ 为温度在 $750^{\circ} \mathrm{C}$ 以上时, $\mathrm{SO}_{3}$ 在固体催化剂的作用下分 解为 $\mathrm{SO}_{2}$ 和 $\mathrm{O}_{2}$.

图5为管式活塞流反应器模型图. 外热源采取逆流 式布置. 为简化反应模型以便于分析, 将参与反应的各 物质均视为理想气体, 忽略反应器内径向梯度, 温度 $T 、$ 压力 $p$ 和摩尔流率 $F$ 等变量只随长度 $z$ 变化. 假定反 应器内物质输送仅由流动造成, 不考虑扩散和反混作 用影响; 且化学反应只受动力学约束, 不考虑内部外 部传热影响.

反应器内压降由厄根(Ergun)方程给出, 即动量守 恒方程为

$\frac{\mathrm{d} P}{\mathrm{~d} z}=-\left[\frac{150 \eta}{D_{\mathrm{p}}^{2}} \frac{(1-\varepsilon)^{2}}{\varepsilon^{3}}+\frac{1.75 \rho_{0} v_{0}}{D_{\mathrm{p}}} \frac{1-\varepsilon}{\varepsilon^{3}}\right] v$,

式中, $D_{\mathrm{p}}$ 为催化剂颗粒直径, $\eta$ 为反应混合物的动力黏 度, $\varepsilon$ 为反应器内床层空隙率, $v$ 为气体流速, $\rho_{0}$ 和 $v_{0}$ 分别 为进口处气体密度和流速.

考虑管外壁与管内反应物间传热服从牛顿传热 定律:

$J_{\mathrm{q}}=U\left(T_{\mathrm{w}}-T\right)$.

能量守恒方程为

$$
\begin{aligned}
\frac{\mathrm{d} T}{\mathrm{~d} z}= & \frac{\pi D J_{\mathrm{q}}+A_{\mathrm{c}} \rho_{\mathrm{b}} \sum_{j}\left[r_{\mathrm{m},}\left(-\Delta_{\mathrm{r}} H_{j}\right)\right]}{\sum_{i}\left(F_{i} C_{\mathrm{p}, i}\right)} \\
& =\frac{\pi D U\left(T_{\mathrm{w}}-T\right)+A_{\mathrm{c}} \rho_{\mathrm{b}} \sum_{j}\left[r_{\mathrm{m},}\left(-\Delta_{\mathrm{r}} H_{j}\right)\right]}{\sum_{i}\left(F_{i} C_{\mathrm{p}, i}\right)}
\end{aligned}
$$

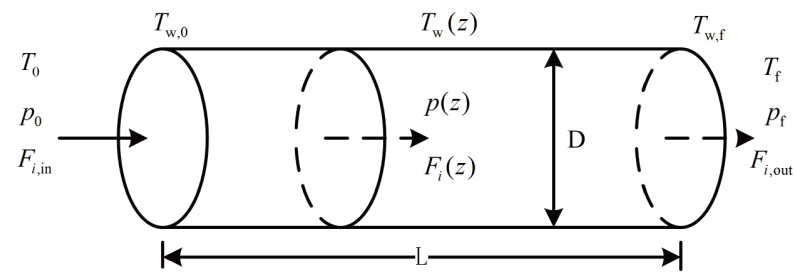

图 5 管式活塞流反应器示意图

Figure 5 Schematic diagram of tubular plug-flow reactor.
式中, $j=1,2$ 分别表示反应(24)和(25), $i=1 \sim 5$ 分别表示反 应各组分, $D$ 为反应器内直径, $U$ 为传热系数, $J_{\mathrm{q}}$ 为管外 壁与管内反应物间热流密度, $A_{\mathrm{c}}$ 为反应器的横截面积, $\rho_{\mathrm{b}}$ 为催化剂密度, $C_{\mathrm{p}, i}$ 为组分 $i$ 的摩尔定压热容. 对于反 应 $j, \Delta_{\mathrm{r}} H_{j}$ 和 $r_{\mathrm{m}, j}$ 分别为其反应焓和单位催化剂质量反应 速率. $F_{i}$ 为沿程某位置组分 $i$ 的摩尔流率.

反应各组分质量守恒方程为

$\frac{\mathrm{d} F_{\mathrm{H}_{2} \mathrm{SO}_{4}}}{\mathrm{~d} z}=-A_{\mathrm{c}} \rho_{\mathrm{b}} r_{\mathrm{m}, 1}$,

$\frac{\mathrm{d} F_{\mathrm{H}_{2} \mathrm{O}}}{\mathrm{d} z}=A_{\mathrm{c}} \rho_{\mathrm{b}} r_{\mathrm{m}, 1}$,

$\frac{\mathrm{d} F_{\mathrm{SO}_{3}}}{\mathrm{~d} z}=A_{\mathrm{c}} \rho_{\mathrm{b}}\left(r_{\mathrm{m}, 1}-r_{\mathrm{m}, 2}\right)$,

$\frac{\mathrm{d} F_{\mathrm{SO}_{2}}}{\mathrm{~d} z}=A_{\mathrm{c}} \rho_{\mathrm{b}} r_{\mathrm{m}, 2}$,

$\frac{\mathrm{d} F_{\mathrm{O}_{2}}}{\mathrm{~d} z}=\frac{1}{2} A_{\mathrm{c}} \rho_{\mathrm{b}} r_{\mathrm{m}, 2}$.

化学反应平衡常数由反应标准态Gibbs自由能 求得:

$\Delta_{\mathrm{r}} G_{T}^{\circ}=-R T \ln K$,

$K_{j}=\exp \left(\frac{\Delta_{\mathrm{r}} G_{T, j}^{\circ}}{-R T}\right)$.

反应速率为

$r_{1}=k_{1}\left(P_{\mathrm{H}_{2} \mathrm{SO}_{4}}-\frac{P_{\mathrm{H}_{2} \mathrm{O}} P_{\mathrm{SO}_{3}}}{K_{1}}\right)$,

$r_{2}=k_{2}\left(P_{\mathrm{SO}_{3}}-\frac{P_{\mathrm{SO}_{2}} \sqrt{P_{\mathrm{O}_{2}}}}{K_{2}}\right)$.

反应(24)为自发反应，反应(25)为催化反应，故有: $r_{\mathrm{m}, 1}=r_{1} / \rho_{\mathrm{b}}, r_{\mathrm{m}, 2}=r_{2}$. 式中 $k_{1}$ 和 $k_{2}$ 为反应速率常数, $P_{i}$ 为组 分 $i$ 的分压力.

目标产物产率是工程追求的首要目标之一, 在热 化学制氢循环中, $\mathrm{H}_{2} \mathrm{SO}_{4}$ 分解过程所得 $\mathrm{SO}_{2}$ 是下一步反 应的原料, 故 $\mathrm{H}_{2} \mathrm{SO}_{4}$ 分解过程 $\mathrm{SO}_{2}$ 产率是分析与优化的 主要目标:

$\Delta F_{\mathrm{SO}_{2}}=F_{\mathrm{SO}_{2}, \text { out }}-F_{\mathrm{SO}_{2} \text {,in }}$.

局部熵产生率由传热、流动、化学反应摘产生率 三项组成: 


$$
\begin{aligned}
\sigma_{\mathrm{tot}}= & \sigma_{\mathrm{ht}}+\sigma_{\mathrm{f}}+\sigma_{\mathrm{cr}} \\
= & \pi D J_{\mathrm{q}} \Delta\left(T^{-1}\right)+A_{\mathrm{c}} v\left[-\frac{1}{T}\left(\frac{\mathrm{d} P}{\mathrm{~d} z}\right)\right] \\
& +A_{\mathrm{c}} \rho_{\mathrm{b}} \sum_{j} r_{\mathrm{m}_{j}}\left(-\frac{\Delta_{\mathrm{r}} G_{j}}{T}\right) \\
= & \pi D J_{\mathrm{q}}\left(\frac{1}{T}-\frac{1}{T_{\mathrm{w}}}\right)+A_{\mathrm{c}} v\left[-\frac{1}{T}\left(\frac{\mathrm{d} P}{\mathrm{~d} z}\right)\right] \\
& +A_{\mathrm{c}} \rho_{\mathrm{b}} \sum_{j} r_{\mathrm{m}_{j} j}\left(-\frac{\Delta_{\mathrm{r}} G_{j}}{T}\right),
\end{aligned}
$$

式中, 下标ht, f和 $\mathrm{cr}$ 分别表示由传热、流体流动和化学 反应引起的局部熵产生率.

反应熵产生率由局部商产生率沿程积分求得:

$\mathrm{d} S / \mathrm{d} t=\int_{0}^{L} \sigma_{\mathrm{tot}} \mathrm{d} z$.

\subsection{2 $\mathrm{H}_{2} \mathrm{SO}_{4}$ 分解过程目标物产率最大优化}

优化问题为进口各组分摩尔流率、反应器尺寸和 催化剂特性等参数给定情况下，允许进口处反应物温 度和压力在一定约束条件下变化, 求解目标产物 $\mathrm{SO}_{2}$ 产率最大值和此时的温度和压力沿程分布 ${ }^{[72]}$.

优化问题的解必须满足能量、动量和摩尔数守恒 方程(26) (33). 选取管外壁温度线性变化 $T_{\mathrm{w}}=975+$ $148 z / L$ 为参考反应器 ${ }^{[171]}$, 以其进口处各组分摩尔流率 为约束, 则优化问题应满足的约束有

$F_{i, \text { in }}=F_{i, \text { in }}^{\text {ref }}$,

式中, 上标ref表示参考反应器的值.

为了对该优化问题进行数值求解，将系统离散为 $n=1, \ldots, N$ 控制体, 约束条件(26), (28), (29) (33)从连 续的微分方程转化为离散的差分方程形式:

$$
\begin{aligned}
& \frac{P(n+1)-P(n)}{z(n+1)-z(n)} \\
& \quad=-\left[\frac{150 \eta}{D_{\mathrm{p}}^{2}} \frac{(1-\varepsilon)^{2}}{\varepsilon^{3}}+\frac{1.75 \rho_{0} v_{0}}{D_{\mathrm{p}}} \frac{1-\varepsilon}{\varepsilon^{3}}\right] v(n) \\
& \frac{T(j+1)-T(j)}{z(j+1)-z(j)} \\
& \quad \frac{\pi D J_{\mathrm{q}}(j)+A_{\mathrm{c}} \rho_{\mathrm{b}} \sum_{j}\left[-r_{\mathrm{m}, j}(j) \Delta_{\mathrm{r}} H_{j}(j)\right]}{\sum_{\mathrm{i}}\left[F_{i}(j) C_{\mathrm{p}, i}(j)\right]} \\
& \frac{F_{\mathrm{H}_{2} \mathrm{SO}_{4}}(j+1)-F_{\mathrm{H}_{2} \mathrm{SO}_{4}}(j)}{z(j+1)-z(j)}=-A_{\mathrm{c}} \rho_{\mathrm{b}} r_{\mathrm{m}, 1}(j) \\
& \frac{F_{\mathrm{H}_{2} \mathrm{O}}(j+1)-F_{\mathrm{H}_{2} \mathrm{O}}(j)}{z(j+1)-z(j)}=A_{\mathrm{c}} \rho_{\mathrm{b}} r_{\mathrm{m}, 1}(j), \\
& \frac{F_{\mathrm{SO}_{3}}(j+1)-F_{\mathrm{SO}_{3}}(j)}{z(j+1)-z(j)}=A_{\mathrm{c}} \rho_{\mathrm{b}}\left[r_{\mathrm{m}, 1}(j)-r_{\mathrm{m}, 2}(j)\right] \\
& \frac{F_{\mathrm{SO}_{2}}(j+1)-F_{\mathrm{SO}_{2}}(j)}{z(j+1)-z(j)}=A_{\mathrm{c}} \rho_{\mathrm{b}} r_{\mathrm{m}, 2}(j), \\
& \frac{F_{\mathrm{SO}_{2}}(j+1)-F_{\mathrm{SO}_{2}}(j)}{z(j+1)-z(j)}=A_{\mathrm{c}} \rho_{\mathrm{b}} r_{\mathrm{m}, 2}(j)
\end{aligned}
$$

目标函数为

$\max \Delta F_{\mathrm{SO}_{2}}=\max F_{\mathrm{SO}_{2}}(N)$.

优化问题变为用非线性规划法在代数方程(41)和 离散约束等式(42) (48)的条件下求解式(49)的最大值.

图6(a)为产率最大反应器管外壁温度 $T_{\mathrm{w}}$ 和管内混 合物温度 $T$ 分布曲线. 图6(b)为两种反应器 $\mathrm{SO}_{2}$ 摩尔流 率沿程分布. 由图可见, 产率最大反应器的 $\mathrm{SO}_{2}$ 摩尔流
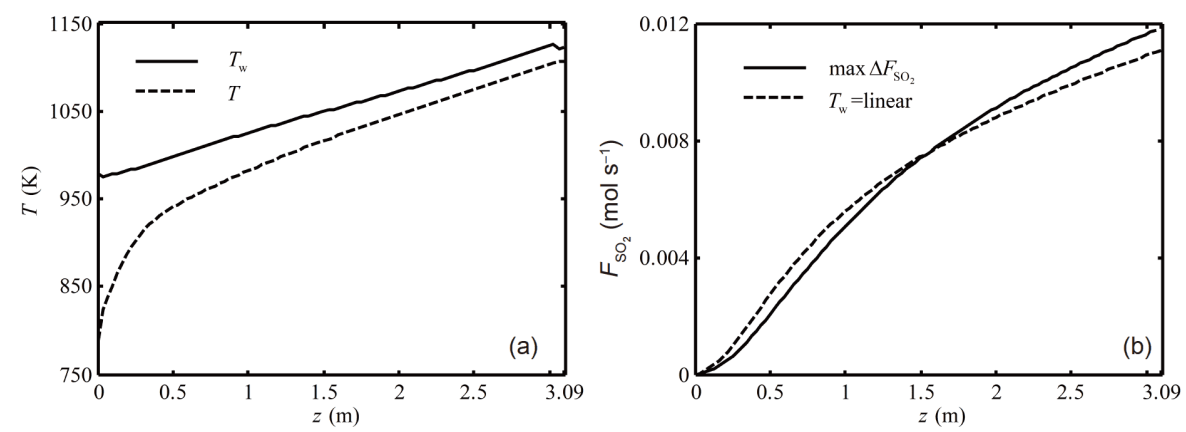

图 $6 \mathrm{H}_{2} \mathrm{SO}_{4}$ 分解过程目标物产率最大优化 ${ }^{[72]}$. (a) 产率最大反应器管外壁温度和管内反应物温度沿程分布; (b) 两种反应器 $\mathrm{SO}_{2}$ 摩尔流率沿程分布

Figure 6 Maximum production rate optimization for $\mathrm{H}_{2} \mathrm{SO}_{4}$ decomposition process [72]. (a) Temperature profiles of the exterior wall and interior reactants of the maximum production rate reactor; (b) profiles of molar flow rates of $\mathrm{SO}_{2}$ of the two reactors. 
率增加率高于参考反应器的. 计算表明, 产率最大反应 器比参考反应器目标产物 $\mathrm{SO}_{2}$ 产率提高了 $7 \%$ 以上; 产 率最大反应器的管外壁温度分布近似线性增加，在近 出口处稍有下降，沿程与参考反应器管外壁温度分布 差别不大; 产率最大反应器内压力沿程近似线性降低, 全程降低了 $9.1 \%$, 产率最大反应器的进口压力比参考 反应器降低了 $38.03 \%$; 可见, 产率最大反应器与参考 反应器的主要区别在于管内压力分布, 即产率提升的 主要途径是降低反应器管内压力 ${ }^{[72]}$.

\subsection{3 $\mathrm{H}_{2} \mathrm{SO}_{4}$ 分解过程不同反应器比较和建议工程实} 现方法

考虑5种管外壁温度分布的反应器, 分别为产率最 大 $\left(\max \Delta F_{\mathrm{SO}_{2}}\right)$ 反应器 ${ }^{[72] 、}$ 、商产生率最小 $(\operatorname{mind} S / \mathrm{d} t)$ 反应 器 ${ }^{[156]}$ 、线性变化外壁温度 $\left(T_{\mathrm{w}}=\right.$ linear $)$ 反应器、恒定外 壁温度 $\left(T_{\mathrm{w}}=\right.$ const $)$ 反应器和恒定热流密度反应器
$\left(J_{\mathrm{q}}=\right.$ const $)$, 设定 $\operatorname{mind} S / \mathrm{d} t$ 反应器、 $T_{\mathrm{w}}=$ const 反应器和 $J_{\mathrm{q}}=$ const 反应器出口处目标产物 $\mathrm{SO}_{2}$ 摩尔流率均与参 考反应器 $T_{\mathrm{w}}=$ linear反应器相同.

图 7(a)为 5 种反应器管外壁温度沿程分布比较. 图7(b)为 5 种反应器反应过程熵产生率沿程分布比较. 图7(c)和图7(d) (f) 分别为 $\max \Delta F_{\mathrm{SO}_{2}}$ 反应器、 $\operatorname{mind} S / \mathrm{d} t$ 反应器和 $J_{\mathrm{q}}=\mathrm{const}$ 反应器的热流密度沿程分布和电阻 丝缠绕示意图. 计算表明, 产率相同时 4 种反应器反应 过程熵产生率由小到大的顺序为: $\operatorname{mind} S / \mathrm{d} t$ 反应器、 $J_{\mathrm{q}}=$ const 反应器、 $T_{\mathrm{w}}=$ linear反应器、 $T_{\mathrm{w}}=$ const 反应器. 降低反应器管内压力在提高目标产物产率的同时会大 大增加反应过程的流动摘产生率; 优化管外壁温度分布 降低反应过程熵产生率能有效降低过程的不可逆性, 主 要降低了过程的传热熵产生率; 工程实际中采用恒热流 密度传热策略优于恒定外壁温度和线性外壁温度传热 策略; 工程中可根据不同最优目标下的热流密度沿程分
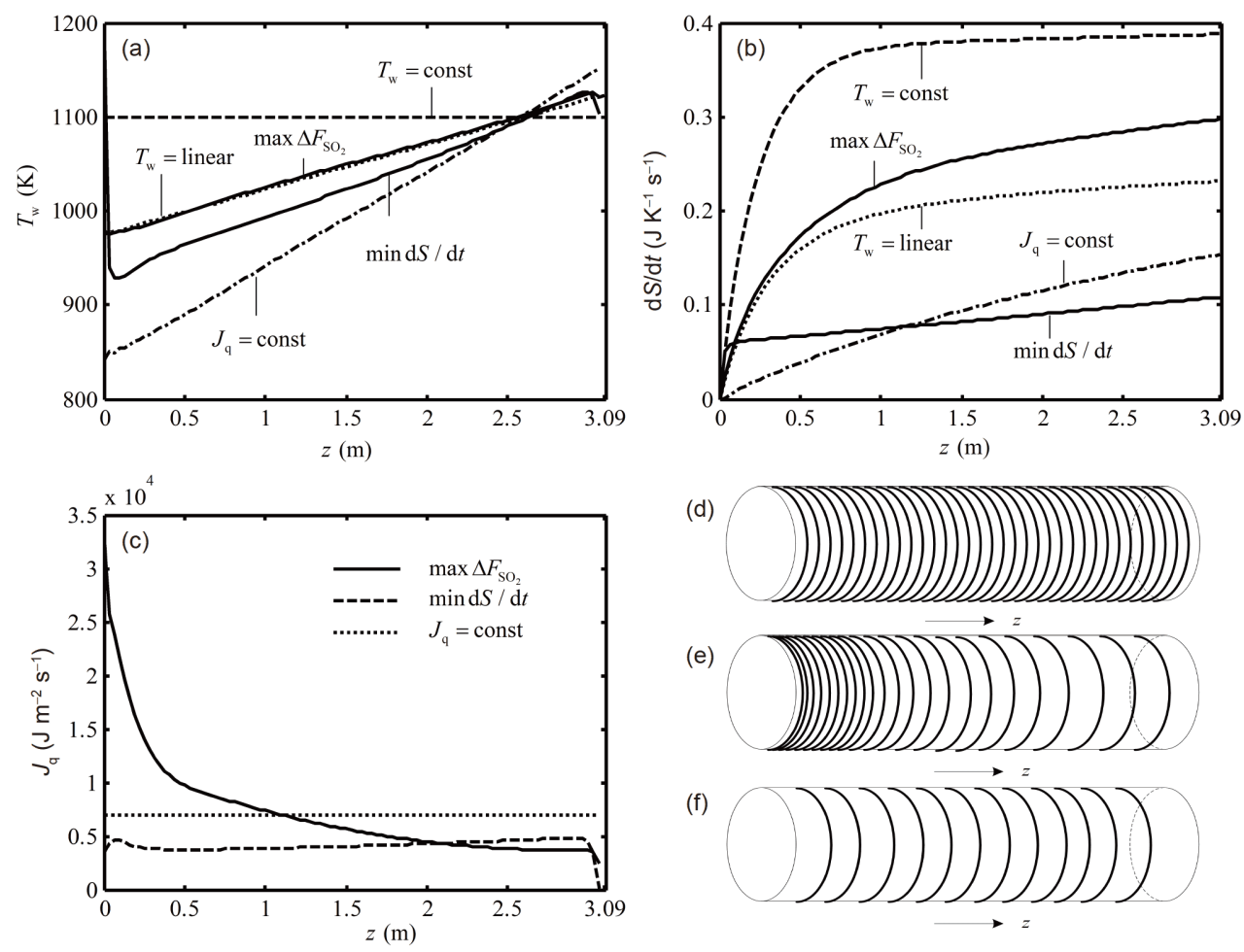

(d)

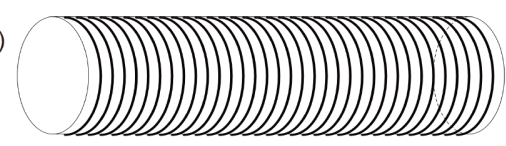

(e)

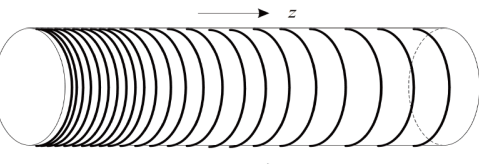

(f)

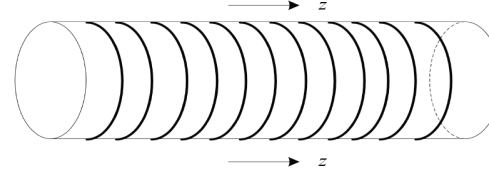

图 7 五种反应器比较和三种反应器电阻丝缠绕示意图 ${ }^{[72]}$. (a) 5 种反应器管外壁温度沿程分布比较; (b) 5 种反应器反应过程 熵产生率沿程分布比较; (c) 3 种反应器热流密度沿程分布比较; (d) 恒定热流密度反应器; (e) 产率最大反应器; (f) 熵产生率最 小反应器

Figure 7 Comparison of the five reactors and schematic diagram of the enwinding modes of the electrical heating wires of three reactors [72]. (a) Comparison of the exterior wall temperature profiles of the five reactors; (b) comparison of the entropy generation rate profiles of the five reactors; (c) comparison of heat fluxes of the three reactors; (d) constant heat flux reactor; (e) maximum production rate reactor; (f) minimum entropy generation rate reactor. 
布, 控制电热丝分布来控制热流密度以实现最优目标.

\subsection{4 $\mathrm{H}_{2} \mathrm{SO}_{4}$ 分解过程的多目标优化}

提高目标产物产率的同时会增加反应过程的熵产 生率. 为此, 以反应物进口温度 $T_{0}$ 、反应物进口压力 $P_{0}$ 和反应物进口总摩尔流率 $F_{\mathrm{tot}, \text { in }}$ 为优化变量, 利用 NSGA-II算法对反应器的熵产生率最小和 $\mathrm{SO}_{2}$ 产率最 大进行多目标优化 ${ }^{[74]}$, 得到两个目标在不同权重下的 最优解.

图8(a)为活塞流反应器基于熵产生率最小和 $\mathrm{SO}_{2}$ 产率最大为目标的Pareto最优前沿，图中 $\mathrm{A}$ 点和 $\mathrm{B}$ 点分 别对应于活塞流反应器的 $\mathrm{SO}_{2}$ 产率最大目标解和总熵 产生率最小目标解，D点对应活塞流反应器的比熵产 率最小时的目标解，E点对应活塞流反应器未优化时 的计算结果，为了使总熵产率降低的同时 $\mathrm{SO}_{2}$ 产率增 加，选取Pareto最优前沿中位于点 $\mathrm{E}$ 左上区域内的一点 $\mathrm{C}$, 使其作为多目标优化的参考解.
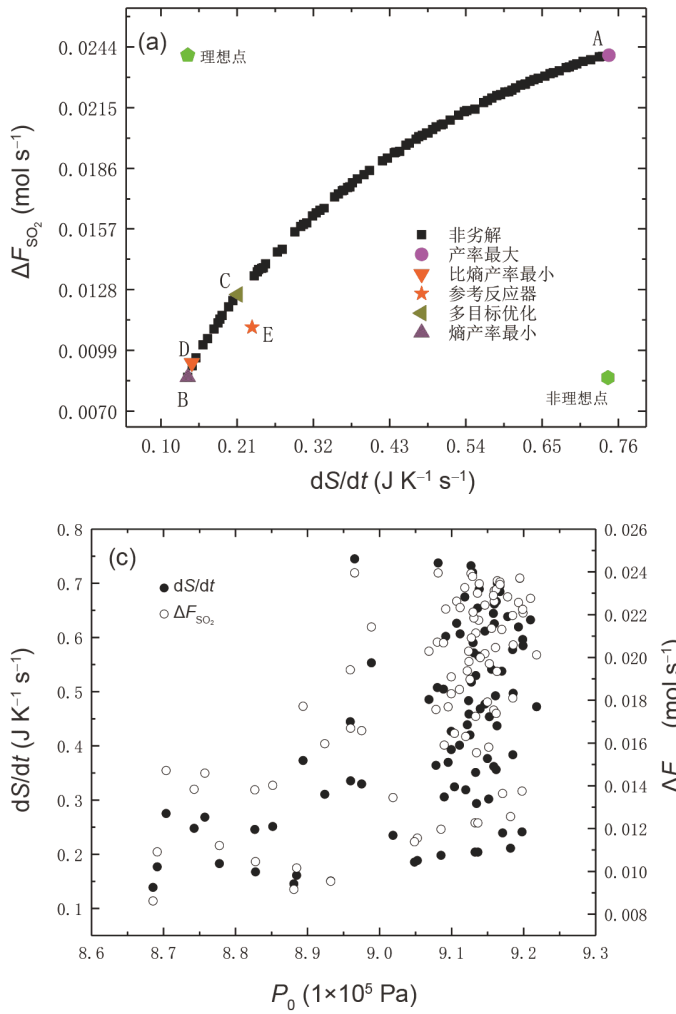

图8(b) (d)分别给出了反应物进口温度、进口压 力和进口总摩尔流率在Pareto最优前沿中的分布规律, 图中黑点和白点分别代表总熵产生率和 $\mathrm{SO}_{2}$ 产率，且 在垂直横坐标轴的方向上成对存在，每一对黑白点都 代表了Pareto最优前沿上的一个最优解.

\subsection{5 化氢分解反应过程的摘产率最小优化}

选用活性炭( $\mathrm{AC})$ 作为碘化氢( $\mathrm{HI})$ 分解反应的催化 剂, 发生化学反应过程如下:

$2 \mathrm{HI} \rightleftharpoons \mathrm{H}_{2}+\mathrm{I}_{2}$

$\Delta_{\mathrm{r}} H=12 \mathrm{~kJ} / \mathrm{mol}$.

反应器内熵产率由化学反应、流动和传热三个过 程产生. 根据最优控制理论, 建立哈密顿函数, 最优控 制问题包括 6 个微分方程、 1 个代数方程和 6 个边界条 件, 可以转化为微分方程组的两点边界值问题. 参考反 应器管外壁温度 $T_{\mathrm{w}}$ 是沿管程线性增加的，优化过程以 参考反应器为基础，催化剂种类、床层孔隙率、反应
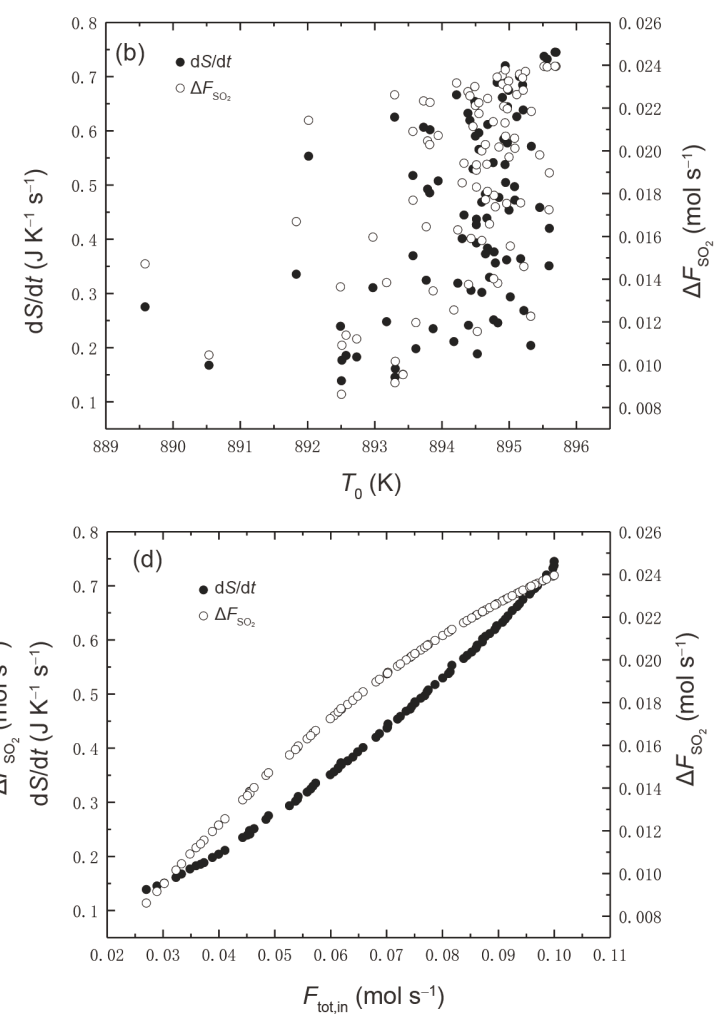

图 8 (网络版彩图) $\mathrm{H}_{2} \mathrm{SO}_{4}$ 分解过程的多目标优化 ${ }^{[74]}$. (a) 活塞流反应器的Pareto最优前沿; (b) Pareto最优前沿中反应混合物进 口温度 $T_{0}$ 分布; (c) Pareto最优前沿中反应混合物进口压力 $P_{0}$ 分布; (d) Pareto最优前沿中反应混合物进口总摩尔流率 $F_{\text {tot,in }}$ 分布 Figure 8 (Color online) Multiobjective optimization for $\mathrm{H}_{2} \mathrm{SO}_{4}$ decomposition process [74]. (a) Pareto optimal frontiers of tubular plug-flow reactor; (b) inlet temperature $T_{0}$ distribution of reaction mixture in Pareto optimal frontiers; (c) inlet pressure $P_{0}$ distribution of reaction mixture in Pareto optimal frontiers; (d) total inlet molar flow rate $F_{\text {tot,in }}$ of reaction mixture in Pareto optimal frontiers. 
管内径均与参考反应器保持一致. 在混合气体进口温 度和进口压力固定的条件下对参考反应器进行优化, 求解最优 $T_{\mathrm{w}}(z)$, 优化结果记为“Case 1 ”; 将管长度 $L$ 作 为附加变量, 求解最优长度下对应的 $T_{\mathrm{w}}(z)$, 此时管长 度变化区间为 $1 \sim 8 \mathrm{~m}$, 优化结果记为“Case 2 ,

计算表明, 随着长度增加, 最优反应器化学反应的 熵产率基本保持为常数, 流动的商产率呈线性增加, 传 热的熵产率不断减小且在长度较短时减小幅度较大. 存在最优的反应器长度 $L_{\mathrm{opt}}=4.91 \mathrm{~m}$ 使总摘产率达到二 次最优值, 这主要是由传热和流动摘产率的折中引起 的. 在管长固定的条件下, Case 1最优反应器的总熵产 率相对参考反应器降低了 $51.3 \%$; 在管长可自由变化 的情况下存在二次最优值, Case 2 最优反应器总摘产 率相对参考反应器降低了 $57.6 \%$; Case 2反应器总摘产 率最小主要是传热和流动过程商产率的折中; 对比结 果发现优化反应器总摘产率的减少主要是通过降低传 热过程的不可逆性实现的. 图9(a)为Case 2 最优反应器 的局部熵产率曲线变化图. 图9(b)为参考反应器和最 优反应器氢气产率 $\Delta F_{\mathrm{H}_{2}}$ 沿管程变化曲线.

硫碘循环制氢的深入研究，可基于高温氦气或太 阳能的熔盐(如 $\mathrm{NaNO}_{3}$ 与 $\mathrm{KNO}_{3}$ 的混合物)等具体载热 工质代替原先假想的抽象高温热源, 研究关键单元的 模型改进和整体流程优化问题.

\section{5 催化合成子系统关键单元热力学分析与 优化研究进展}

在催化合成子系统模块研究方面, NRL前期主要

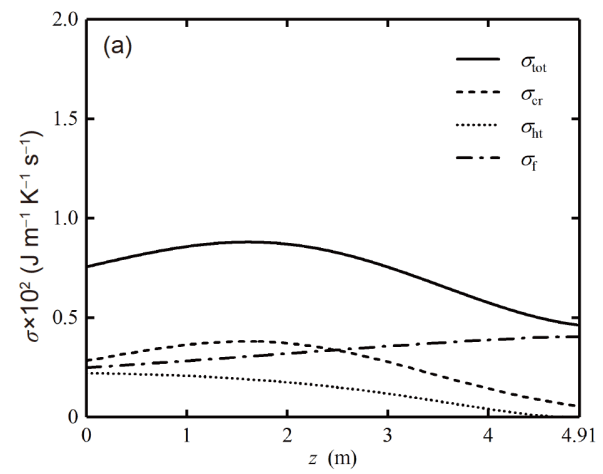

针对“短链烃聚合”合成燃油技术路径开展了深入研 究, 考察了催化剂助剂 ${ }^{[29,30,35,36]}$ 、载体 ${ }^{[27,32]}$ 、反应条 件 ${ }^{[26,31,33,34]}$ 等对 $\mathrm{CO}_{2}$ 氢化合成低碳烯烃反应性能的影 响, 最终篮选出性能满足“短链烃聚合”合成燃油路线 要求的 $\mathrm{Fe}$ 基催化剂, 并对后续的烯烃齐聚反应进行了 催化剂初选 ${ }^{[32]}$. 黄延强 ${ }^{[43-46]}$ 搭建了各单元反应的性能 测试装置, 以提高燃油总体收率为目标, 分别对 $\mathrm{CO}_{2}$ 氢 化合成低碳烯烃和烯烃齐聚反应催化剂配方进行了优 化设计，探索了不同助剂、载体和反应条件对催化剂 性能的影响规律, 完成了催化剂的初步篮选. 周旭和 吴文宏 ${ }^{[47 ~ 50]}$ 完成了不同逆水气变换(RWGS)反应和费 托(FT)合成反应催化剂性能的评价工作，以提高目标 燃油选择性、优化组分分布为目标, 研究了催化剂制 备工艺、成分和反应条件等对反应性能的影响.

对催化合成子系统关键单元的热力学研究, 张磊 等人 ${ }^{[58]}$ 以传热、化学反应和黏性流动过程总熵产生 率最小为优化目标，研究了“长链烃裂解”合成路径中 的RWGS反应器最优构型. 张䂞等人 ${ }^{[60,68]}$ 建立了使用 高温氦气加热RWGS反应器的二维拟均相数学模型, 分析了不同操作的影响规律 ${ }^{[60]}$, 并以最大径向温差最 小和平均转化率最大为优化目标, 借助NSGA-II多目 标遗传算法对反应器进行了多目标优化 ${ }^{[68]}$. 张磊 ${ }^{[69]}$ 以 总熵产生率最小为目标，研究了FT合成反应器最优性 能和最优构型; 求解了比熵产生率(对目标产物产率平 均的熵产生率)最小时所对应的最佳参数取值; 并以总 熵产生率最小和目标产物产率最大为目标对反应器进 行了多目标优化. 张否等人 ${ }^{[51,53]}$ 考虑了催化剂选择性 效应，使用经典热力学方法对“短链烃聚合”合成路径

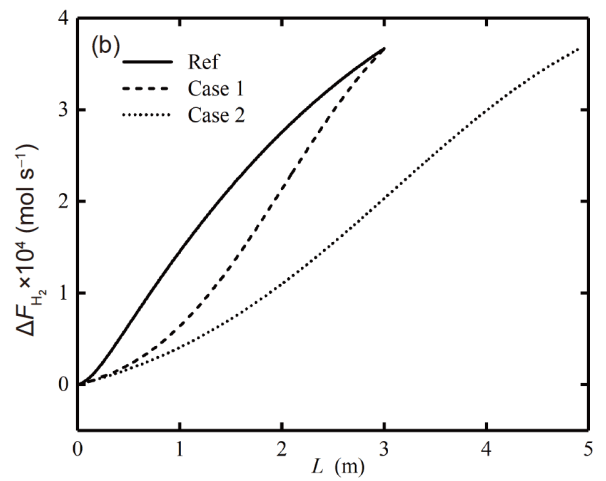

图 9 碘化氢分解反应过程的熵产率最小优化 ${ }^{[71]}$. (a) Case 2 最优反应器的局部熵产率沿程分布; (b) 参考反应器和最优反应器 氢气产率沿程分布

Figure 9 Entropy generation rate minimization for hydrogen iodide decomposition reaction process [71]. (a) Local entropy generation rate profiles of Case 2 optimal reactor; (b) hydrogen generation rate profiles of the reference reactor and optimal reactors. 
中的 $\mathrm{CO}_{2}$ 氢化合成低碳烯烃反应体系进行了分析. 陈 林根等人 ${ }^{[57]}$ 和张磊等人 ${ }^{[55,67]}$ 进一步考虑动力学因素, 分别以 $\mathrm{NRL}^{[55,57]}$ 和中国科学院大连化学物理研究所 ${ }^{[67]}$ 的实验数据为基础，以比熵产生率 ${ }^{[57]}$ 和过程总熵产生 率最小 ${ }^{[55,67]}$ 为优化目标, 研究了 $\mathrm{CO}_{2}$ 氢化合成低碳烯 烃反应器最优构型. 张磊 ${ }^{[69]}$ 以总摘产生率最小为优化 目标，研究了烯烃齐聚单元反应器最优性能和最优构 型; 求解了比摘产生率最小时所对应的最佳参数取值; 并以总熵产生率最小和目标产物产率最大为目标对反 应器进行多目标优化. 张否 ${ }^{[69]}$ 基于经典热力学, 建立 了两种技术路径催化合成子系统的理论模型，求解了 子系统的理论最小耗功、最大能量效率及物质最大转 化率，并分析了单元反应温度和压力对能量效率和燃 油收率的影响规律.

\subsection{RWGS单元反应过程分析与优化}

RWGS反应为海基合成燃油技术提供了一条在技 术成熟度上较易实现的间接合成路径: $\mathrm{CO}_{2}$ 首先通过 RWGS反应合成活性更高的 CO，生成的 CO进一步通 过FT合成反应器生成目标燃油。该反应尚未工业化应 用，国内外的研究重点主要集中于新型催化剂性能的 优化和反应机理的探索，一些学者 ${ }^{[173,174]}$ 对RWGS反应 进行了一些初步的建模仿真与动力学性能研究工作. 张否等人 ${ }^{[58,60,68]}$ 建立了 RWGS 反应器反应过程的有限 时间热力学模型, 获得了最优结果.

5.1.1 RWGS反应器一维活塞流反应过程物理和数学 模型

在管式固定床反应器中进行的RWGS 反应为

$\mathrm{CO}_{2}+\mathrm{H}_{2} \rightleftharpoons \mathrm{CO}+\mathrm{H}_{2} \mathrm{O}$

$\Delta_{\mathrm{r}} H>0$.

基于一维活塞流假设, 反应管由长度 $L$ 、内径 $d_{\mathrm{i}}$ 的 管式固定床反应器构成; 直径为 $d_{\mathrm{p}}$ 的球形催化剂均匀 分布在反应器内, 形成多孔介质反应通道; 温度为 $T_{\mathrm{a}}$ 的 管外热源与管内反应混合物在反应器径向上通过对流 换热方式进行热量传递. 反应器内气相混合物特性由 状态变量温度 $T$ 、压力 $P$ 和反应 $j$ 的反应转化率 $\xi_{j}$ 或组 分 $k$ 的摩尔流率 $F_{k}$ 进行描述, 它们均随反应器轴向位置 $z$ 的变化而变化.

反应 $j$ 的转化率为
$\xi_{j}(z)=\frac{\Delta F_{\mathrm{key}, j}}{F_{\mathrm{key}, \mathrm{in}}}$,

式中, $\Delta F_{\mathrm{key}, j}$ 表示反应 $j$ 消耗关键反应物的摩尔流率, $F_{\text {key,in }}$ 为关键反应物的进口摩尔流率，下标“in”表示进 口状态.

各反应组分在反应器任意位置的摩尔流率根据关 键反应物的进口摩尔流率及反应转化率求解, 即组分 $k$ 的摩尔流率 $F_{k}$ 为

$F_{k}(z)=F_{k, \text { in }}+F_{\text {key,in }} \sum_{j} v_{k, j} \xi_{j}(z)$,

式中, $v_{k, j}$ 为反应 $j$ 中组分 $k$ 的化学计量系数.

各组分的摩尔分数表示为

$y_{k}(z)=\frac{F_{k}(z)}{F_{\mathrm{T}}(z)}$,

式中, $F_{\mathrm{T}}$ 为总摩尔流率.

反应器轴向微元控制体内的能量守恒方程为

$\frac{\mathrm{d} T}{\mathrm{~d} z}=\frac{\pi d_{\mathrm{i}} q-A_{\mathrm{c}} \rho_{\mathrm{b}} \sum_{j} \eta_{j} r_{j} \Delta_{\mathrm{r}} H_{j}}{\sum_{k} F_{k} C_{\mathrm{p}, k}}$,

式中, $A_{\mathrm{c}}$ 为反应器横截面积, $\rho_{\mathrm{b}}$ 为催化床层堆密度, $r$ 和 $\Delta_{\mathrm{r}} H$ 分别为本征化学反应速率和反应焓, $\eta$ 为内扩散有 效因子，表征催化剂的内扩散效率， $C_{\mathrm{p}, k}$ 为组分 $k$ 的等 压摩尔热容, $q$ 为经管壁径向传递的热流密度, 考虑管 外热源温度与管内反应混合物的传热过程服从牛顿传 热定律 $[q \propto \Delta(T)]$, 热流密度为 $q=U\left(T_{\mathrm{a}}-T\right)$, 其中 $U$ 为总 传热系数.

使用Hicks方程描述反应器内的动量守恒特性:

$\frac{\mathrm{d} P}{\mathrm{~d} z}=-6.8 \frac{(1-\varepsilon)^{1.2}}{\varepsilon^{3}} \operatorname{Re}^{-0.2} \frac{\rho_{\mathrm{m}} \nu_{\mathrm{m}}^{2}}{d_{\mathrm{p}}}$,

式中, $\varepsilon$ 为催化床层空隙率, $R e$ 为反应混合物气体在固 定床反应器中流动过程的雷诺数: $R e=v_{\mathrm{m}} \rho_{\mathrm{m}} d_{\mathrm{p}} / \mu_{\mathrm{m}}, \rho_{\mathrm{m}}$ 和 $\mu_{\mathrm{m}}$ 分别为反应混合物的密度和黏性系数, $v_{\mathrm{m}}$ 为反应混 合物平均流速: $v_{\mathrm{m}}=F_{\mathrm{T}} R_{\mathrm{g}} T /\left(P A_{\mathrm{c}}\right)$, 其中 $R_{\mathrm{g}}$ 为普适气体 常数.

质量守恒方程可分别用转化率 $\xi_{j}$ 或组分摩尔流率 $F_{k}$ 的微分方程表示:

$$
\begin{aligned}
& \frac{\mathrm{d} \xi_{j}}{\mathrm{~d} z}=\frac{A_{\mathrm{c}} \rho_{\mathrm{b}}}{F_{\text {key,in }}} \sum_{j} \eta_{j} r_{j} \text { 或 } \\
& \frac{\mathrm{d} F_{k}}{\mathrm{~d} z}=A_{\mathrm{c}} \rho_{\mathrm{b}} \sum_{j} \eta_{j} v_{k, j} r_{j} .
\end{aligned}
$$


使用不考虑具体反应机理的经验反应速率方程:

$r=k \frac{P_{\mathrm{CO}_{2}} P_{\mathrm{H}_{2}}-P_{\mathrm{CO}} P_{\mathrm{H}_{2} \mathrm{O}} / K}{P_{\mathrm{CO}}+a_{\mathrm{H}_{2} \mathrm{O}} P_{\mathrm{H}_{2} \mathrm{O}}+b_{\mathrm{CO}_{2}} P_{\mathrm{CO}_{2}}}$,

式中, $P_{k}$ 为组分 $k$ 的分压力; $a_{\mathrm{H}_{2} \mathrm{O}}$ 和 $b_{\mathrm{CO}_{2}}$ 分别为组分 $\mathrm{H}_{2} \mathrm{O}$ 和 $\mathrm{CO}_{2}$ 的吸附常数, 代表了组分对反应速率的抑制效 应; $K$ 为平衡常数, 可通过反应标准 Gibbs自由焓 $\Delta_{\mathrm{r}} G_{j}^{\circ}$ 计算求得; $k$ 为速率常数, 是温度 $T$ 的函数, 满足Arrhenius关系:

$k=A \exp \left[-E /\left(R_{\mathrm{g}} T\right)\right]$,

式中, $A$ 为指前因子, $E$ 为反应活化能.

总的局部熵产生率为

$$
\begin{aligned}
\sigma_{\mathrm{tot}}= & \pi d_{\mathrm{i}} q\left(\frac{1}{T}-\frac{1}{T_{a}}\right)+A_{\mathrm{c}} v_{\mathrm{m}}\left[-\frac{1}{T}\left(\frac{\mathrm{d} P}{\mathrm{~d} z}\right)\right] \\
& +A_{\mathrm{c}} \rho_{\mathrm{b}} \sum_{j}\left[\eta_{j} r_{j}\left(\frac{\Delta_{\mathrm{r}} G_{j}}{T}\right)\right],
\end{aligned}
$$

式中, 等号右边三项分别表示传热、黏性流动和化学 反应过程的局部熵产生率, 每一项均为相应传输过程 “流”和“力”的乘积. 传热过程的“流”为单位面积热流 率, 即热流密度 $q$, 热力学驱动力为 $\Delta(1 / T)=(1 / T)-$ $\left(1 / T_{\mathrm{a}}\right)$; 黏性流动过程的“流”为气体表面平均流速 $v_{\mathrm{m}}$, 对应的黏性流力为 $[-(1 / T)(\mathrm{d} P / \mathrm{d} z)]$; 化学反应过程的
“流”为表征化学速率 $\eta_{j} r_{j}$, 化学反应驱动力为 $-\Delta_{\mathrm{r}} G_{j} / T$, $\Delta_{\mathrm{r}} G_{j}$ 为反应Gibbs自由焓.

对于RWGS反应, 化学反应驱动力为

$-\frac{\Delta_{\mathrm{r}} G}{T}=-R_{\mathrm{g}} \ln \frac{P_{\mathrm{CO}} P_{\mathrm{H}_{2} \mathrm{O}}}{P_{\mathrm{CO}_{2}} P_{\mathrm{H}_{2}} K}$.

反应器内总摘产生率 $\Sigma_{\mathrm{tot}}$ 为局部商产生率在反应 器轴向位置 $z$ 上的积分:

$\Sigma_{\text {tot }}=\int_{0}^{L} \sigma_{\text {tot }} \mathrm{d} z=\Sigma_{\mathrm{h}}+\Sigma_{\mathrm{ff}}+\Sigma_{\mathrm{r}}$,

式中, 下标 $\mathrm{h}, \mathrm{ff}$ 和 $\mathrm{r}$ 分别表示传热过程、黏性流动过程 和化学反应过程.

\subsubsection{RWGS反应器熵产生率最小化}

在给定RWGS反应器目标产物 $(\mathrm{CO})$ 产率的约束条 件下, 以总熵产生率最小为优化目标, 分别从有限时间 热力学的最优性能问题(求解给定管外热源温度分布 曲线时的目标极值)和最优构型问题(求解目标极值和 取极值时所对应的最优管外热源温度分布曲线)两方 面对反应器进行优化求解.

(1) 最优性能

优化问题以进口温度、压力和组分摩尔流率为优 化变量. 除施加的产率约束外, 优化问题的求解还必须 满足能量、动量和质量守恒方程. 引入拉格朗日函数 $L$ :

$$
\begin{aligned}
L= & \Sigma_{\text {tot }}(x)+\lambda_{\Delta F_{\mathrm{CO}}}\left[\left(F_{\mathrm{CO}, \text { out }}^{\text {ref }}-F_{\mathrm{CO}, \text { in }}^{\text {ref }}\right)-\left(F_{\mathrm{CO}, \text { out }}-F_{\mathrm{CO}, \text { in }}\right)\right]+\lambda_{T}\left(\frac{\mathrm{d} T}{\mathrm{~d} z}-\frac{\pi d_{\mathrm{i} q} q A_{\mathrm{c}} \rho_{\mathrm{b}} \eta r \Delta_{\mathrm{r}} H}{\sum_{k} F_{k} C_{\mathrm{p}, k}}\right) \\
& +\lambda_{P}\left[\frac{\mathrm{d} P}{\mathrm{~d} z}+6.8 \frac{(1-\varepsilon)^{1.2}}{\varepsilon^{3}} \operatorname{Re}^{-0.2 \rho_{\mathrm{m}} v_{\mathrm{m}}^{2}} d_{\mathrm{p}}\right]+\sum_{k} \lambda_{F_{k}}\left(\frac{\mathrm{d} F_{k}}{\mathrm{~d} z}-v_{k} A_{\mathrm{c}} \rho_{\mathrm{b}} \eta r\right)+\sum_{i} \lambda_{i} \Phi_{i}(x),
\end{aligned}
$$

式中, $x$ 为优化变量, $\lambda_{\Delta F_{\mathrm{CO}}}$ 为与目标产物产率约束相关 的拉格朗日乘子, 上标“ref”表示参考反应器; $\lambda_{T}, \lambda_{P}$ 和 $\lambda_{F_{k}}$ 分别为与能量、动量和质量守恒方程约束相关 的拉格朗日乘子; $\Phi_{i}(x)$ 和 $\lambda_{i}$ 分别为其他与进口条件有 关的约束函数和相应的拉格朗日乘子.

采用非线性规划数值方法求解优化问题. 选择不 同组合的进口条件作为优化变量分别对RWGS反应器 进行优化, 以研究不同变量对过程最小总熵产生率的 影响. 因此, 将优化问题分为以下几类. Case 1: 以组 分进口摩尔流率 $F_{\mathrm{CO}_{2}, \text { in }}, F_{\mathrm{H}_{2}, \text { in }}, F_{\mathrm{H}_{2} \mathrm{O}, \mathrm{in}}$ 为优化变量, $\mathrm{CO}$ 进
口摩尔分数、进口温度和进口压力与参考反应器相 同, 即 $y_{\mathrm{CO}, \mathrm{in}}=y_{\mathrm{CO}, \mathrm{in}}^{\mathrm{ref}}, T_{\mathrm{in}}=T_{\mathrm{in}}^{\mathrm{ref}}, P_{\mathrm{in}}=P_{\mathrm{in}}^{\mathrm{ref}}$; 并对进口总摩 尔流率施加约束, 即 $F_{\mathrm{T}, \mathrm{in}}=F_{\mathrm{T}, \mathrm{in}}^{\mathrm{ref}}$. Case 2: 在Case 1 的基 础上增加 $T_{\mathrm{in}}$ 为优化变量. Case 3: 在Case 2的基础上增 加 $P_{\text {in }}$ 为优化变量. Case 4: 在Case 3 的基础上释放进口 总摩尔流率的约束.

图10(a)给出了参考反应器和最优反应器混合物 温度 $T$ 和热源温度 $T_{\mathrm{a}}$ 的沿程变化曲线, 图10(b)给出了 参考反应器和最优反应器总的局部熵产生率 $\sigma_{\mathrm{tot}}$ 的沿 程变化曲线, 局部摘产生率曲线下方面积即为过程总 

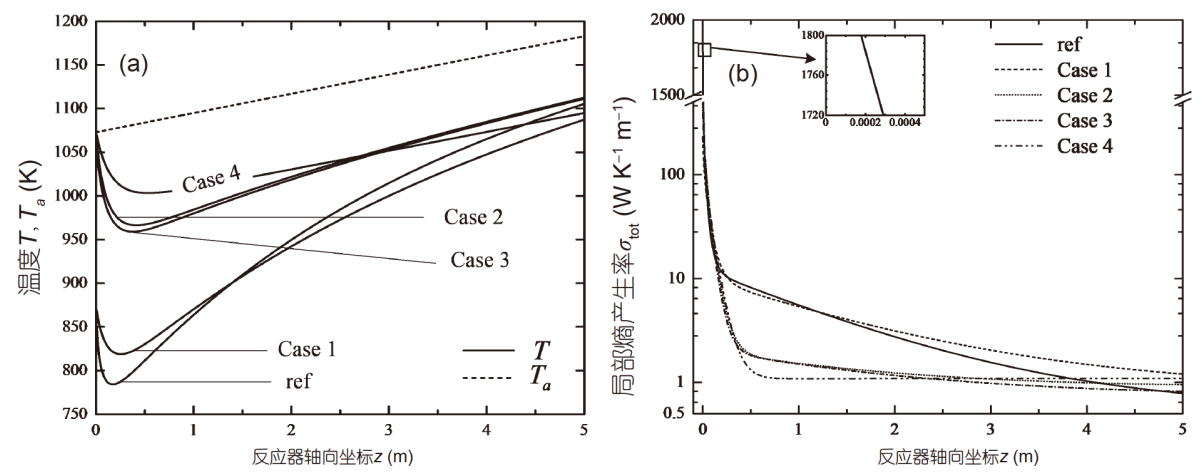

图 10 RWGS反应器熵产生率最小化 ${ }^{[69]}$. (a) 参考反应器和最优反应器温度 $T$ 和 $T_{\mathrm{a}}$ 沿程变化曲线; (b) 参考反应器和最优反应器 总的局部熵产生率 $\sigma_{\mathrm{tot}}$ 沿程变化曲线

Figure 10 Entropy generation rate minimization for RWGS reactor [69]. (a) Variations of temperatures $T$ and $T_{\mathrm{a}}$ along the axial coordinate in the reference and optimal reactors; (b) variations of total local entropy generation rates $\sigma_{\text {tot }}$ along the axial coordinate in the reference and optimal reactors.

熵产生率. 图中ref表示参考反应器. 从图中可较明显 地观察到释放了进口温度 $T_{\text {in }}$ 优化自由度的最优反应 器(Case 2, Case 3 和Case 4) 的反应混合物温度 $T$ 与热源 温度 $T_{\mathrm{a}}$ 的温差分布更加均匀. 参考反应器和最优反应 器的不可逆性主要集中在反应器入口处, 总的局部摘 产生率均是从一个极大值迅速降低, 随后平缓变化. 最优反应器在入口处的极大值相比参考反应器要有所 降低, 相比参考反应器, 最优反应器总的局部熵产生率 在反应器大部分区域都分布的更为均匀, 在一定程度 上符合“熵产均分原则”。

（2）最优构型

优化问题为在 $\mathrm{CO}$ 产率一定的约束条件下求解 RWGS反应器总熵产生率的最小值，同时求解总熵产 生率最小的最优热力过程, 即反应器最优构型. 基于 最优控制理论构建优化问题，首先构建问题的哈密顿 函数 $H$ :

$$
\begin{gathered}
H[\mathbf{x}(z), \lambda(z), u(z)]=\sigma[\mathbf{x}(z), u(z)] \\
+\sum_{i=1}^{3} \lambda_{i}(z) f_{i}[\mathbf{x}(z), u(z)],
\end{gathered}
$$

式中, $\mathbf{x}=[T, P, \xi]$ 为状态变量向量, 受状态方程约束; $\lambda=$ $\left[\lambda_{T}, \lambda_{P}, \lambda_{\xi}\right]$ 为相应状态方程的协态变量向量; 考虑管外 热源温度 $T_{\mathrm{a}}(z)$ 为控制变量, 即 $u(z)=T_{\mathrm{a}}(z)$; 假设热源温度 $T_{\mathrm{a}}(z)$ 可随反应器轴向位置自由变化, 且取为正值. 当哈 密顿函数 $H$ 不显含位置变量 $z$ 时, $H$ 沿最优轨线保持为 常数; 当反应器长度可自由变化时, 即末态轴向坐标 自由变化时, 哈密顿函数 $H=0$.

根据极小值原理, 当目标函数取极小值时, 动态系
统应满足以下必要条件:

$\mathrm{d} T / \mathrm{d} z=\partial H / \partial \lambda_{T}$,

$\mathrm{d} P / \mathrm{d} z=\partial H / \partial \lambda_{P}$,

$\mathrm{d} \xi / \mathrm{d} z=\partial H / \partial \lambda_{\xi}$,

$\mathrm{d} \lambda_{T} / \mathrm{d} z=-\partial H / \partial T$,

$\mathrm{d} \lambda_{P} / \mathrm{d} z=-\partial H / \partial P$,

$\mathrm{d} \lambda_{\xi} / \mathrm{d} z=-\partial H / \partial \xi$.

哈密顿函数相对最优控制取极小值:

$T_{\mathrm{a}}=\underset{T_{\mathrm{a}} \in(0,+\infty)}{\operatorname{argmin}} H, \quad z \in[0, L]$.

式(71)的代数方程给出了状态方程和协态变量之 间的函数关系，根据工程实际经验和控制变量连续变 化的假设条件, 式(71)可进一步简化为

$\mathrm{d} H / \mathrm{d} T_{\mathrm{a}}=0$.

通过求解式(72)可得到在管内混合物与管外热源 传热符合牛顿传热定律 $[q \propto(\Delta T)]$ 条件下, 最优轨迹满 足的代数方程:

$T_{\mathrm{a}}=T\left(1+\frac{\lambda_{T} T}{\sum_{k} F_{k} C_{\mathrm{p}, k}}\right)^{-1 / 2}$.

以 $T_{\mathrm{a}}$ 为控制变量, 在进口温度 $T_{\mathrm{in}}$ 固定的条件下对 参考反应器进行优化, 优化结果记为“Case 1”; 以反应 器长度 $L$ 为附加变量, 在 $L \in[11 \mathrm{~m}, 12 \mathrm{~m}]$ 的范围内重复 上一步, 最佳反应器长度 $L^{\mathrm{opt}}$ 对应的优化结果记为 “Case 2"; 以 $T_{\mathrm{a}}$ 为控制变量, 在进口温度 $T_{\text {in }}$ 自由的条件 
下对参考反应器进行优化, 优化结果记为“Case 3”; 以 反应器长度 $L$ 为附加变量, 在 $L \in[0.5 \mathrm{~m}, 1.5 \mathrm{~m}]$ 的范围内 重复上一步, 最佳反应器长度 $L^{\mathrm{opt}}$ 对应的优化结果即为 “Case 4".

图11(a)和(b)分别给出了在反应混合物进口温度 $T_{\mathrm{in}}$ 固定和自由条件下, 最优反应器过程总熵产生率 $\Sigma_{\mathrm{tot}}$ 和各传递过程的熵产生率 $\Sigma_{\mathrm{r}}, \Sigma_{\mathrm{ff}}, \Sigma_{\mathrm{h}}$ 随反应器长度的变 化规律. 图11(c)给出了参考反应器和最优反应器管外 热源温度 $T_{\mathrm{a}}$ 的变化曲线. 图11(d)给出了参考反应器和 最优反应器管内混合物温度 $T$ 的变化曲线. 图11(e)给 出了最优反应器管外热源温度和反应混合物温度的分 布曲线(温度最优构型). 图11(f)给出了参考反应器和 最优反应器总的局部商产生率 $\sigma_{\mathrm{tot}}$ 沿程分布对比曲线. 图11(g)给出了参考反应器和最优反应器转化率 $\xi$ 的沿 程分布曲线. 与热源温度线性分布的参考反应器相比, 同时优化热源温度分布、反应混合物进口温度和反应 器长度, RWGS反应器的总摘产生率可降低 $27.1 \%$. 综 合上述数值优化结果可发现，在运行的温度范围内尽 可能地提高反应混合物进口温度, 即使使用较短的紧 凑式模块化反应器设计也能在极大降低反应器运行过 程总熵产生率的同时较好地完成预定的产率目标，但 该最优设计方案还要综合考虑反应器和催化剂的结构 强度与耐高温性.

\subsubsection{RWGS反应器多目标优化}

以目标产物 $\mathrm{CO}$ 产率最大和总熵产生率最小为优 化目标对反应器进行多目标优化:

$$
\left\{\begin{array}{l}
\min \Sigma_{\text {tot }}, \\
\max \Delta F_{\mathrm{CO}} .
\end{array}\right.
$$

选取反应混合物进口温度 $T_{\mathrm{in}}$ 、进口压力 $P_{\mathrm{in}}$ 和进 口总摩尔流率 $F_{\mathrm{T}, \mathrm{in}}$ 为多目标优化的决策变量. 该多目 标优化问题属于有限时间热力学中的最优性能研究.

同时，将目标产物(CO)产率平均的熵产生率定义 为比熵产生率:

$\Sigma_{\mathrm{tot}}^{\mathrm{spec}}=\frac{\Sigma_{\mathrm{tot}}}{\Delta F_{\mathrm{CO}}}$.

图12给出了 RWGS 反应器基于总熵产生率 $\Sigma_{\mathrm{tot}}$ 最 小和 $\mathrm{CO}$ 产率 $\Delta F_{\mathrm{CO}}$ 最大多目标优化的最优Pareto前沿, 最优Pareto前沿的两个端点(点 $\mathrm{A}$ 和点 $\mathrm{B}$ )分别表示在单 目标优化时的最优性能, 点 $\mathrm{A}$ 对应于 $\mathrm{CO}$ 产率 $\Delta F_{\mathrm{CO}}$ 最大
点, 点 $\mathrm{B}$ 对应于总熵产生率 $\Sigma_{\mathrm{tot}}$ 最小点. 点 $\mathrm{C}$ 是选取的一 个较为适中的最优解, 点 $\mathrm{D}$ 为比熵产生率最小单目标 优化的最优解. 最优设计点 $\mathrm{C}$ 能使反应器在 $\mathrm{CO}$ 产率增 加 $12 \%$ 的同时总熵产生率减小 $6 \%$. 提升进口温度能同 时有利于降低反应器总熵产生率和提升 $\mathrm{CO}$ 产率; 调整 进口压力和进口总摩尔流率是“中和”提升产率和降低 总熵产生率之间矛盾的重要手段.

5.1.4 基于二维拟均相模型的高温氦气加热RWGS反 应器多目标优化

对以氦气作为高温连续流体热源载热工质的 RWGS 反应器, 基于二维拟均相反应器模型对工业 RWGS 反应器的转化管进行建模. 以 $\mathrm{CO}_{2}$ 为关键反应 物的转化率为

$\xi(z, R)=\left[F_{\mathrm{CO}_{2}, \mathrm{in}}-F_{\mathrm{CO}_{2}}(z, R)\right] / F_{\mathrm{CO}_{2}, \mathrm{in}}$,

式中, $F_{k, \mathrm{in}}$ 和 $F_{k}(z, R)$ 分别表示组分 $k$ 在进口和反应器任 意位置 $(z, R)$ 处的摩尔流率, 组分 $k$ 的摩尔流率为

$F_{k}=F_{k, \text { in }}+F_{\mathrm{CO}_{2}, \mathrm{in}} v_{k} \xi$,

式中, $v_{k}$ 为化学反应式中组分 $k$ 的化学计量系数.

转化管内温度变化使用能量守恒方程进行描述:

$\frac{\partial T}{\partial z}=\frac{\lambda_{\mathrm{er}}}{G c_{\mathrm{p}}}\left(\frac{\partial^{2} T}{\partial R^{2}}+\frac{1}{R} \frac{\partial T}{\partial R}\right)-\frac{\rho_{\mathrm{b}} \Delta_{\mathrm{r}} H r \eta}{G c_{\mathrm{p}}}$,

式中, $G=\rho_{\mathrm{m}} v_{\mathrm{m}}$ 和 $c_{\mathrm{p}}$ 分别为反应混合物质量流率和等压 比热容.

反应转化率的变化使用质量守恒方程进行描述:

$\frac{\partial \xi}{\partial z}=\frac{D_{\mathrm{er}}}{v_{\mathrm{m}}}\left(\frac{\partial^{2} \xi}{\partial R}+\frac{1}{R} \frac{\partial \xi}{\partial R}\right)+\frac{\rho_{\mathrm{b}} A_{\mathrm{c}} r \eta}{F_{\mathrm{CO}_{2}, \mathrm{in}}}$,

式中, $D_{\mathrm{er}}$ 为床层径向有效扩散系数, $A_{\mathrm{c}}$ 为以转化管内 径计算的横截面积.

考虑边界条件、催化剂颗粒模型、环形加热空间 模型、径向能量守恒方程、物性和传递参数后, 建立 数学模型, 其求解属于偏微分方程组、常微分方程组 与代数方程组的混合求解问题 ${ }^{[68]}$. 由于模型较为复杂, 且物性系数和传递参数均随状态变量的变化而变化, 无法得到解析解, 需要对问题进行数值求解. 按照高温 氦气流动布置形式的不同, 转化管与环形加热空间模 型的求解分为偏微分方程组的初值问题(顺流式反应 器)和边值问题(逆流式反应器). 

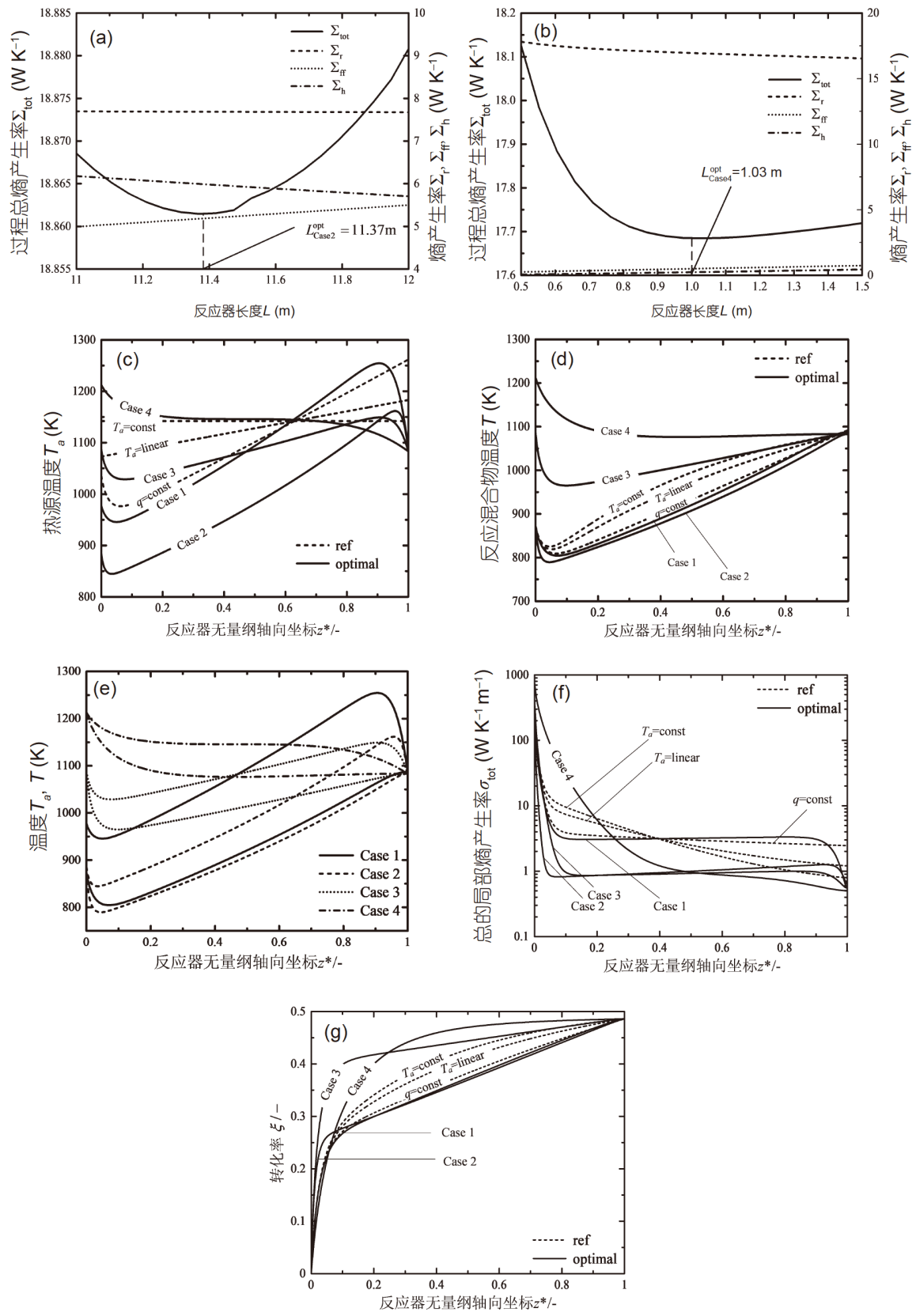

图 11 RWGS反应器摘产生率最小化对应的最优构型 ${ }^{[69]}$. (a) 进口温度 $T_{\mathrm{in}}$ 固定条件下最优反应器熵产生率随反应器长度 $L$ 变 化曲线; (b) 进口温度 $T_{\text {in }}$ 自由变化条件下最优反应器摘产生率随反应器长度 $L$ 变化曲线; (c) 热源温度 $T_{\mathrm{a}}$ 随无量纲轴向坐标变 化曲线; (d) 反应混合物温度 $T$ 随无量纲轴向坐标变化曲线; (e) 最优反应器温度最优构型; (f) 总的局部摘产生率 $\sigma_{\mathrm{to}}$ 随无量纲轴 向坐标变化曲线; $(\mathrm{g})$ 化学转化率邛迶无量纲轴向坐标变化曲线

Figure 11 Optimal configuration for entropy generation rate minimization of RWGS reactor [69]. (a) Variations of entropy generation rates versus the reactor length $L$ with a fixed inlet temperature $T_{\mathrm{in}}$; (b) variations of entropy generation rates versus the reactor length $L$ with free inlet temperature $T_{\mathrm{in}}$; (c) variations of the heat reservoir temperatures $T_{\mathrm{a}}$ along the dimensionless axial coordinate; (d) variations of the temperatures $T$ of reaction mixtures along the dimensionless axial coordinate; (e) optimal temperature configurations of the optimal reactors; (f) variations of total local entropy generation rates $\sigma_{\text {to }}$ along dimensionless axial coordinate; $(\mathrm{g})$ variations of the chemical conversion rates $\xi$ along the dimensionless axial coordinate.

选取氦气进口温度 $T_{\mathrm{a}, \text { in }}$ 、进口摩尔流率 $F_{\mathrm{a}, \mathrm{in}}$ 、反 应混合物进口温度 $T_{\mathrm{in}}$ 、进口总摩尔流率 $F_{\mathrm{T}, \mathrm{in}}$ 和进口总
压力 $P_{\mathrm{in}}$ 这 5 个独立参数作为决策变量. 从热管理和产 率提升两方面考虑，以最大径向温差最小和出口平均 


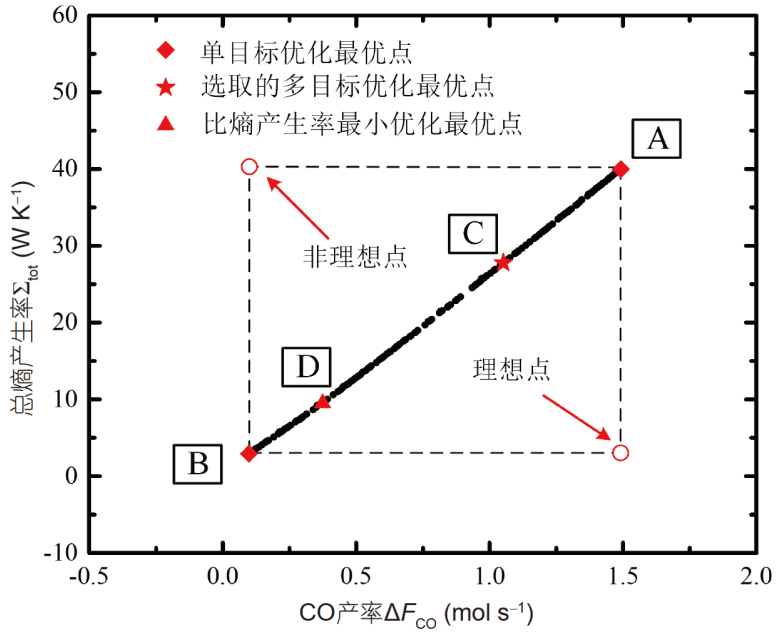

图 12 (网络版彩图) RWGS反应器多目标优化Pareto最优 前沿 $[68]$

Figure 12 (Color online) Pareto optimal frontier for the multiobjective optimization of the RWGS reactor [68].

转化率最大为优化目标对反应器进行多目标优化:

$\left\{\begin{array}{l}\min \max \Delta T, \\ \max \bar{\xi}_{\text {out }}\end{array}\right.$

式中, $\max \Delta T=\max \left(T_{R=R_{\mathrm{i}}}-T_{R=0}\right)$ 表示反应器最大径向 温差, $\bar{\xi}_{\text {out }}$ 为转化管出口平均转化率.

图13(a)和(b)分别给出了顺流式反应器和逆流式 反应器基于NSGA-II多目标优化算法的Pareto最优前 沿. 由图可见, 最优Pareto前沿近似一条曲抛物线, 曲线 上的的两个端点 (点 $\mathrm{A}$ 和点 $\mathrm{B}$ )分别表示系统在单目标 优化时的最优性能, 点A对应于出口平均转化率 $\bar{\xi}_{\text {out }}$ 最
大时的性能点，点 $\mathrm{B}$ 对应于最大径向温差 $\max (\Delta T)$ 最小 时的性能点. 对于顺流式反应器, 在给定的决策变量数 值变化范围内, 最优出口平均转化率 $\bar{\xi}_{\text {out }}$ 的变化范围为 $0.4268 \sim 0.538$, 最大径向温差 $\max (\Delta T)$ 的变化范围为 $15.5 \sim 87.8 \mathrm{~K}$; 对于逆流式反应器, 最优出口平均转化 率 $\bar{\xi}_{\text {out }}$ 的变化范围为 $0.4366 \sim 0.5466$, 产率性能明显优于 顺流式反应器，最大径向温差 $\max (\Delta T)$ 的变化范围为 $16.9 \sim 71.6 \mathrm{~K}$. 可以选取一个较为适中的点 $\mathrm{C}$ 作为最优 设计点, 对于顺流式反应器, 点 $\mathrm{C}$ 在出口平均转化率提 升 $5 \%$ 的同时最大径向温差降低了 $29 \%$; 对于逆流式反 应器，点C在出口平均转化率提高 $7 \%$ 的同时最大径向 温差降低了 $24 \%$.

\subsection{FT合成单元反应器反应过程分析与优化}

FT合成反应是能将合成气 $\left(\mathrm{CO}\right.$ 和 $\left.\mathrm{H}_{2}\right)$ 转化为烃类 产物的一类化学反应. 众多学者从经典热力学 ${ }^{[175,176]}$ 、 动力学和反应器建模仿真 ${ }^{[177 ~ 180]}$ 的角度对FT反应进行 了研究. Iandoli和Kjelstrup ${ }^{[181]}$ 对包含浆态床FT合成反 应器在内的“气转液”过程进行了分析, 得到了全流程 的第二定律效率和熵产率在各子系统中的分布. 张 䂞 ${ }^{[69]}$ 建立了FT反应器反应过程的有限时间热力学模 型, 获得了最优结果.

\subsubsection{FT合成反应器反应过程物理和数学模型}

FT过程是由成百上千种中间组分以高度耦合的 方式进行, 因此, 在对FT反应体系进行设计和优化研 究时, 不可能对每一步反应都构建出详细的化学反应
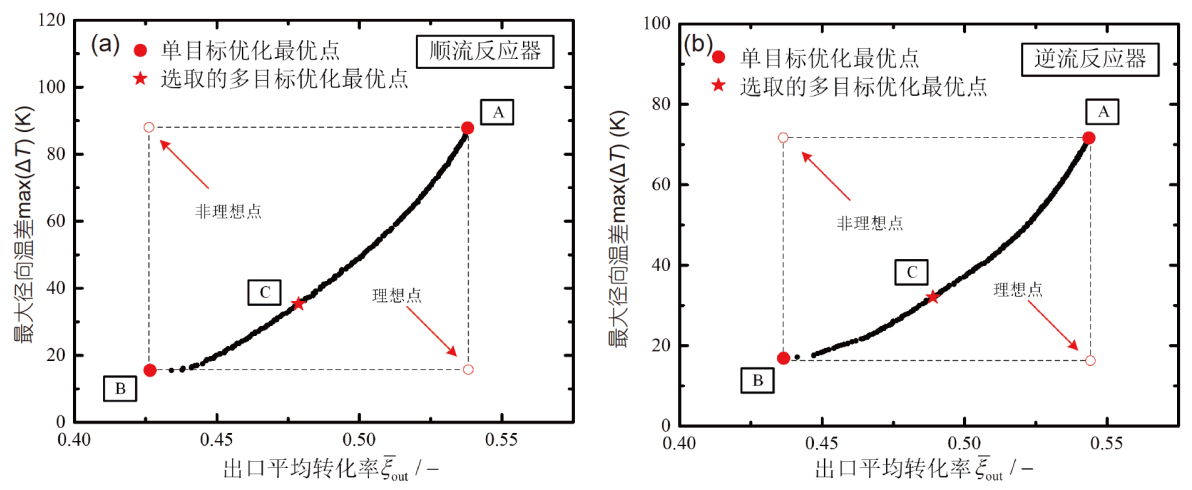

图 13 (网络版彩图) RWGS反应器多目标优化 ${ }^{[69]}$. (a) 顺流式反应器多目标优化Pareto最优前沿; (b) 逆流式反应器多目标优化 Pareto最优前沿

Figure 13 (Color online) Multi-objective optimization of RWGS reactor [69]. (a) Pareto optimal frontier for the multi-objective optimization of the parallel-flow reactor; (b) Pareto optimal frontier for the multi-objective optimization of the counter-flow reactor. 
式. 对某个真实实验装置, 按照组分的含量把产物归纳 为 $\mathrm{CO}_{2}, \mathrm{CH}_{4}$, 低碳烃 $\left(\mathrm{C}_{2} \sim \mathrm{C}_{5}\right)$, 高碳油品 $\left(\mathrm{C}_{5+}\right)$ 和 $\mathrm{H}_{2} \mathrm{O}$. 以 丙烯 $\mathrm{C}_{3} \mathrm{H}_{6}$ 表示低碳烃, $\mathrm{C}_{10} \mathrm{H}_{20}$ 表示高碳油品, 则FT反应 化学式可表示为

$\mathrm{CO}+3 \mathrm{H}_{2} \rightleftharpoons \mathrm{CH}_{4}+\mathrm{H}_{2} \mathrm{O}, \quad \Delta_{\mathrm{r}} H_{1}<0$,

$\mathrm{CO}+2 \mathrm{H}_{2} \rightleftharpoons \frac{1}{3} \mathrm{C}_{3} \mathrm{H}_{6}+\mathrm{H}_{2} \mathrm{O}, \quad \Delta_{\mathrm{r}} H_{2}<0$,

$\mathrm{CO}+2 \mathrm{H}_{2} \rightleftharpoons \frac{1}{10} \mathrm{C}_{10} \mathrm{H}_{20}+\mathrm{H}_{2} \mathrm{O}, \Delta_{\mathrm{r}} H_{3}<0$,

$\mathrm{CO}+\mathrm{H}_{2} \mathrm{O} \rightleftharpoons \mathrm{CO}_{2}+\mathrm{H}_{2}, \quad \Delta_{\mathrm{r}} H_{4}<0$,

式中, $\Delta_{\mathrm{r}} H_{j}$ 为反应 $j(j=1,2,3,4)$ 的化学反应焓.

FT合成反应是强放热反应，反应过程中放出的大 量热量会使反应器形成极高的“热点”，甚至在操作参 数发生较小扰动时出现“飞温”的现象. 因此, 考虑使 用惰性气体 $\mathrm{N}_{2}$ 作为保护性气体, 以降低反应器出现 “飞温”和催化剂烧结失活的风险。反应器内气相混合 物特性由反应混合物温度 $T(z)$ 、压力 $P(z)$ 、组分 $k$ $\left(k=\mathrm{CO}, \mathrm{H}_{2}, \mathrm{CH}_{4}, \mathrm{C}_{3} \mathrm{H}_{6}, \mathrm{C}_{10} \mathrm{H}_{20}, \mathrm{CO}_{2}, \mathrm{H}_{2} \mathrm{O}, \mathrm{N}_{2}\right.$ ) 的摩尔流 率 $F_{k}(z)$ 或反应 $j(j=1,2,3,4)$ 的转化率 $\xi_{j}(z)$ 表示. 关键反 应物 $\mathrm{CO}$ 的转化率 $X_{\mathrm{CO}}$ 根据反应进、出口的 $\mathrm{CO}$ 摩尔流 率计算:

$X_{\mathrm{CO}}=\left(F_{\mathrm{CO}, \text { in }}-F_{\mathrm{CO}, \text { out }}\right) / F_{\mathrm{CO}, \text { in }}$.

$\mathrm{CH}_{4}, \mathrm{C}_{3} \mathrm{H}_{6}, \mathrm{C}_{10} \mathrm{H}_{20}$ 和 $\mathrm{CO}_{2}$ 的收率以生成该组分所 消耗的 $\mathrm{CO}$ 物质量与反应器进口处 $\mathrm{CO}$ 物质量之比 表示:

$$
\begin{aligned}
& Y_{\mathrm{CH}_{4}}=\left(F_{\mathrm{CH}_{4}, \text { out }}-F_{\mathrm{CH}_{4}, \text { in }}\right) / F_{\mathrm{CO}, \text { in }}, \\
& Y_{\mathrm{C}_{3} \mathrm{H}_{6}}=3 \times\left(F_{\mathrm{C}_{3} \mathrm{H}_{6}, \text { out }}-F_{\mathrm{C}_{3} \mathrm{H}_{6}, \text { in }}\right) / F_{\mathrm{CO}, \text { in }}, \\
& Y_{\mathrm{C}_{10} \mathrm{H}_{20}}=10 \times\left(F_{\mathrm{C}_{10} \mathrm{H}_{20} \text {,out }}-F_{\mathrm{C}_{10} \mathrm{H}_{20}, \text { in }}\right) / F_{\mathrm{CO}, \text { in }}, \\
& Y_{\mathrm{CO}_{2}}=\left(F_{\mathrm{CO}_{2}, \text { out }}-F_{\mathrm{CO}_{2}, \text { in }}\right) / F_{\mathrm{CO}, \text { in }} .
\end{aligned}
$$

$\mathrm{CO}$ 参与了所有的子反应，选择 $\mathrm{CO}$ 作为关键组分 来表示各子反应的转化率, 则反应 $j$ 的转化率为

$\xi_{j}(z)=\Delta F_{\mathrm{CO}, j}(z) / F_{\mathrm{CO}, \text { in }}$.

反应器中任意轴向坐标 $z$ 上组分 $k$ 的摩尔流率为

$$
F_{k}(z)=F_{k, \text { in }}+F_{\mathrm{CO}, \text { in }} \sum_{j} v_{k, j} \xi_{j}(z) .
$$

考虑能量守恒、动量守恒、质量守恒和反应速率 方程, 建立反应过程模型. 反应器中考虑传热、黏性流 动和化学反应过程的局部商产生率与式(60)相同. 总
熵产生率为局部熵产生率 $\sigma_{\mathrm{tot}}$ 在反应器长度上的积分 与式(62)相同.

\subsubsection{FT合成反应器摘产生率最小化}

在给定FT反应器目标产物(高碳油品 $\mathrm{C}_{10} \mathrm{H}_{20}$ ) 产率 的约束条件下, 以总熵产生率最小为优化目标, 求解最 优构型问题. 为研究各种优化变量对最优化结果的影 响, 分别考虑两种优化策略: 以 $T_{\mathrm{a}}$ 为控制变量, 在进口 温度 $T_{\text {in }}$ 固定的条件下对参考反应器进行优化, 优化结 果记为“Case 1 ”; 以 $T_{\mathrm{a}}$ 为控制变量, 在进口温度 $T_{\text {in }}$ 自由 的条件下对参考反应器进行优化, 优化结果记为“Case 2”. 最优控制问题的必要条件包括 12 个微分方程、 1 个 代数方程和与不同优化问题相对应的 12 个边界条件. 因此，动态优化问题转化为求解微分方程组的两点边 界值问题 ${ }^{[69]}$.

图14(a)和(b)分别给出了参考反应器和最优反应 器管外热源温度 $T_{\mathrm{a}}$ 和反应混合物温度 $T$ 的变化曲线, 图 中“ref”表示参考反应器, “optimal”表示最优反应器. 图14(c)给出了最优反应器管外热源温度和反应混合 物温度的分布曲线(温度最优构型).

\subsubsection{FT合成反应器多目标优化}

以目标产物 $\mathrm{C}_{10} \mathrm{H}_{20}$ 产率 $\Delta F_{\mathrm{C}_{10} \mathrm{H}_{20}}$ 最大和总摘产生率 $\Sigma_{\mathrm{tot}}$ 最小为优化目标对反应器进行多目标优化. 选取反 应混合物进口温度 $T_{\mathrm{in}}$ 、进口压力 $P_{\mathrm{in}}$ 、进口总摩尔流 率 $F_{\mathrm{T}, \mathrm{in}}$ 和反应器内径 $d_{\mathrm{i}}$ 、长度 $L$ 、催化剂堆密度 $\rho_{\mathrm{b}}$ 、催 化剂颗粒直径 $d_{\mathrm{p}}$ 为决策变量. 图 15 给出了 FT反应器基 于总熵产生率 $\Sigma_{\mathrm{tot}}$ 最小和 $\mathrm{C}_{10} \mathrm{H}_{20}$ 产率 $\Delta F_{\mathrm{C}_{10} \mathrm{H}_{20}}$ 最大多目 标优化的最优Pareto前沿. 选取较适中的多目标最优解 (点C)为设计点, 能使 $\mathrm{FT}$ 反应器在 $\mathrm{C}_{10} \mathrm{H}_{20}$ 产率增加 $6 \%$ 的 同时使总熵产生率减小 $11 \%$.

\section{$5.3 \mathrm{CO}_{2}$ 氢化合成低碳烯烃单元反应过程分析与 优化}

$\mathrm{CO}_{2}$ 氢化合成低碳烯烃反应为乙烯、丙烯等低碳 烯烃产品的生产提供了一条更加环保、经济的非石油 合成路径. $\mathrm{CO}_{2}$ 氢化合成低碳烯烃反应机理复杂, 张磊 等人 ${ }^{[51,53]}$ 从经典热力学理论出发, 使用 Gibbs自由能最 小化和熵最大化方法对 $\mathrm{CO}_{2}$ 氢化合成低碳烯烃反应体 系进行平衡态分析, 系统地研究反应温度、压力、进 

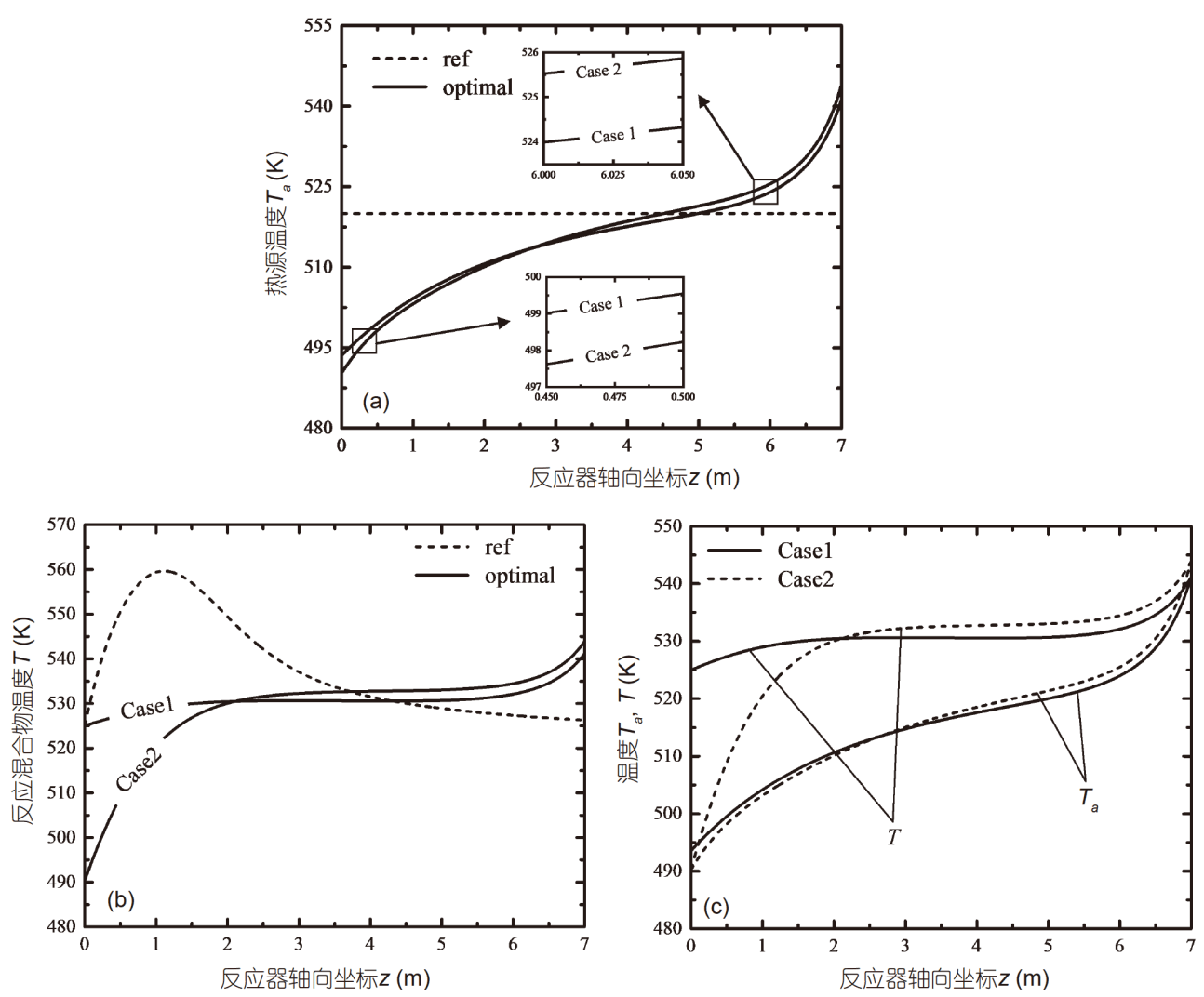

图 14 FT合成反应器熵产生率最小化 ${ }^{[69]}$. (a) 热源温度 $T_{\mathrm{a}}$ 随反应器轴向坐标变化曲线; (b) 反应混合物温度 $T$ 随反应器轴向坐 标变化曲线; (c) 最优反应器温度最优构型

Figure 14 Entropy generation rate minimization for Fischer-Tropsch reactor [69]. (a) Variations of the heat reservoir temperatures $T_{\mathrm{a}}$ along the axial coordinate of the reactor; (b) variations of the temperatures $T$ of reaction mixtures along the axial coordinate of the reactor; (c) optimal temperature configurations of the optimal reactors.

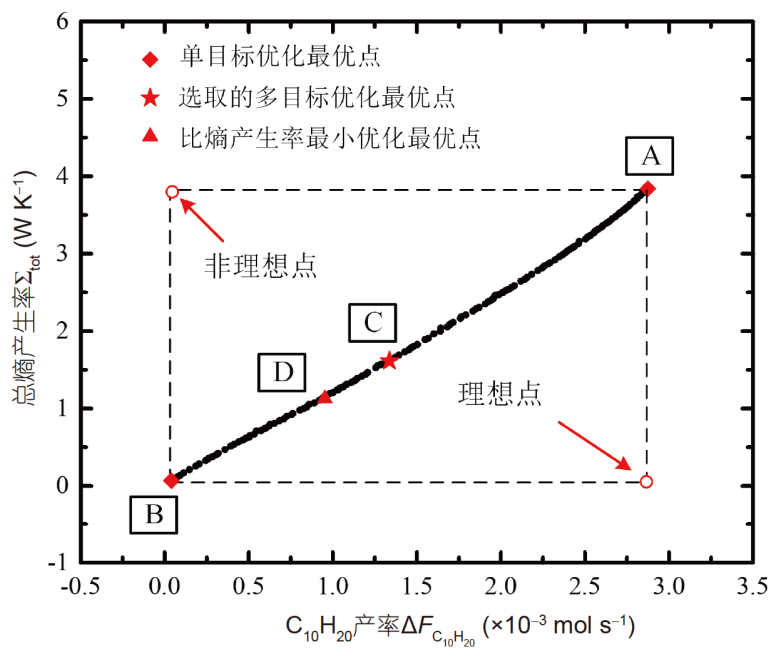

图 15 (网络版彩图) FT反应器多目标优化Pareto最优前 沿 $[69]$

Figure 15 (Color online) Pareto optimal frontier for the multiobjective optimization of the FT reactor [69].
料气摩尔比和不同的化学和工业技术对平衡状态的影 响. 陈林根等人 ${ }^{[51]}$ 和张磊等人 ${ }^{[55,67]}$ 进一步考虑动力学 因素, 建立了其反应过程的有限时间热力学模型, 获 得了最优结果.

\subsection{1 $\mathrm{CO}_{2}$ 氢化合成低碳烯烃单元反应过程物理和数} 学模型

在 $\mathrm{Fe}$ 基催化剂上进行的 $\mathrm{CO}_{2}$ 氢化合成低碳烯烃反 应一般认为符合“两步合成机制”, 即 $\mathrm{CO}_{2}$ 经过RWGS反 应过程转化为 $\mathrm{CO}$ 和 $\mathrm{CO}$ 通过FT反应加氢生成低碳烯烃 两步反应 ${ }^{[31,182]}$. 图16给出了基于 $\mathrm{Na}-5 \mathrm{Mn}-\mathrm{Fe}_{3} \mathrm{O}_{4}$ 催化剂 的燃料合成技术路线流程图, 虚线框内即是所研究的 子过程. 以 $\mathrm{C}_{3} \mathrm{H}_{6}$ 代表低碳烯烃产物, $\mathrm{C}_{10} \mathrm{H}_{20}$ 代表高碳油 品. 根据实际反应产物种类, 该 $\mathrm{Fe}$ 基催化剂表面发生的 氢化反应为 


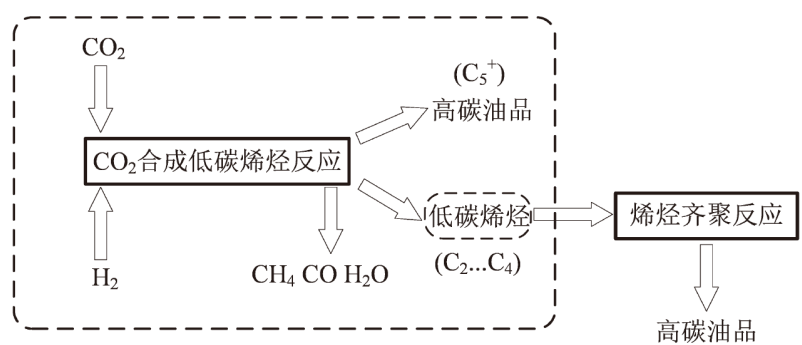

图 16 燃料合成技术路线流程图

Figure 16 Flow diagram for technical route of fuel synthesis.

$\mathrm{CO}_{2}+\mathrm{H}_{2} \rightleftharpoons \mathrm{CO}+\mathrm{H}_{2} \mathrm{O}, \quad \Delta_{\mathrm{r}} H_{1}>0$,

$\frac{1}{2} \mathrm{CO}+\mathrm{H}_{2} \rightleftharpoons \frac{1}{6} \mathrm{C}_{3} \mathrm{H}_{6}+\frac{1}{2} \mathrm{H}_{2} \mathrm{O}, \quad \Delta_{\mathrm{r}} H_{2}<0$,

$\frac{1}{2} \mathrm{CO}+\mathrm{H}_{2} \rightleftharpoons \frac{1}{20} \mathrm{C}_{10} \mathrm{H}_{20}+\frac{1}{2} \mathrm{H}_{2} \mathrm{O}, \Delta_{\mathrm{r}} H_{3}<0$,

$\frac{1}{3} \mathrm{CO}+\mathrm{H}_{2} \rightleftharpoons \frac{1}{3} \mathrm{CH}_{4}+\frac{1}{3} \mathrm{H}_{2} \mathrm{O}, \Delta_{\mathrm{r}} H_{4}<0$,

基于一维活塞流假设对单个FT反应器进行建模, 反应器模型和模型假设与5.1.1节相同. 反应器内气相 混合物特性由反应混合物温度 $T(z)$ 、压力 $P(z)$ 、组分 $k$ $\left(k=\mathrm{CO}_{2}, \mathrm{H}_{2}, \mathrm{CO}, \mathrm{C}_{3} \mathrm{H}_{6}, \mathrm{C}_{10} \mathrm{H}_{20}, \mathrm{CH}_{4}, \mathrm{H}_{2} \mathrm{O}\right)$ 的摩尔流率 $F_{k}(z)$ 或反应 $j(j=1,2,3,4)$ 的转化率 $\xi_{j}(z)$ 表示.

$\mathrm{CO}_{2}$ 转化率根据反应器进、出口的 $\mathrm{CO}_{2}$ 摩尔流率 计算:

$X_{\mathrm{CO}_{2}}=\left(F_{\mathrm{CO}_{2}, \text { in }}-F_{\mathrm{CO}_{2}, \text { out }}\right) / F_{\mathrm{CO}_{2}, \text { in }}$.

$\mathrm{CH}_{4}, \mathrm{C}_{3} \mathrm{H}_{6}, \mathrm{C}_{10} \mathrm{H}_{20}$ 和 $\mathrm{CO}$ 的收率表示为生成该组分 所消耗的 $\mathrm{CO}_{2}$ 物质量与反应器进口处 $\mathrm{CO}_{2}$ 物质量之比:

$Y_{\mathrm{CH}_{4}}=\left(F_{\mathrm{CH}_{4}, \text { out }}-F_{\mathrm{CH}_{4}, \text { in }}\right) / F_{\mathrm{CO}_{2}, \text { in }}$,

$Y_{\mathrm{C}_{3} \mathrm{H}_{6}}=3 \times\left(F_{\mathrm{C}_{3} \mathrm{H}_{6}, \text { out }}-F_{\mathrm{C}_{3} \mathrm{H}_{6}, \text { in }}\right) / F_{\mathrm{CO}_{2}, \text { in }}$,

$Y_{\mathrm{C}_{10} \mathrm{H}_{20}}=10 \times\left(F_{\mathrm{C}_{10} \mathrm{H}_{20}, \text { out }}-F_{\mathrm{C}_{10} \mathrm{H}_{20}, \text { in }}\right) / F_{\mathrm{CO}_{2} \text {, in }}$,

$Y_{\mathrm{CO}}=\left(F_{\mathrm{CO}, \text { out }}-F_{\mathrm{CO}, \text { in }}\right) / F_{\mathrm{CO}_{2}, \text { in }}$.

对于化学反应体系(式(91) (94)), $\mathrm{H}_{2}$ 参与了所有 的子反应，因此，选择 $\mathrm{H}_{2}$ 作为关键反应物组分来表示 各子反应的转化率, 则反应 $j$ 的转化率为

$\xi_{j}(z)=\Delta F_{H_{2}, j}(z) / F_{H_{2}, \text { in }}$.

反应器中任意轴向坐标 $z$ 上组分 $k$ 的摩尔流率为

$F_{k}(z)=F_{k, \text { in }}+F_{\mathrm{H}_{2}, \text { in }} \sum_{j} v_{k, j} \xi_{j}(z)$.

考虑能量守恒、动量守恒、质量守恒和反应速率
方程, 建立反应过程模型. 反应器中考虑传热、黏性流 动和化学反应过程的局部熵产生率和总摘产生率同式 (60)和(62).

5.3.2 $\mathrm{CO}_{2}$ 氢化合成低碳烯烃单元反应过程比熵产生 率分析与优化

比熵产生率优化问题为

$\left\{\begin{array}{l}\min \Sigma_{\mathrm{spec}}, \\ \Sigma_{\mathrm{spec}}=f(x),\end{array}\right.$

式中, $x$ 为决策变量, 包括进口条件和反应器结构参数 等在工程上可进行设计和调整的变量. 求解比熵产生 率最小所对应的最佳参数取值, 该优化问题属于有限 时间热力学中的最优性能研究.

图17(a) (c)分别给出了反应混合物进口压力 $P_{\text {in }}$ 、 反应混合物进口总摩尔流率 $F_{\mathrm{T}, \mathrm{in}}$ 和反应管内径 $d_{\mathrm{i}}$ 对比 熵产生率和 $\mathrm{C}_{10} \mathrm{H}_{20}$ 产率的影响规律. 计算表明, 对反应 器进行比熵产生率最小优化后, 反应器的总比熵产生

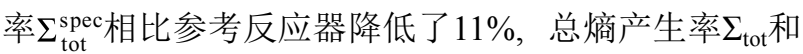
$\mathrm{C}_{10} \mathrm{H}_{20}$ 产率 $\Delta F_{\mathrm{C}_{10} \mathrm{H}_{20}}$ 也分别降低了 $76 \%$ 和 $73 \%$, 说明最小 的比熵产生率是反应器总熵产生率和目标产物产率变 化折中的结果.

\subsection{3 $\mathrm{CO}_{2}$ 氢化合成低碳烯烃单元反应过程多目标} 优化

以目标产物 $\mathrm{C}_{10} \mathrm{H}_{20}$ 产率最大和总熵产生率最小为 优化目标对反应器进行多目标优化. 选取反应混合物 进口温度 $T_{\text {in }}$ 、进口压力 $P_{\text {in }}$ 、进口总摩尔流率 $F_{\mathrm{T}, \mathrm{in}}$ 、反 应器内径 $d_{\mathrm{i}}$ 、长度 $L$ 和催化剂堆密度 $\rho_{\mathrm{b}}$ 为决策变量. 多 目标优化问题为

$\left\{\begin{array}{l}\min \Sigma_{\text {tot }} \\ \max \Delta F_{\mathrm{C}_{10} \mathrm{H}_{20}} .\end{array}\right.$

图18(a)给出了 $\mathrm{CO}_{2}$ 氢化合成低碳烯烃反应器基于 总熵产生率 $\Sigma_{\mathrm{tot}}$ 最小和 $\mathrm{C}_{10} \mathrm{H}_{20}$ 产率 $\Delta F_{\mathrm{C}_{10} \mathrm{H}_{20}}$ 最大多目标 优化的最优Pareto前沿. 图18(b)给出了 $\mathrm{CO}_{2}$ 氢化合成低 碳烯烃反应器在多目标优化、单目标优化和未优化情 况下各目标值的对比关系. 最优Pareto前沿上的两个端 点, 点 $\mathrm{A}$ 代表 $\Delta F_{\mathrm{C}_{10} \mathrm{H}_{20}}$ 最大. 点 $\mathrm{D}$ 表示5.3.2节比摘产生率 最小单目标优化的最优解. 选取较适中的多目标最优 

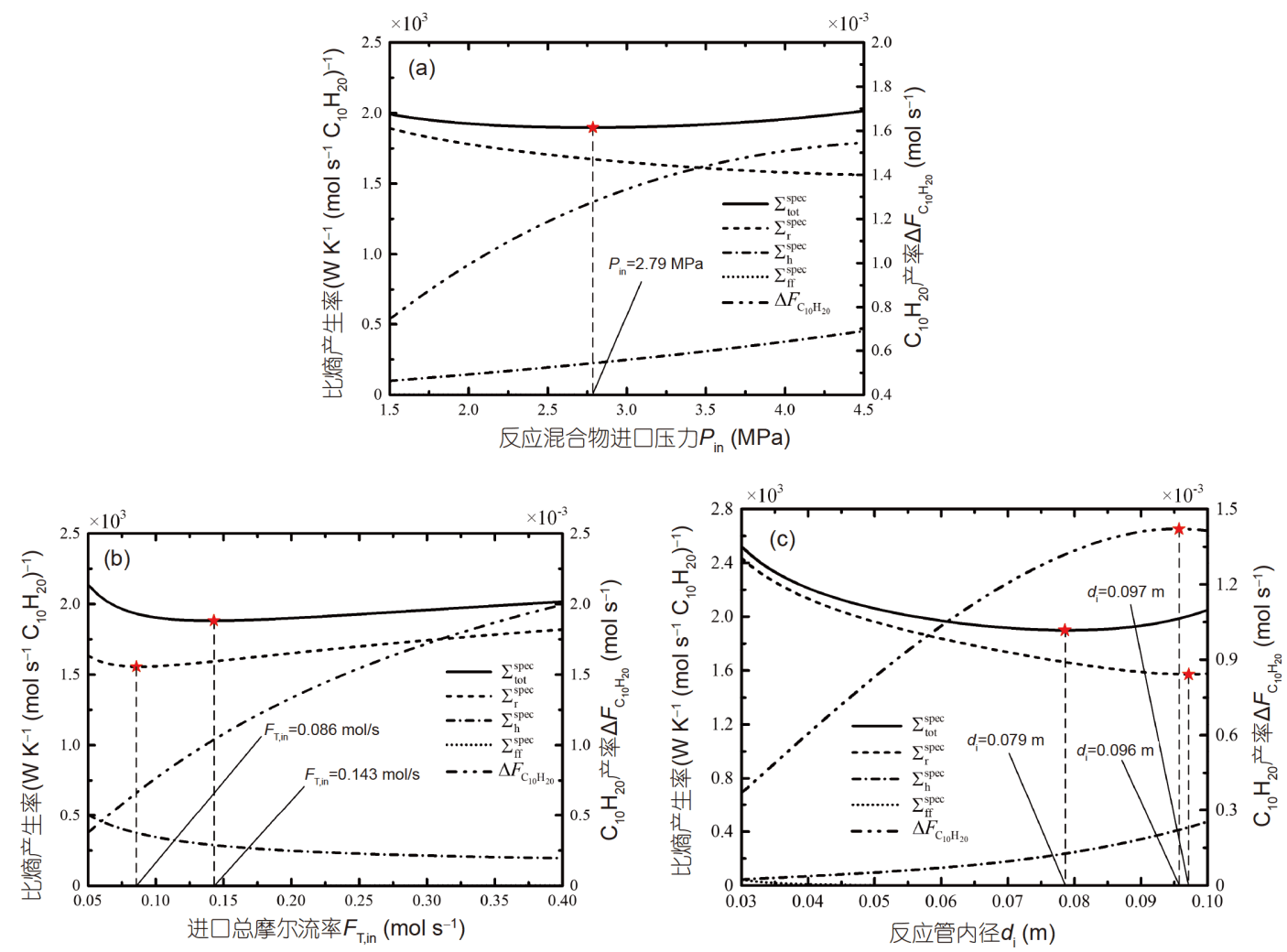

图 17 (网络版彩图) $\mathrm{CO}_{2}$ 氢化合成低碳烯烃反应器比熵产生率最小化和 $\mathrm{C}_{10} \mathrm{H}_{20}$ 产率变化规律 ${ }^{[69]}$. (a) 比熵产生率和 $\mathrm{C}_{10} \mathrm{H}_{20}$ 产率 随反应混合物进口压力 $P_{\text {in }}$ 的变化规律; (b) 比摘产生率和 $\mathrm{C}_{10} \mathrm{H}_{20}$ 产率随进口总摩尔流率 $F_{\mathrm{T}, \mathrm{in}}$ 的变化规律; (c) 比摘产生率和 $\mathrm{C}_{10} \mathrm{H}_{20}$ 产率随反应管内径 $d_{\mathrm{i}}$ 的变化规律

Figure 17 (Color online) Specific entropy generation rate minimization and variations of production rate of $\mathrm{C}_{10} \mathrm{H}_{20}$ for of the $\mathrm{CO}_{2}$ hydrogenation to light olefins reactor [69]. (a) Variations of the specific entropy generation rates and production rate of $\mathrm{C}_{10} \mathrm{H}_{20}$ with the inlet pressure $P_{\text {in }}$ of reaction mixtures; (b) variations of the specific entropy generation rates and production rate of $\mathrm{C}_{10} \mathrm{H}_{20}$ with the inlet total molar flow rate $F_{\mathrm{T}, \text { in }}$; (c) variations of the specific entropy generation rates and production rate of $\mathrm{C}_{10} \mathrm{H}_{20}$ with the inner diameter $d_{\mathrm{i}}$ of the reactor.
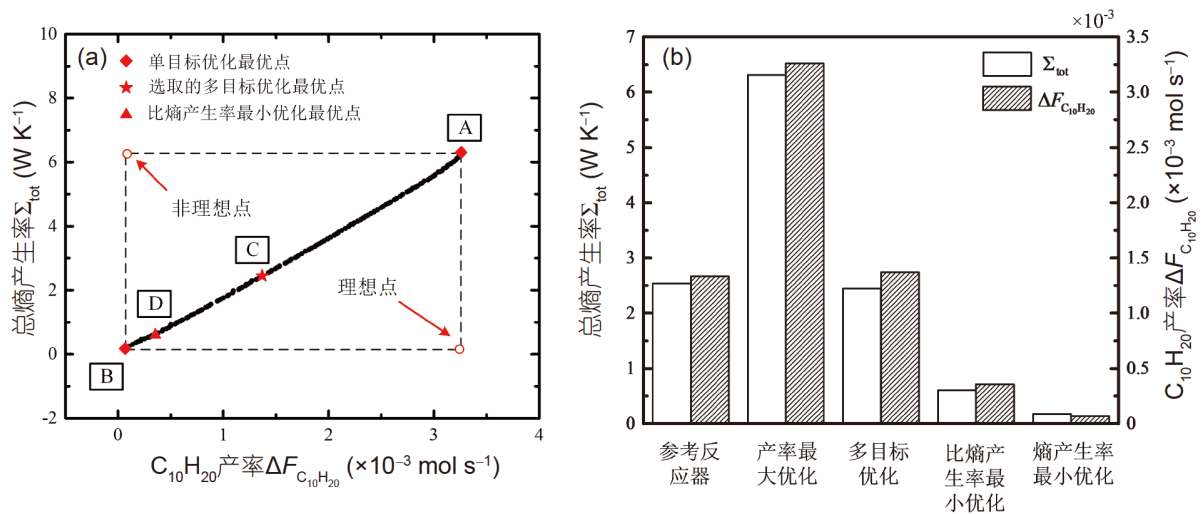

图 18 (网络版彩图) $\mathrm{CO}_{2}$ 氢化合成低碳烯烃反应器多目标优化 ${ }^{[69]}$. (a) 多目标优化Pareto最优前沿; (b) 参考反应器与最优反应 器总熵产生率和产率对比图

Figure 18 (Color online) Multi-objective optimization of the $\mathrm{CO}_{2}$ hydrogenation to light olefins reactor [69]. (a) Pareto optimal frontier for multiobjective optimization; (b) comparisons of the total entropy generation rates and production rates for the reference and optimal reactors. 
解(点C)为设计点, 能使 $\mathrm{CO}_{2}$ 氢化合成低碳烯烃反应器 在 $\mathrm{C}_{10} \mathrm{H}_{20}$ 产率增加 $2 \%$ 的同时使总熵产生率减小 $4 \%$. $\mathrm{C}_{10} \mathrm{H}_{20}$ 产率 $\Delta F_{\mathrm{C}_{10} \mathrm{H}_{20}}$ 最大单目标优化的最优反应器相比 参考反应器, $\Delta F_{\mathrm{C}_{10} \mathrm{H}_{20}}$ 增加了 $143 \%$, 但单目标最优解却 导致总熵产生率 $\Sigma_{\mathrm{tot}}$ 增加了 $149 \%$; 在所给的决策变量 取值范围内，在没有产率约束的情况下单独优化总熵 产生率可使 $\Sigma_{\text {tot }}$ 降低 $93 \%$, 但 $\Delta F_{\mathrm{C}_{10} \mathrm{H}_{20}}$ 也同时降低了 $95 \%$, 此时的结果可以理解为“反应过程最大限度地停止”, 优化结果对实际工程毫无意义; 比熵产生率最小单目 标优化的最优反应器相比参考反应器，总熵产生率 $\Sigma_{\mathrm{tot}}$ 和 $\mathrm{C}_{10} \mathrm{H}_{20}$ 产率 $\Delta F_{\mathrm{C}_{10} \mathrm{H}_{20}}$ 分别降低了 $76 \%$ 和 $73 \%$, 说明对于 $\mathrm{CO}_{2}$ 氢化合成低碳烯烃反应器性能优化问题, 比摘产 生率复合目标函数最小更倾向于降低过程的不可逆 性. 多目标优化能够协调 $\mathrm{CO}_{2}$ 氢化合成低碳烯烃反应 器产率提升与降低过程不可逆性之间的相互矛盾制约 关系, 使反应器在多个目标下达到协同最优.

\section{4 烯烃齐聚单元反应过程分析与优化}

在“短链烃聚合”合成燃油路径中, 原料气 $\mathrm{CO}_{2}$ 经 过催化加氢反应后，一次转化产物中除可直接收集的 液态燃料产物外还有相当一部分的低碳烯烃 $\mathrm{C}_{2}^{=} \sim \mathrm{C}_{4}^{=}$, 这部分产物需要经过齐聚反应转化为高碳烃燃油，从 而进一步提高合成燃油路线的总体收率。一些学者主 要从经典热力学 ${ }^{[183]}$ 、动力学建模仿真 ${ }^{[184,185]}$ 和反应工 艺条件优化 ${ }^{[186]}$ 等方面对乙烯齐聚反应进行了研究. 张 否融建立了其烯烃齐聚单元反应器反应过程的有限 时间热力学模型, 获得了最优结果.

\subsection{1 烯烃齐聚单元反应过程物理和数学模型}

$\mathrm{CO}_{2}$ 氢化合成低碳烯烃反应产物中包括了 $\mathrm{C}_{2}^{=} \sim \mathrm{C}_{4}^{=}$ 的低碳烯烃混合物. 以丁烯 $\mathrm{C}_{4} \mathrm{H}_{8}$ 表示低聚产物, $\mathrm{C}_{10} \mathrm{H}_{20}$ 表示高碳烃产物 $\left(\mathrm{C}_{5}^{+}\right)$, 即高碳油品, 则烯烃齐聚反应化 学式为

$\mathrm{C}_{2} \mathrm{H}_{4} \rightleftharpoons \frac{1}{2} \mathrm{C}_{4} \mathrm{H}_{8}, \quad \Delta_{\mathrm{r}} H_{1}<0$,

$\mathrm{C}_{2} \mathrm{H}_{4} \rightleftharpoons \frac{1}{5} \mathrm{C}_{10} \mathrm{H}_{20} \quad \Delta_{\mathrm{r}} \mathrm{H}_{2}<0$.

假设列管式反应器中单个反应管的反应条件均相 同，基于一维活塞流假设对单个烯烃齐聚反应器进行
建模，反应器模型和模型假设与5.1.1节相同，建模过 程中考虑使用惰性气体 $\mathrm{N}_{2}$ 作为保护性气体. 反应器内 气相混合物特性由反应混合物温度 $T(z)$ 、压力 $P(z)$ 、 组分 $k\left(k=\mathrm{C}_{2} \mathrm{H}_{4}, \mathrm{C}_{4} \mathrm{H}_{8}, \mathrm{C}_{10} \mathrm{H}_{20}, \mathrm{~N}_{2}\right)$ 的摩尔流率 $F_{k}(z)$ 或反 应 $j(j=1,2)$ 的转化率 $\xi_{j}(z)$ 表示.

选择 $\mathrm{C}_{2} \mathrm{H}_{4}$ 为关键组分, 则反应 $j$ 的转化率为

$\xi_{j}(z)=\Delta F_{\mathrm{C}_{2} H_{4}, j}(z) / F_{\mathrm{C}_{2} H_{4}, \text { in }}$.

反应器中任意轴向坐标 $z$ 上组分 $k$ 的摩尔流率为

$F_{k}(z)=F_{k, \text { in }}+F_{\mathrm{C}_{2} H_{4}, \mathrm{in}} \sum_{j} v_{k, j} \xi_{j}(z)$.

$\mathrm{C}_{2} \mathrm{H}_{4}$ 转化率根据反应器进出口的 $\mathrm{C}_{2} \mathrm{H}_{4}$ 摩尔流率 计算:

$X_{\mathrm{C}_{2} \mathrm{H}_{4}}=\left(F_{\mathrm{C}_{2} \mathrm{H}_{4}, \text { in }}-F_{\mathrm{C}_{2} \mathrm{H}_{4}, \text { out }}\right) / F_{\mathrm{C}_{2} \mathrm{H}_{4}, \text { in }}$.

低碳烃 $\mathrm{C}_{3} \mathrm{H}_{6}$ 和高碳烃 $\mathrm{C}_{10} \mathrm{H}_{20}$ 的收率表示为生成该 组分所消耗的 $\mathrm{C}_{2} \mathrm{H}_{4}$ 物质量与反应器进口处 $\mathrm{C}_{2} \mathrm{H}_{4}$ 物质 量之比:

$Y_{\mathrm{C}_{4} \mathrm{H}_{8}}=2 \times\left(F_{\mathrm{C}_{4} \mathrm{H}_{8}, \text { out }}-F_{\mathrm{C}_{4} \mathrm{H}_{8}, \text { in }}\right) / F_{\mathrm{C}_{2} \mathrm{H}_{4}, \text { in }}$,
$Y_{\mathrm{C}_{10} \mathrm{H}_{20}}=5 \times\left(F_{\mathrm{C}_{10} \mathrm{H}_{20} \text {,out }}-F_{\mathrm{C}_{10} \mathrm{H}_{20}, \text { in }}\right) / F_{\mathrm{C}_{2} \mathrm{H}_{4}, \text { in }}$.

考虑能量守恒、动量守恒、质量守恒和反应速率 方程, 建立反应过程模型. 反应器中考虑传热、黏性流 动和化学反应过程的局部熵产生率和总摘产生率同式 (60)和(62).

\subsection{2 烯烃齐聚单元反应过程摘产率最小最优构型}

基于最优控制理论构建优化问题的哈密顿函数 $H$, 根据极小值原理获得动态系统应满足的必要条件, 考 虑两种边界条件约束下的最优控制问题，逐步释放优 化自由度, 进行计算. 最优控制问题的必要条件包括8 个微分方程, 一个代数方程和不同优化问题对应的 8 个 边界条件. 动态优化问题转化为求解微分方程组的两 点边界值问题. 以 $T_{\mathrm{a}}$ 为控制变量, 在进口温度 $T_{\mathrm{in}}$ 固定 的条件下对参考反应器进行优化, 优化结果记为“Case 1 ”; 以 $T_{\mathrm{a}}$ 为控制变量, 在进口温度 $T_{\text {in }}$ 自由的条件下对参 考反应器进行优化, 优化结果记为“Case 2”.

图19(a)和(b)分别给出了参考反应器和最优反应 器管外热源温度 $T_{\mathrm{a}}$ 和反应混合物温度 $T$ 的变化曲线, 图 中“ref”表示参考反应器, “optimal”表示最优反应器. 图19(c)给出了最优反应器管外热源温度和反应混合 

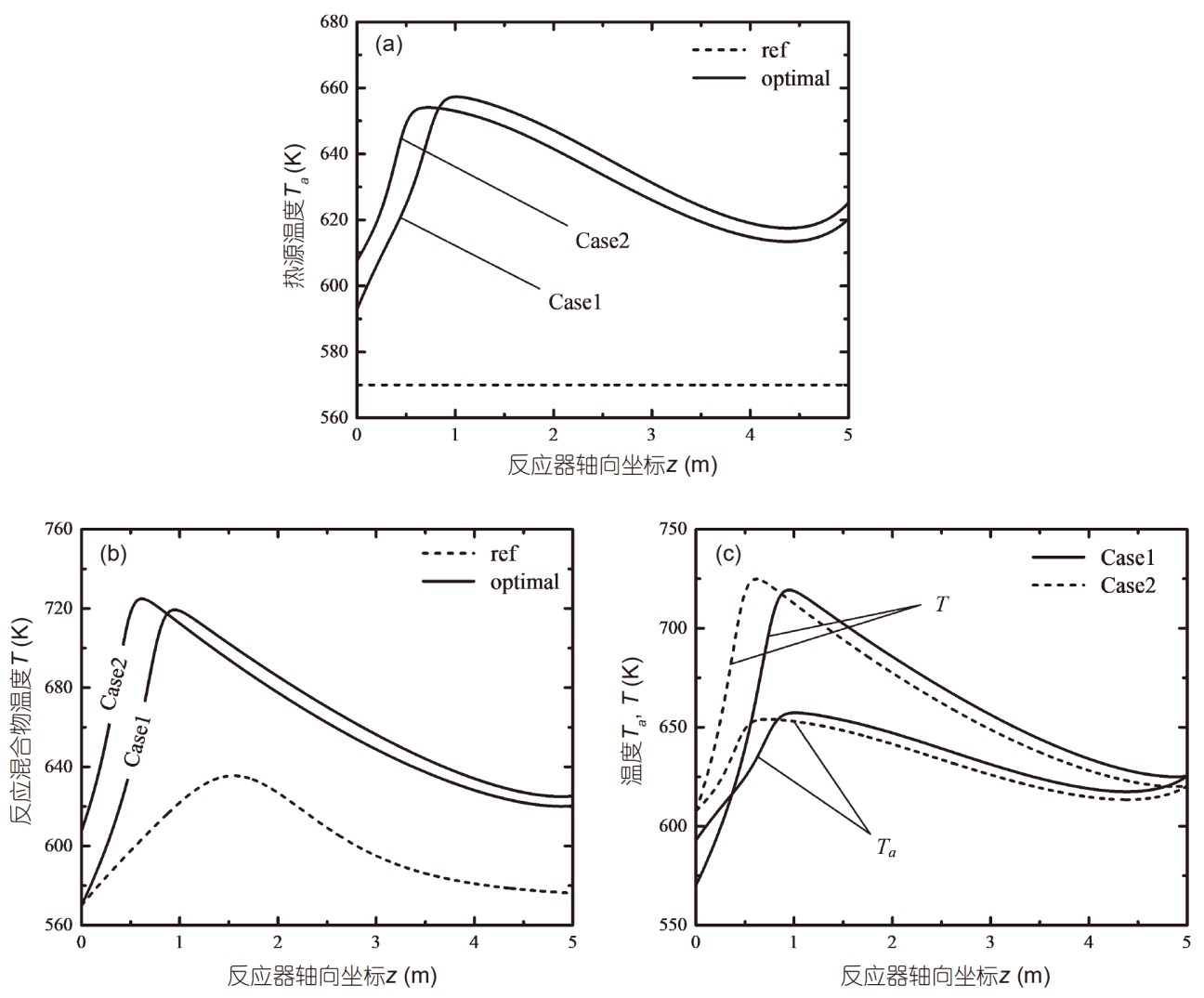

图 19 烯烃齐聚单元反应过程熵产率最小最优构型 ${ }^{[69]}$. (a) 热源温度 $T_{\mathrm{a}}$ 随反应器轴向坐标变化曲线; (b) 反应混合物温度 $T$ 随 反应器轴向坐标变化曲线; (c) 最优反应器温度最优构型

Figure 19 Optimal configuration for entropy generation rate minimization of olefins oligomerization unit reactorin [69]. (a) Variations of the heat reservoir temperatures $T_{\mathrm{a}}$ along the axial coordinate of the reactor; (b) variations of the temperatures $T$ of reaction mixtures along the axial coordinate of the reactor; (c) optimal temperature configurations of the optimal reactors.

物温度的分布曲线(温度最优构型).

\subsection{3 烯烃齐聚单元反应过程多目标优化}

选取反应混合物进口温度 $T_{\text {in }}$ 、进口压力 $P_{\text {in }}$ 、进 口总摩尔流率 $F_{\mathrm{T}, \mathrm{in}}$ 、反应器内径 $d_{\mathrm{i}}$ 、长度 $L$ 、催化剂堆 密度 $\rho_{\mathrm{b}}$ 、催化剂颗粒直径 $d_{\mathrm{p}}$ 为决策变量, 以目标产物 $\mathrm{C}_{10} \mathrm{H}_{20}$ 产率最大和总熵产生率最小为目标对反应器进 行多目标优化. 该多目标优化问题同式(104). 图20(a) 给出了烯烃齐聚反应器基于总熵产生率 $\Sigma_{\text {tot }}$ 最小和 $\mathrm{C}_{10} \mathrm{H}_{20}$ 产率 $\Delta F_{\mathrm{C}_{10} \mathrm{H}_{20}}$ 最大多目标优化的最优Pareto前沿. 选择的多目标最优设计点能使烯烃齐聚反应器在 $\mathrm{C}_{10} \mathrm{H}_{20}$ 产率增加 $8 \%$ 的同时使总熵产生率减小 $2 \%$. 图20(b) (h) 分别给出了Pareto最优前沿中反应混合物 进口温度 $T_{\text {in }}$ 、进口压力 $P_{\text {in }}$ 、催化剂堆床层密度 $\rho_{\mathrm{b}}$ 、催 化剂颗粒直径 $d_{\mathrm{p}}$ 、反应混合物进口总摩尔流率 $F_{\mathrm{T}, \mathrm{in}}$ 、 反应管内径 $d_{\mathrm{i}}$ 和长度 $L$ 在其取值范围内的分布情况. 最
优解的催化剂颗粒直径、反应混合物进口总摩尔流 率、反应管内径和长度在整个取值区间内均匀分布, 对这些决策变量进行调整是“中和”提升产率和降低过 程熵产生率之间矛盾的重要手段.

\section{6 结束语}

结合热力学、传热学、流体力学、化学反应动力 学、最优控制理论和多目标优化方法, 建立模型, 优化 性能, 一些学者探索了海基合成燃油系统关键单元的 热设计与优化问题. 由浅入深, 从建立热源温度完全 可控的一维活塞流反应器模型到建立以真实热源载热 工质的二维拟均相反应器模型; 由可逆模型到不可逆 模型, 从建立经典平衡态热力学模型到建立考虑多种 不可逆因素的有限时间热力学模型; 由单目标优化到 多目标优化, 从熵产生率最小和比熵产生率(对目标产 

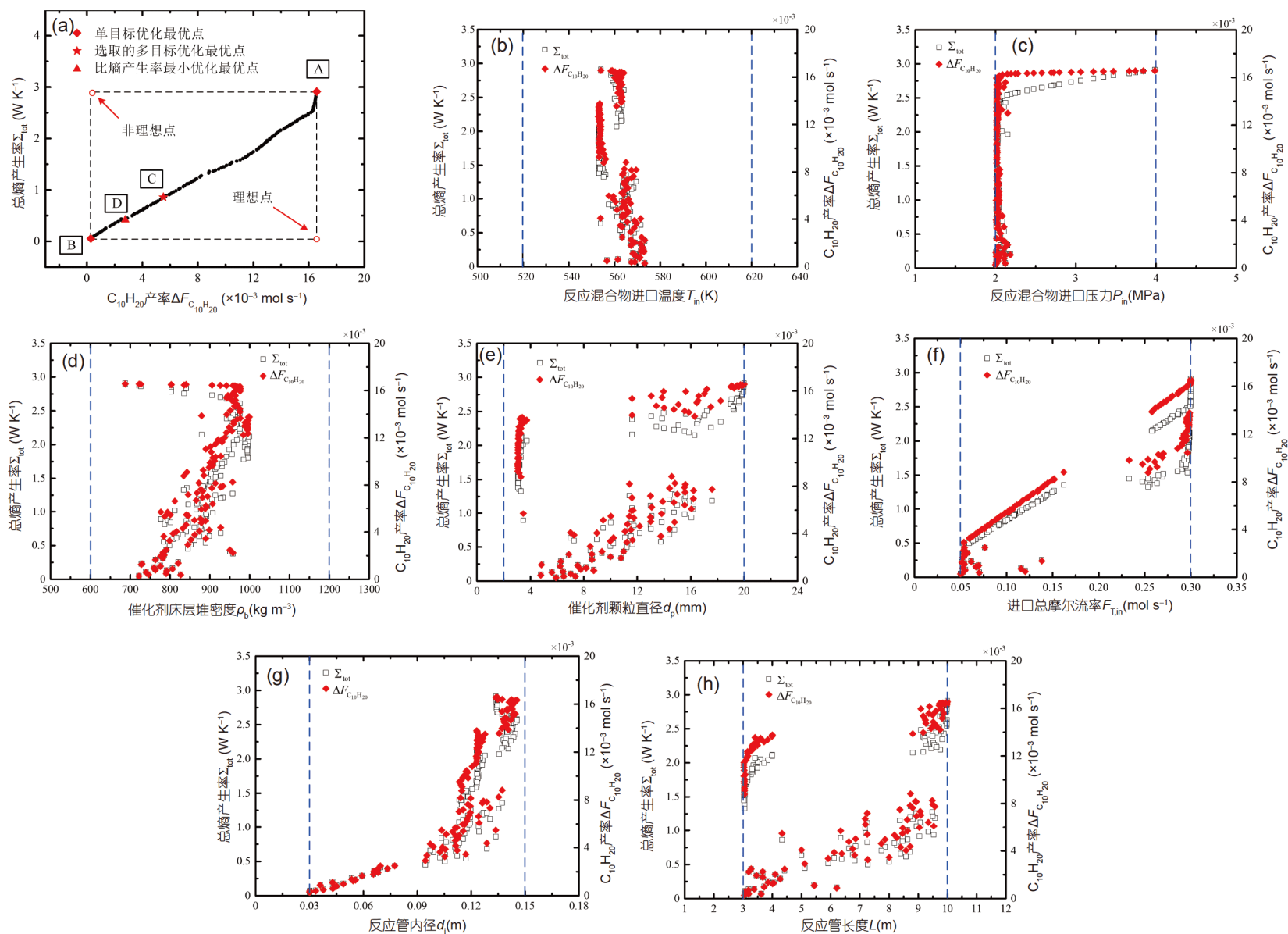

图 20 (网络版彩图)烯烃齐聚反应器多目标优化 ${ }^{[69]}$. (a) 多目标优化Pareto最优前沿; (b) Pareto前沿中反应混合物温度 $T_{\text {in }}$ 在取 值范围内的分布; (c) Pareto前沿中反应混合物压力 $P_{\text {in }}$ 在取值范围内的分布; (d) Pareto前沿中催化剂床层堆密度 $\rho_{\mathrm{b}}$ 在取值范围 内的分布; (e) Pareto前沿中催化剂颗粒直径 $d_{\mathrm{p}}$ 在取值范围内的分布; (f) Pareto前沿中反应混合物进口总摩尔流率 $F_{\mathrm{T}, \mathrm{in}}$ 在取值范 围内的分布; (g) Pareto前沿中反应管内径 $d_{\mathrm{i}}$ 在取值范围内的分布; (h) Pareto前沿中反应管长度 $L$ 在取值范围内的分布

Figure 20 (Color online) Multi-objective optimization of the olefin oligomerization reactor [69]. (a) Pareto optimal frontier for the multi-objective optimization; (b) distribution of the inlet temperature $T_{\text {in }}$ of reaction mixtures within parameter range in the Pareto frontier; (c) distribution of the inlet pressure $P_{\text {in }}$ of reaction mixtures within parameter range in the Pareto frontier; (d) distribution of the catalyst bed density $\rho_{\mathrm{b}}$ within parameter range in the Pareto frontier; (e) distribution of the diameter $d_{\mathrm{p}}$ of catalyst particles within parameter range in the Pareto frontier; (f) distribution of inlet total flow rate $F_{\text {T,in }}$ of reaction mixtures within parameter range in the Pareto frontier; (g) distribution of the inner diameter $d_{\mathrm{i}}$ of the reactor within parameter range in the Pareto frontier; (h) distribution of the reactor length $L$ within parameter range in the Pareto frontier.

物产率平均的熵产生率)最小的单目标优化到综合考 虑目标产物产率最大和熵产生率最小、出口平均转化 率最高和最大径向温差最小的多目标优化. 取得了一 些具有重要理论意义和实用价值的研究成果，所完成 的一系列工作，为从理论上提出海水电解合成燃油技 术的最优发展方向打下了重要基础，拓展了有限时间 热力学的内涵和应用范围, 有助于促进FTT的发展.

下一步的工作, 主要将是以下三个方面: (1) 在已 分别完成氢、碳源捕获子系统 ${ }^{[66]}$ 和催化合成子系 统 ${ }^{[69]}$ 经典热力学研究工作的基础上，基于高温氦气、
太阳能的熔盐等具体载热工质代替原先假想的抽象高 温热源, 改进各化学反应器模型, 并基于广义热力学优

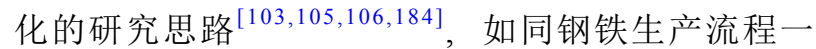

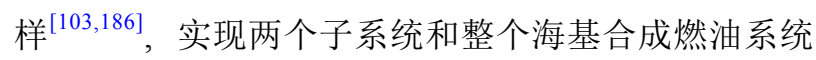
流程层面的FTT建模和优化; (2) 在完成本文所介绍的 各主要单元FTT优化研究的基础上，基于构形理

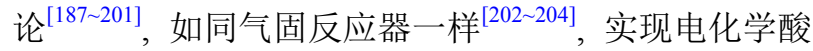
化池、 $\mathrm{H}_{2} \mathrm{SO}$ 反应器、 $\mathrm{HI}$ 分解反应器、 RWGS 反应 器、FT合成反应器等主要单元内部结构和外部形状 优化; (3) 基于构形定律将热力学优化与工程设计和自 
然演化相结合，在有限尺寸约束条件下，以为内部的 “流”提供越来越容易通过的路径为主要目标，通过寻 求最佳结构参数和热力学参数实现优化存在传热、流 体流动、传质和热功转换不可逆性的各种传统和类热
力过程和系统性能, 为构形热力学 ${ }^{[205]}$. 将单元的构形 优化与系统流程层面的FTT优化相结合,如同海洋热能 转换系统一样 ${ }^{[206]}$, 实现单元与系统流程一体化的构形 热力学优化.

\section{参考文献}

1 Bogart S L, Schultz K, Brown L, et al. Production of liquid synthetic fuels from carbon, water and nuclear power on ships and at shore bases for military and potential commercial applications. In: Proceedings of the 2006 International Congress on Advances in Nuclear Power Plants (ICAPP 2006). Reno, 2006

2 Yang S J. The amazing energy source: Seawater to fuel (in Chinese). Sci Tech Rev, 2014, $32: 7$ [杨书卷. 惊现“逆天”能源: 海水变燃油. 科技导 报, 2014, 32: 7]

3 Zhang W Q. The US Navy demonstrates the technology of sea water to fuel (in Chinese). Pet Process Petrochem, 2014, 45: 71 [张伟清. 美国海 军演示海水变燃料技术. 石油炼制与化工, 2014, 45: 71]

4 Willauer H D. Transforming seawater into designer fuel. Sea Technol, 2014, 55: 81

5 Porosoff M D, Yan B, Chen J G. Catalytic reduction of $\mathrm{CO}_{2}$ by $\mathrm{H}_{2}$ for synthesis of $\mathrm{CO}$, methanol and hydrocarbons: Challenges and opportunities. Energy Environ Sci, 2016, 9: 62-73

6 Brown L C, Besenbruch G E, Schultz K R, et al. High efficiency generation of hydrogen fuels using thermochemical cycles and nuclear power. Technical Report. General Atomics Report GA-A24326, 2002

7 Onuki K, Nomura M, Nakajima H R D. On thermochemical Iodine-sulfur process at JAERI. In: Nuclear Production of Hydrogen. 2nd Information Exchange Meeting on Nuclear Production of Hydrogen, Argonne, 2003. Paris: Org Econ Co-Operat\&Devpublications, 2004

8 Zhang P, Wang L J, Chen S Z, et al. Progress of nuclear hydrogen production through the iodine-sulfur process in China. Renew Sust Energy Rev, 2018, 81: 1802-1812

9 Kasahara S, Iwatsuki J, Takegami H, et al. Current R\&D status of thermochemical water splitting iodine-sulfur process in Japan Atomic Energy Agency. Int J Hydrogen Energy, 2017, 42: 13477-13485

10 Liang B L, Duan H M, Hou B L, et al. Progress in the catalytic hydrogenation of carbon dioxide to light olefins (in Chinese). Chem Ind Eng Prog, 2015, 34: 3746-3754 [梁兵连, 段洪敏, 侯宝林, 等. 二氧化碳加氢合成低碳烯烃的研究进展. 化工进展, 2015, 34: 3746-3754]

11 Dai B C, Zhou G L. Perspective on catalyst investigation for reverse water-gas shift reaction (RWGS) (in Chinese). Chem Ind Eng Prog, 2017, 36: 2473-2480 [代必灿, 周桂林. 逆水煤气变换(RWGS)催化剂研究进展. 化工进展, 2017, 36: 2473-2480]

12 Hardy D R. Sea-based fuel synthesis work at NRL from FY02 to FY07 (October 2001-October 2006). Technical Report. Memorandum Report 6180-10-9276. Washington DC: Naval Research Laboratory, August 5, 2010

13 Willauer H D, Hardy D R, Ndubizu E C, et al. Extraction of carbon dioxide from seawater by ion exchange resin part II: Using strong base anion exchange resin. Technical Report. Memorandum Report 6180-09-9211. Washington DC: Naval Research Laboratory, September 29, 2009

14 DiMascio F, Willauer H D, Hardy D R, et al. Extraction of carbon dioxide from seawater by an electrochemical acidification cell part I-Initial feasibility studies. Technical Report. Memorandum Report 6180-10-9274. Washington DC: Naval Research Laboratory, July 23, 2010

15 Willauer H D, DiMascio F, Hardy D R, et al. Extraction of carbon dioxide from seawater by an electrochemical acidification cell part IILaboratory scaling studies. Technical Report. Memorandum Report 6180-11-9329. Washington DC: Naval Research Laboratory, April 11, 2011

16 Willauer H D, DiMascio F, Hardy D R, et al. Development of an electrochemical acidification cell for the recovery of $\mathrm{CO}_{2}$ and $\mathrm{H}_{2}$ from seawater. Ind Eng Chem Res, 2011, 50: 9876-9882

17 Willauer H D, Hardy D R, Williams F W, et al. Extraction of carbon dioxide and hydrogen from seawater by an electrochemical acidification cell part III: Scaled-up mobile unit studies (calender year-2011). Technical Report. Memorandum Report 6300-12-9414. Washington DC: Naval Research Laboratory, May 30, 2012

18 Willauer H D, DiMascio F, Hardy D R, et al. Development of an electrochemical acidification cell for the recovery of $\mathrm{CO}_{2}$ and $\mathrm{H}_{2}$ from seawater II. Evaluation of the cell by natural seawater. Ind Eng Chem Res, 2012, 51: 11254-11260

19 Willauer H D, Hardy D R, Williams F W, et al. Extraction of carbon dioxide and hydrogen from seawater by an electrochemical acidification 
cell part IV: Electrode compartments of cell modified and tested in scaled-up mobile unit. Technical Report. Memorandum Report 6300-139463. Washington DC: Naval Research Laboratory, September 3, 2013

20 Willauer H D, DiMascio F, Hardy D R, et al. Feasibility of $\mathrm{CO}_{2}$ extraction from seawater and simultaneous hydrogen gas generation using a novel and robust electrolytic cation exchange module based on continuous electrodeionization technology. Ind Eng Chem Res, 2014, 53: 1219212200

21 Willauer H D, DiMascio F, Hardy D R. Extraction of carbon dioxide and hydrogen from seawater by an electrolytic cation exchange module (ECEM) part V: E-CEM effluent discharge composition as a function of electrode water composition. Technical Report. Memorandum Report 6360-17-9743. Washington DC: Naval Research Laboratory, August 1, 2017

22 Willauer H D, DiMascio F, Hardy D R, et al. Development of an electrolytic cation exchange module for the simultaneous extraction of carbon dioxide and hydrogen gas from natural seawater. Energy Fuels, 2017, 31: 1723-1730

23 Willauer H D, Hardy D R, Ndubizu E C, et al. Recovery of $\left[\mathrm{CO}_{2}\right]_{\mathrm{T}}$ from aqueous bicarbonate using a gas permeable membrane. Technical Report. Memorandum Report 6180-08-9129. Washington DC: Naval Research Laboratory, July 25, 2008

24 Willauer H D, Hardy D R, Lewis M K, et al. Recovery of $\mathrm{CO}_{2}$ by phase transition from an aqueous bicarbonate system under pressure by means of multilayer gas permeable membranes. Energy Fuels, 2009, 23: 1770-1774

25 Willauer H D, Hardy D R, Lewis $\mathrm{M} \mathrm{K}$, et al. Extraction of $\mathrm{CO}_{2}$ from seawater and aqueous bicarbonate systems by ion-exchange resin processes. Energy Fuels, 2010, 24: 6682-6688

26 Dorner R W, Hardy D R, Williams F W, et al. Influence of gas feed composition and pressure on the catalytic conversion of $\mathrm{CO}_{2}$ to hydrocarbons using a traditional cobalt-based Fischer-Tropsch catalyst. Energy Fuels, 2009, 23: 4190-4195

27 Dorner R W, Hardy D R, Williams F W, et al. Effects of ceria-doping on a $\mathrm{CO}_{2}$ hydrogenation iron-manganese catalyst. Catal Commun, 2010, 11: $816-819$

28 Dorner R W, Hardy D R, Williams F W, et al. Heterogeneous catalytic $\mathrm{CO}_{2}$ conversion to value-added hydrocarbons. Energy Environ Sci, 2010, 3: $884-890$

29 Dorner R W, Hardy D R, Williams F W, et al. K and Mn doped iron-based $\mathrm{CO}_{2}$ hydrogenation catalysts: Detection of $\mathrm{KAlH}_{4}$ as part of the catalyst's active phase. Appl Catal A-General, 2010, 373: 112-121

30 Dorner R W, Hardy D R, Williams F W, et al. $\mathrm{C}_{2}-\mathrm{C}_{5^{+}}$olefin production from $\mathrm{CO}_{2}$ hydrogenation using ceria modified Fe/Mn/K catalysts. Catal Commun, 2011, 15: 88-92

31 Willauer H D, Ananth R, Olsen M T, et al. Modeling and kinetic analysis of $\mathrm{CO}_{2}$ hydrogenation using a Mn and K-promoted Fe catalyst in a fixed-bed reactor. $\mathrm{J} \mathrm{CO}_{2}$ Utiliz, 2013, 3-4: 56-64

32 Drab D M, Willauer H D, Olsen M T, et al. Hydrocarbon synthesis from carbon dioxide and hydrogen: A two-step process. Energy Fuels, 2013, 27: $6348-6354$

33 Drab D M, Hardy D R, Dimascio F, et al. Optimizing Fe-based catalysis in carbon dioxide hydrogenation reactions for future synthesis of liquid hydrocarbons from seawater. Chim Oggi, 2013, 31: 20-22

34 Bradley M J, Ananth R, Willauer H D, et al. The role of catalyst environment on $\mathrm{CO}_{2}$ hydrogenation in a fixed-bed reactor. $\mathrm{J} \mathrm{CO}_{2} \mathrm{Utiliz}_{2}, 2017$, 17: $1-9$

35 Bradley M J, Ananth R, Willauer H D, et al. The effect of copper addition on the activity and stability of iron-based $\mathrm{CO}_{2}$ hydrogenation catalysts. Molecules, 2017, 22: 1579

36 Dorner R W, Willauer H D, Hardy D R, et al. Effects of loading and doping on iron-based $\mathrm{CO}_{2}$ hydrogenation catalysts. Techinical Report. Memorandum Report 6180-09-9200. Washington DC: Naval Research Laboratory, August 24, 2009

37 Willauer H D, Hardy D R, Schultz K R, et al. The feasibility and current estimated capital costs of producing jet fuel at sea using carbon dioxide and hydrogen. J Renew Sust Energy, 2012, 4: 033111

38 Willauer H D, Hardy D R, Moyer S A, et al. An economic basis for littoral land-based production of low carbon fuel from nuclear electricity and seawater for naval or commercial use. Energy Policy, 2015, 81: 67-75

39 Willauer H D, Hardy D R, Baldwin J W, et al. Economic comparisons of littoral production of low carbon fuel from non-fossil energy sources and seawater. J Cleaner Product, 2018, 170: 1473-1483

40 Porosoff M D, Baldwin J W, Peng X, et al. Potassium-promoted molybdenum carbide as a highly active and selective catalyst for $\mathrm{CO}_{2}$ conversion to CO. ChemSusChem, 2017, 10: 2408-2415 
41 Patterson B D, Mo F, Borgschulte A, et al. Renewable $\mathrm{CO}_{2}$ recycling and synthetic fuel production in a marine environment. Proc Natl Acad Sci USA, 2019, 116: 12212-12219

42 De Lannoy C F, Eisaman M D, Jose A, et al. Indirect ocean capture of atmospheric $\mathrm{CO}_{2}$ : Part I. Prototype of a negative emissions technology. Int J Greenh Gas Control, 2018, 70: 243-253

43 Huang Y Q. Study of the fuel synthesizing technology by seawater electrolysis under typical way (in Chinese). Technical Report. Dalian: Dalian Institute of Chemical Physics, Chinese Academy of Sciences, 2015 [黄延强. 典型途径下海水电解合成燃油技术研究. 技术报告. 大连: 中国 科学院大连化学物理研究所, 2015]

44 Huang Y Q. Study of the fuel synthesizing technology by seawater electrolysis under typical way (in Chinese). Technical Report. Dalian: Dalian Institute of Chemical Physics, Chinese Academy of Sciences, 2016 [黄延强. 典型途径下海水电解合成燃油技术研究. 技术报告. 大连: 中国 科学院大连化学物理研究所, 2016]

45 Huang Y Q. Study of the fuel synthesizing technology by seawater electrolysis under typical way (in Chinese). Technical Report. Dalian: Dalian Institute of Chemical Physics, Chinese Academy of Sciences, 2017 [黄延强. 典型途径下海水电解合成燃油技术研究. 技术报告. 大连: 中国 科学院大连化学物理研究所, 2017]

46 Huang Y Q. Study of the fuel synthesizing technology by seawater electrolysis under typical way (in Chinese). Technical Report. Dalian: Dalian Institute of Chemical Physics, Chinese Academy of Sciences, 2018 [黄延强. 典型途径下海水电解合成燃油技术研究. 技术报告. 大连: 中国 科学院大连化学物理研究所, 2018]

47 Zhou X, Wu W H. Study of the fuel synthesizing technology by seawater electrolysis under typical way (2) (in Chinese). Technical Report. Handan: The 718th Research Institute of CSIC, 2015 [周旭, 吴文宏. 典型途径下海水电解合成燃油技术研究(二). 技术报告. 邯単: 中国船 舶重工集团公司第七一八研究所, 2015]

48 Zhou X, Wu W H. Study of the fuel synthesizing technology by seawater electrolysis under typical way (2) (in Chinese). Technical Report. Handan: The 718th Research Institute of CSIC, 2016 [周旭, 吴文宏. 典型途径下海水电解合成燃油技术研究(二). 技术报告. 邯単: 中国船 舶重工集团公司第七一八研究所, 2016]

49 Zhou X, Wu W H. Study of the fuel synthesizing technology by seawater electrolysis under typical way (2) (in Chinese). Technical Report. Handan: The 718th Research Institute of CSIC, 2017 [周旭, 吴文宏. 典型途径下海水电解合成燃油技术研究(二). 技术报告. 邯戦: 中国船 舶重工集团公司第七一八研究所, 2017]

50 Zhou X, Wu W H. Study of the fuel synthesizing technology by seawater electrolysis under typical way (2) (in Chinese). Technical Report. Handan: The 718th Research Institute of CSIC, 2018 [周旭, 吴文宏. 典型途径下海水电解合成燃油技术研究(二). 技术报告. 邯単: 中国船 舶重工集团公司第七一八研究所, 2018]

51 Zhang L, Chen L G, Xia S J, et al. Thermodynamics analysis of hydrogenation of carbon dioxide to light olefins based on Gibbs free energy minimization and entropy maximization methods (in Chinese). In: Proceedings of the Academic Conference on Engineering Thermodynamics and Energy Utilization of China Society of Engineering Thermophysics. Guangzhou, 2016. 161175 [张否, 陈林根, 夏少军, 等. 基于Gibbs自由 能最小化和熵最大化方法的二氧化碳加氢合成低碳烯烃热力学分析. 见: 中国工程热物理学会工程热力学与能源利用学术会议论文集. 广州, 2016. 161175]

52 Wang C, Chen L G, Xia S J, et al. The removal rate and entropy generation rate analyses of the removal process of carbon dioxide from seawater by using hollow fiber membrane contactor (in Chinese). In: Proceedings of the 22nd Academic Conference of College Engineering Thermodynamics. Harbin, 2016. A-2016013 [王超, 陈林根, 夏少军, 等. 中空纤维膜接触器脱除海水中二氧化碳过程脱除率及熵产率分析. 见: 高等学校工程热物理第二十二届全国学术会议论文集. 哈尔滨, 2016. A-2016013]

53 Zhang L, Chen L G, Xia S J, et al. Thermodynamics analyses of hydrogenation of carbon dioxide to light olefins (in Chinese). J Eng Thermophys, 2017, 38: 1135-1143 [张否, 陈林根, 夏少军, 等. $\mathrm{CO}_{2}$ 加氢合成低碳烯烃反应热力学分析. 工程热物理学报, 2017, 38: 11351143]

54 Zhang L, Chen L G, Xia S J, et al. Second law analyses of hydrogenation of $\mathrm{CO}_{2}$ to light olefins (in Chinese). In: Proceedings of the 23nd Academic Conference of College Engineering Thermodynamics. Chengdu, 2017. A-2017008 [张否, 陈林根, 夏少军, 等. $\mathrm{CO}_{2}$ 合成低碳烯烃反 应第二定律分析. 见: 高等学校工程热物理第二十三届全国学术会议论文集. 成都, 2017. A-2017008]

55 Zhang L, Xia S J, Chen L G, et al. Entropy generation rate minimization of hydrogenation of carbon dioxide to light olefins reactor (in Chinese). In: Proceedings of the Academic Conference on Engineering Thermodynamics and Energy Utilization of China Society of Engineering Thermophysics. Ningbo, 2017. 171064 [张磊, 夏少军, 陈林根, 等. $\mathrm{CO}_{2}$ 氢化合成低碳烯烃反应器熵产率最小优化. 见: 中国工程热物理学 


\section{会工程热力学与能源利用学术会议论文集. 宁波, 2017. 171064]}

56 Wang C, Chen L G, Xia S J, et al. Entropy generation rate minimization for the extraction process of $\mathrm{CO}_{2}$ by using hollow fiber membrane contactor (in Chinese). J Eng Thermophys, 2017, 38: 2509-2514 [王超, 陈林根, 夏少军, 等. 中空纤维膜接触器脱出 $\mathrm{CO}_{2}$ 过程熵产率最小化. 工程热物理学报, 2017, 38: 2509-2514]

57 Chen L G, Zhang L, Xia S J, et al. Entropy generation minimization for $\mathrm{CO}_{2}$ hydrogenation to light olefins. Energy, 2018, 147: 187-196

58 Zhang L, Chen L G, Xia S J, et al. Entropy generation minimization for reverse water gas shift (RWGS) reactors. Entropy, 2018, 20: 415

59 Zhang L, Xia S J, Chen L G, et al. Entropy generation rate minimization for reverse water gas shift reactor (in Chinese). In: Proceedings of the 24nd Academic Conference of College Engineering Thermodynamics. Tangshan, 2018. A-2018036 [张磊, 夏少军, 陈林根, 等. 逆水气变换反 应器熵产生率最小优化. 见: 高等学校工程热物理第二十四届全国学术会议. 唐山, 2018. A-2018036]

60 Zhang L, Chen L G, Xia S J, et al. Thermodynamic performance analysis of reverse water gas shift reactor heating by high-temperature helium (in Chinese). In: Proceedings of the Academic Conference on Engineering Thermodynamics and Energy Utilization of China Society of Engineering Thermophysics. Dalian, 2018. 181188 [张否, 陈林根, 夏少军, 等. 基于高温氦气加热的逆水气变换反应器热力学性能分析. 见: 中国工程热物理学会工程热力学与能源利用学术会议论文集. 大连, 2018. 181188]

61 Wang C, Chen L G, Xia S J, et al. Grey system modeling of the process of lowering seawater pH by using electrochemical acidification cell (in Chinese). Energy Conserv, 2018, 37: 75-80 [王超, 陈林根, 夏少军, 等. 电化学酸化池降低海水pH值过程灰色系统模型研究. 节能, 2018, 37: 75-80]

62 Chen L G, Wang C, Xia S J, et al. Thermodynamic analyses and optimizations of extraction process of $\mathrm{CO}_{2}$ from acidic seawater by using hollow fiber membrane contactor. Int J Heat Mass Transfer, 2018, 124: 1310-1320

63 Zhang L, Chen L G, Xia S J, et al. Thermodynamic performance analysis of reverse water gas shift reactor heated by high-temperature helium. In: The 2019 American Society of Thermal and Fluids Engineers (ASTFE) Conference. Las Vegas, 2019

64 Chen L G, Zhang L, Xia S J, et al. Hydrocarbon synthesis reactor from carbon dioxide and hydrogen: An entropy generation rate minimization case. In: The 2019 American Society of Thermal and Fluids Engineers (ASTFE) Conference. Las Vegas, 2019. TFEC-2019-27515

65 Wang C, Xia S J, Chen L G, et al. Modeling of the acidification process of the seawater by using electrochemical acdification cell (in Chinese). In: Proceedings of the 24nd Academic Conference of College Engineering Thermodynamics. Tangshan, 2018. A-2018035 [王超, 夏少军, 陈林 根, 等. 电化学酸化池酸化海水过程建模分析. 见: 高等学校工程热物理第二十四届全国学术会议论文集. 唐山, 2018. A-2018035]

66 Wang C. Thermodynamic analyses and optimizations of the carbon and hydrogen capture subsystem of the sea-based fuel synthesis system (in Chinese). Dissertation for Doctoral Degree. Wuhan: Naval University of Engineering, 2018 [王超. 海基燃油合成系统碳、氢源捕获子系统的 热力学分析与优化. 博士学位论文. 武汉: 海军工程大学, 2018]

67 Zhang L, Xia S J, Chen L G, et al. Entropy generation rate minimization for hydrocarbon synthesis reactor from carbon dioxide and hydrogen. Int J Heat Mass Transfer, 2019, 137: 1112-1123

68 Zhang L, Chen L G, Xia S J, et al. Multi-objective optimization for helium-heated reverse water gas shift reactor by using NSGA-II. Int J Heat Mass Transfer, 2020, 148: 119025

69 Zhang L. Thermodynamic analyses and optimizations for catalytic synthesis subsystem of sea-based fuel synthesis system (in Chinese). Dissertation for Doctoral Degree. Wuhan: Naval University of Engineering, 2019 [张否. 海基合成燃油系统催化合成子系统的热力学分析与 优化. 博士学位论文. 武汉: 海军工程大学, 2019]

70 Wang C, Xia S J, Chen L G, et al. Effects of design parameters on entropy generation rate of sulphuric acid decomposition process. Int J Ambient Energy, 2019, doi: 10.1080/01430750.2019.1684993

71 Kong R, Chen L G, Xia S J, et al. Minimization of entropy generation rate during hydrogen iodide decomposition reaction process (in Chinese). Sci Sin Tech, 2020, doi: 10.1360/SST-2020-0008 [孔锐, 陈林根, 夏少军, 等. 碘化氢分解反应器熵产生率最小化. 中国科学: 技术科学, 2020, doi: 10.1360/SST-2020-0008]

72 Wang C, Chen L G, Xia S J, et al. Maximum production rate optimization for sulphuric acid decomposition process in tubular plug-flow reactor. Energy, 2016, 99: 152-158

73 Wang C, Ge Y L, Xia S J, et al. Analysis of the specific entropy generation rate of the sulphuric acid decomposition process. In: The 2019 American Society of Thermal and Fluids Engineers (ASTFE) Conference. Las Vegas, 2019

74 Sun M, Xia S J, Chen L G, et al. Multi-objective optimization of sulfuric acid decomposition process using NSGA-II algorithm (in Chinese). Energy Conserv, 2020, 40: 118-123 [孙铭, 夏少军, 陈林根, 等. 应用NSGA-II算法的硫酸分解过程多目标优化. 节能, 2020, 40: 118-123] 
75 Chen L G, Wang C, Zhang L, et al. Thermodynamic Optimization Theory for Key Units of Sea-Based Fuel Synthesis System (in Chinese). Beijing: Science Press, 2021 [陈林根, 王超, 张磊, 等. 海基合成燃油系统关键单元的热力学优化理论. 北京: 科学出版社, 2021]

76 Carnot S. Reflections on the Motive Power of Heat. Paris: Bachelier, 1824

77 Reitlinger H B. Sur l'utilisation de la Chaleur Dans les Machines a Feu. Liege: Vaillant-Carmanne, 1929

78 Vaudrey A, Lanzetta F, Feidt M. H. B. Reitlinger and the origins of the efficiency at maximum power formula for heat engines. J Non-Equilib Thermodyn, 2014, 39: 199-203

79 Yvon Y. The scalay reactor: Two years experience on heat transfer by means of compressed gas. In: Proceedings of the International Conference on Peaceful Uses of Atomic Energy. Geneva, 1955

80 Novikov I I. The efficiency of atomic power stations (A review). J Nucl Energy, 1958, 7: 125-128

81 Chambdal P. Les Centrales Nucleases. Paris: Armand Colin, 1957

82 Curzon F L, Ahlborn B. Efficiency of a Carnot engine at maximum power output. Am J Phys, 1975, 43: 22-24

83 Andresen B, Berry R S, Ondrechen M J, et al. Thermodynamics for processes in finite time. Acc Chem Res, 1984, 17: 266-271

84 Bejan A. Entropy generation minimization: The new thermodynamics of finite-size devices and finite-time processes. J Appl Phys, 1996, 79: $1191-1218$

85 Chen L G, Wu C, Sun F R. Finite time thermodynamic optimization or entropy generation minimization of energy systems. J Non-Equilib Thermodyn, 1999, 24: 327-359

86 Chen L G, Sun F R. Advances in Finite Time Thermodynamics: Analysis and Optimization. New York: Nova Science Publishers, 2004

87 Chen L G. Finite-Time Thermodynamic Analysis of Irreversible Processes and Cycles (in Chinese). Beijing: Higher Education Press, 2005 [陈 林根. 不可逆过程和循环的有限时间热力学分析. 北京: 高等教育出版社, 2005]

88 Wu F, Chen L G, Sun F R, et al. Finite-Time Thermodynamic Optimization of Stirling Engine (in Chinese). Beijing: Chemical Industry Press, 2008 [吴锋, 陈林根, 孙丰瑞, 等. 斯特林机的有限时间热力学优化. 北京: 化学工业出版社, 2008]

89 Chen L G, Xia S J. Generalized Thermodynamic Dynamic-Optimization for Irreversible Processes (in Chinese). Beijing: Science Press, 2017 [陈林根, 夏少军. 不可逆过程的广义热力学动态优化. 北京: 科学出版社, 2017]

90 Bi Y H, Chen L G. Finite-Time Thermodynamic Optimization of the Air Heat Pump (in Chinese). Beijing: Science Press, 2017 [毕月虹, 陈林 根. 空气热原性能有限时间热力学优化. 北京: 科学出版社, 2017]

91 Badescu V. Optimal Control in Thermal Engineering. New York: Springer, 2017

92 Chen L G, Xia S J. Generalized Thermodynamic Dynamic-Optimization for Irreversible Cycles-Thermodynamic and Chemical Theoretical Cycles (in Chinese). Beijing: Science Press, 2018 [陈林根, 夏少军. 不可逆循环的广义热力学动态优化一一热力与化学理论循环. 北京: 科 学出版社, 2018]

93 Chen L G, Xia S J. Generalized Thermodynamic Dynamic-Optimization for Irreversible Cycles-Engineering Thermodynamic Plants and Generalized Engine Cycles (in Chinese). Beijing: Science Press, 2018 [陈林根, 夏少军. 不可逆循环的广义热力学动态优化一工程热力装 置与广义机循环. 北京: 科学出版社, 2018]

94 Xia S J, Chen L G. Generalized dissipation minimization for generalized flow transfer processes (in Chinese). Sci Sin Tech, 2019, 49: 501-517 [夏少军, 陈林根. 广义流传递过程的广义耗散最小化. 中国科学: 技术科学, 2019, 49: 501-517]

95 Chen L G, Li J. Thermodynamic Optimization Theory for Two-Heat-Reservoir Cycles (in Chinese). Beijing: Science Press, 2020 [陈林根, 李俊. 两热源循环热力学优化理论. 北京: 科学出版社, 2020]

96 Xia S J, Chen L G, Feng H J. Optimal configurations for maximizing generalized output of two-finite-potential-reservoir endoreversible generalized engine cycles (in Chinese). Sci Sin Tech, 50: 276-286 [夏少军, 陈林根, 冯辉君. 两有限势库内可逆广义机最大广义输出的最优 构型. 中国科学: 技术科学, 2020, 50: 276-286]

97 Chen L G, Ge Y L. Thermodynamic Optimization Theory for Internal Combustion Engine Cycles (in Chinese). Beijing: Science Press, 2021 [陈 林根, 戈延林. 内燃机循环热力学优化理论. 北京: 科学出版社, 2021]

98 Chen L G, Ding Z M, Zhou J L. Thermodynamic Optimization for Irreversible Microscopic Energy Conversion Systems (in Chinese). Beijing: Science Press, 2021 [陈林根, 丁泽民, 周俊乐. 不可逆微型能量转换系统的热力学优化. 北京: 科学出版社, 2021]

99 Andresen B. Current trends in finite-time thermodynamics. Angew Chem Int Ed, 2011, 50: 2690-2704

100 Li J, Chen L G, Ge Y L, et al. Progress in the study on finite time thermodynamic optimization for direct and reverse two-heat-reservoir thermodynamic cycles (in Chinese). Acta Phys Sin, 2013, 62: 130501 [李俊, 陈林根, 戈延林, 等. 正反向两源热力循环有限时间热力学性能 
优化的研究进展. 物理学报, 2013, 62: 130501]

101 Ge Y L, Chen L G, Sun F R. Progress in finite time thermodynamic studies for internal combustion engine cycles. Entropy, 2016, 18: 139

102 Ding Z M, Chen L G, Wang W H, et al. Progress in study on finite time thermodynamic performance optimization for three kinds of microscopic energy conversion systems (in Chinese). Sci Sin Tech, 2015, 45: 889-918 [丁泽民, 陈林根, 王文华, 等. 三类微型能量转换系统有限时间热 力学性能优化的研究进展.中国科学: 技术科学, 2015, 45: 889-918]

103 Chen L G, Feng H J, Xie Z H, et al. Interaction mechanism among material flows, energy flows and environment and generalized thermodynamic optimizations for iron and steel production processes (in Chinese). Sci Sin Tech, 2017, 48: 111-135 [陈林根, 冯辉君, 谢志辉, 等. 钢铁生产流程物流-能流-环境作用机理及广义热力学优化. 中国科学: 技术科学, 2017, 48: 111-135]

104 Chen L G, Meng F K, Sun F R. Thermodynamic analyses and optimization for thermoelectric devices: The state of the arts. Sci China Tech Sci, 2016, 59: 442-455

105 Chen L G, Xia S J. Progresses in generalized thermodynamic dynamic-optimization of irreversible processes (in Chinese). Sci Sin Tech, 2019, 49: 981-1022 [陈林根, 夏少军. 不可逆过程广义热力学动态优化研究进展.中国科学: 技术科学, 2019, 49: 981-1022]

106 Chen L G, Xia S J, Feng H J. Progress in generalized thermodynamic dynamic-optimization of irreversible cycles (in Chinese). Sci Sin Tech, 2019, 49: 1223-1267 [陈林根, 夏少军, 冯辉君. 不可逆循环广义热力学动态优化研究进展. 中国科学: 技术科学, 2019, 49: 1223-1267]

107 Ding Z M, Chen L G, Liu X W. Thermodynamic optimization for irreversible thermal Brownian motors, energy selective electron engines and thermionic devices. Int J Ambient Energy, 2018, doi: 10.1080/01430750.2018.1517681

108 Ondrechen M J, Berry R S, Andresen B. Thermodynamics in finite time: A chemically driven engine. J Chem Phys, 1980, 72: 5118-5124

109 Ondrechen M J, Andresen B, Berry R S. Thermodynamics in finite time: Processes with temperature-dependent chemical reactions. J Chem Phys, 1980, 73: 5838-5843

110 Chen L G, Sun F R, Chen W Z. Power optimization of a chemically driven thermal engine (in Chinese). J Navy Acad Eng, 1993, 5: 51-54 [陈林 根, 孙丰瑞, 陈文振. 化学反应驱动热机的功率优化. 海军工程学院学报, 1993, 5: 51-54]

111 Zhang L, Chen L G, Sun F R. Power optimization of chemically driven heat engine based on first and second order reaction kinetic theory and probability theory. Physica A, 2016, 445: 221-230

112 Zhang L, Chen L G, Sun F R. Finite-time thermodynamic analysis for a chemically driven heat engine based on probability theory (in Chinese). Sci Sin Tech, 2016, 46: 535-546 [张否, 陈林根, 孙丰瑞. 基于概率方法的化学反应驱动热机有限时间热力学分析. 中国科学: 技术科学, 2016, 46: 535-546]

113 Badescu V, Andresen B. Probabilistic finite time thermodynamics: A chemically driven engine. J Non-Equilib Thermodyn, 1996, 21: 291-306

114 Bharucha-Reid A T. Elements of the Theory of Markov Processes and Their Applications. New York: McGraw-Hill, 1960

115 De Vos A. Endoreversible thermodynamics and chemical reactions. J Phys Chem, 1991, 95: 4534-4540

116 Gordon J M. Maximum work from isothermal chemical engines. J Appl Phys, 1993, 73: 8-11

117 Chen L G, Sun F R, Wu C, et al. Performance characteristic of isothermal chemical engines. Energy Convers Manage, 1997, 38: 1841-1846

118 Chen L G, Sun F R, Wu C, et al. Maximum power of a combined-cycle isothermal chemical engine. Appl Thermal Eng, 1997, 17: 629-637

119 Chen L G, Sun F R, Wu C. Performance of chemical engines with a mass leak. J Phys D-Appl Phys, 1998, 31: 1595-1600

120 Chen L G, Duan H, Sun F R, et al. Performance of combined-cycle chemical engines with mass leak. J Non-Equilib Thermodyn, 1999, 24: 280290

121 Xia D, Chen L G, Sun F R. Optimal performance of a generalized irreversible chemical engine with diffusive mass transfer law. Math Comput Model, 2010, 51: 127-136

122 Chen L G, Xia D, Sun F R. Ecological optimization of generalized irreversible chemical engines. Int J Chem Reactor Eng, 2010, 8: 47-54

123 Xia D, Chen L G, Sun F R. Ecological optimisation of chemical engines with irreversible mass transfer and mass leakage. J Energy Inst, 2010, 83: $151-159$

124 Xia D, Chen L G, Sun F R. Ecological optimization of endoreversible chemical engines. Int J Energy Environ, 2011, 2: 909-920 Xia S J, Chen L G, Sun F R. Maximum power configuration for multireservoir chemical engines. J Appl Phys, 2009, 105: 124905

Xia S J, Chen L G, Sun F R. Optimal configuration of a
mass transfer law. Rev Mex Fis, 2009, 55: 399-408

127 Xia S J, Chen L G, Sun F R. Endoreversible modeling and optimization of multistage isothermal chemical engines under linear mass transfer law via Hamilton-Jacobi-Bellman theory. Int J Low-Carbon Tech, 2016, 11: 349-362 
128 Ocampo-García A, Barranco-Jiménez M A, Angulo-Brown F. Thermodynamic and themoeconomic optimization of isothermal endoreversible chemical engine models. Physica A, 2017, 488: 149-161

129 Watowich S J, Berry R S. Optimal current paths for model electrochemical systems. J Phys Chem, 1986, 90: 4624-4631

130 Schön J C, Andresen B. Finite-time optimization of chemical reactions: $n \mathrm{~A} \Leftrightarrow m$ B. J Phys Chem, 1996, 100: 8843-8853

131 Bak T A, Salamon P, Andresen B. Optimal behavior of consecutive chemical reactions A $\Leftrightarrow B \Leftrightarrow C$. J Phys Chem A, 2002, 106: 10961-10964

132 Chen L, Song H, Sun F. Optimal path of the consecutive chemical reactions $x A \Leftrightarrow y B \Leftrightarrow z C$. Phys Scr, 2009, 79: 055802

133 Sciacovelli A, Verda V, Sciubba E. Entropy generation analysis as a design tool—A review. Renew Sust Energy Rev, 2015, 43: 1167-1181

134 Li W S, Zhao Y X, Wang Q, et al. Twenty years of entropy research: A bibliometric overview. Entropy, 2019, 21: 694

135 Wang $\mathrm{C}$, Chen L G, Xia S J, et al. Optimal concentration configuration of consecutive chemical reaction $\mathrm{A} \Leftrightarrow \mathrm{B} \Leftrightarrow \mathrm{C}$ for minimum entropy generation. J Non-Equilib Thermodyn, 2016, 41: 313-326

136 Lems S, van der Kooi H J, de Swaan Arons J. Thermodynamic optimization of energy transfer in (bio)chemical reaction systems. Chem Eng Sci, 2003, 58: 2001-2009

137 Sánchez-Salas N, Chimal-Eguía J C, Ramírez-Moreno M A. Optimum performance for energy transfer in a chemical reaction system. Physica A, 2016, 446: 224-233

138 Tsirlin A M, Kazakov V, Kan N M, et al. Thermodynamic analysis and thermodynamic efficiency of chemical reactors. J Phys Chem B, 2006, 110: $2338-2342$

139 Tsirlin A M, Kan N M, Trushkov V V. Thermodynamic analysis and evaluation of the feasibility range of a chemical reactor. Theor Found Chem Eng, 2006, 40: 32-37

140 Xia S J, Chen L G, Wang C. Optimal current paths for a class of generalized electrochemical reaction system (in Chinese). Sci Sin Tech, 2020, doi: 10.1360/SST-2020-0074 [夏少军, 陈林根, 王超. 一类普适电化学反应系统的最优电流路径. 中国科学: 技术科学, 2020, doi: 10.1360/ SST-2020-0074]

141 Måansson B, Andresen B. Optimal temperature profile for an ammonia reactor. Ind Eng Chem Proc Des Dev, 1986, 25: 59-65

142 Piña J, Schbib N S, Bucalá V, et al. Influence of the heat-flux profiles on the operation of primary steam reformers. Ind Eng Chem Res, 2001, 40: 5215-5221

143 Piña J, Bucalá V, Borio D O. Optimization of steam reformers: Heat flux distribution and carbon formation. Int J Chem Reactor Eng, 2003, 1:

144 Pantoleontos G, Kikkinides E S, Georgiadis M C. A heterogeneous dynamic model for the simulation and optimisation of the steam methane reforming reactor. Int J Hydrogen Energy, 2012, 37: 16346-16358

145 Li P L, Chen L G, Xia S J, et al. Maximum hydrogen production rate optimization for tubular steam methane reforming reactor. Int J Chem Reactor Eng, 2019, 17: 20180191

146 Li P L, Xia S J, Chen L G, et al. Maximum production rate optimization of hydrogen in tubular steam reforming reactor (in Chinese). In: Proceedings of the Academic Conference on Engineering Thermodynamics and Energy Utilization of China Society of Engineering Thermophysics. Ningbo, 2017. 171246 [李鹏蕾, 夏少军, 陈林根, 等. 管式甲烷蒸汽重整反应器氢气产率最大优化. 见: 中国工程热物理学 会工程热力学与能源利用学术会议论文集. 宁波, 2017. 171246]

147 Li P L, Chen L G, Xia S J, et al. Entropy generation rate and hydrogen production rate analyses for steam methane reforming reactor heated by molten salt (in Chinese). Power Gen Technol, 2020, doi: 10.12096/j.2096-4528.pgt.19106 [李鹏蕾, 陈林根, 夏少军, 等. 基于熔融盐加热的甲 烷蒸汽重整反应器的熵产率和氢气产率分析. 发电技术, 2020, doi: 10.12096/j.2096-4528.pgt.19106]

148 Li P L, Xia S J, Chen L G, et al. Maximum methanol yield in methanol synthesis via $\mathrm{CO}_{2}$ hydrogenation reactor (in Chinese). In: Proceedings of the Academic Conference on Engineering Thermodynamics and Energy Utilization of China Society of Engineering Thermophysics. Dalian, 2018. 181188 [李鹏蕾, 夏少军, 陈林根, 等. $\mathrm{CO}_{2}$ 加氢合成甲醇反应器甲醇收率最大优化. 见: 中国工程热物理学会工程热力学与能源利用 学术会议论文集. 大连, 2018. 181188]

149 Kjelstrup S, Johannessen E, Røsjorde A, et al. Minimizing the entropy production of the methanol producing reaction in a methanol reactor. Int J Thermodyn, 2000, 3: 147-153

150 Li P L, Chen L G, Xia S J, et al. Entropy generation rate minimization for methanol synthesis via a $\mathrm{CO}_{2}$ hydrogenation reactor. Entropy, 2019, 21: 174

151 Li P L, Chen L G, Xia S J, et al. Minimum entropy generation rate in methanol synthesis via $\mathrm{CO}_{2}$ hydrogenation reactor (in Chinese). In: Proceedings of the 24nd Academic Conference of College Engineering Thermodynamics. Tangshan, 2018. A-2018033 [李鹏蕾, 陈林根, 夏少 
军, 等. 管式 $\mathrm{CO}_{2}$ 加氢合成甲醇反应器熵产率最小优化. 见: 高等学校工程热物理第二十四届全国学术会议论文集. 唐山, 2018. A2018033]

152 Li P L, Chen L G, Xia S J, et al. Entropy generation rate minimization for steam methane reforming reactor heated by molten salt. Energy Rep, 2020, 6: 685-697

153 Nummedal L, Kjelstrup S, Costea M. Minimizing the entropy production rate of an exothermic reactor with a constant heat-transfer coefficient: The ammonia reaction. Ind Eng Chem Res, 2003, 42: 1044-1056

154 Nummedal L, Røsjorde A, Johannessen E, et al. Second law optimization of a tubular steam reformer. Chem Eng Process, 2005, 44: 429-440

155 Johannessen E, Kjelstrup S. Minimum entropy production rate in plug flow reactors: An optimal control problem solved for $\mathrm{SO}_{2}$ oxidation. Energy, 2004, 29: 2403-2423

156 Johannessen E, Kjelstrup S. A highway in state space for reactors with minimum entropy production. Chem Eng Sci, 2005, 60: 3347-3361

157 van der Ham L V, Gross J, Verkooijen A, et al. Efficient conversion of thermal energy into hydrogen: Comparing two methods to reduce exergy losses in a sulfuric acid decomposition reactor. Ind Eng Chem Res, 2009, 48: 8500-8507

158 van der Ham L V, Gross J, Kjelstrup S. Two performance indicators for the characterization of the entropy production in a process unit. Energy, 2011, 36: 3727-3732

159 Wilhelmsen Ø, Johannessen E, Kjelstrup S. Energy efficient reactor design simplified by second law analysis. Int J Hydrogen Energy, 2010, 35: 13219-13231

160 Ao C Y, Xia S J, Song H J, et al. Entropy generation minimization of steam methane reforming reactor with linear phenomenological heat transfer law (in Chinese). Sci Sin Tech, 2018, 48: 25-38 [敖晨阳, 夏少军, 宋汉江, 等. 线性唯象传热条件下甲烷蒸汽重整反应器熵产生最 小化. 中国科学: 技术科学, 2018, 48: 25-38]

161 Chen Q X, Xia S J, Wang W H, et al. Entropy generation rate minimization of steam methane reforming reactor with Dulong-Petit heat transfer law (in Chinese). Energy Conserv, 2018, 37: 31-40 [陈庆晓, 夏少军, 王文华, 等. Dulong-Petit传热规律下甲烷蒸汽重整反应器熵产率最小 化. 节能, 2018, 37: 31-40]

162 Kingston D, Razzitte A C. Entropy production in chemical reactors. J Non-Equilib Thermodyn, 2017, 42: 265-275

163 Kingston D, Razzitte A C. Entropy generation minimization in dimethyl ether synthesis: A case study. J Non-Equilib Thermodyn, 2018, 43: 111-120

164 Cao G, Huang Y, Liao Q, et al. Entropy generation analysis of transfer and conversion process in photobioreactor (in Chinese). J Eng Thermophys, 2016, 37: 573-580 [曹刚, 黄云, 廖强, 等. 光生物反应器内传递及转化过程的熵产率分析. 工程热物理学报, 2016, 37: 573580]

165 Cao X P, Jia S K, Luo Y Q, et al. Multi-objective optimization method for enhancing chemical reaction process. Chem Eng Sci, 2019, 195: 494506

166 Szwast Z, Sieniutycz S. Optimization of the reactor-regenerator system with catalytic parallel-consecutive reactions. Catal Today, 1999, 48: 175-184

167 Szwast Z, Sieniutycz S. Optimal temperature profiles for parallel-consecutive reactions with deactivating catalyst. Catal Today, 2001, 66: 461466

168 Szwast Z, Sieniutycz S. Optimal dynamical processes in tubular reactor with deactivation of multi-run moving catalyst. Chem Eng J, 2004, 103: $45-50$

169 Frolov S V, Tret'yakov A A, Nazarov V N. Problem of optimal control of monomethylaniline synthesis in a tubular reactor. Theor Found Chem Eng, 2006, 40: 349-356

170 Deng J L. Foundation of Gray Theroy (in Chinese). Wuhan: Huazhong University of Science and Technology Press, 2002 [邓聚龙. 灰理论基 础. 武汉: 华中科技大学出版社, 2002]

171 Wang Z X. Grey multivariable power model GM(1,N) and its application (in Chinese). System Eng Theor Prac, 2014, 34: 2537-2363 [王正新. 灰色多变 $\mathrm{GM}(1, N)$ 幂模型及其应用. 系统工程理论与实践, 2014, 34: 2537-2363]

172 Drioli E, Criscuoli A, Curcio E. Li N, Jia Y Y, Su X S, et al., translate. Membrane Contactor-Fundamentals, Applications and Potentials (in Chinese). Beijing: Chemical Industry Press, 2009 [恩瑞克·德利奥里, 阿来桑德拉·克里斯科利, 艾弗雷姆·库尔乔. 李娜, 贾原媛, 苏学素, 等, 译. 膜接触器——原理、应用及发展前景. 北京: 化学工业出版社, 2009]

173 Unde R B. Kinetics and reaction engineering aspects of syngas production by the heterogeneously catalysed reverse water gas shift reaction. 
Dissertation for Doctoral Degree. Bayreuth: Universität Bayreuth, 2012

174 Jadhav S G, Vaidya P D, Bhanage B M, et al. Kinetics of reverse water-gas shift reaction over Pt/ $\mathrm{Al}_{2} \mathrm{O}_{3}$ catalyst. Can J Chem Eng, 2016, 94 : $101-106$

175 Masuku C M, Hildebrandt D, Glasser D. Olefin pseudo-equilibrium in the Fischer-Tropsch reaction. Chem Eng J, 2012, 181-182: 667-676

$176 \mathrm{Lu} \mathrm{X} \mathrm{J,} \mathrm{Hildebrandt} \mathrm{D,} \mathrm{Liu} \mathrm{X} \mathrm{Y,} \mathrm{et} \mathrm{al.} \mathrm{A} \mathrm{thermodynamic} \mathrm{approach} \mathrm{to} \mathrm{olefin} \mathrm{product} \mathrm{distribution} \mathrm{in} \mathrm{fischer-tropsch} \mathrm{synthesis.} \mathrm{Ind} \mathrm{Eng} \mathrm{Chem} \mathrm{Res,}$ 2012, 51: 16544-16551

177 Marvast M A, Sohrabi M, Zarrinpashne S, et al. Fischer-Tropsch synthesis: Modeling and performance study for Fe-HZSM5 bifunctional catalyst. Chem Eng Technol, 2005, 28: 78-86

178 Park N, Kim J R, Yoo Y, et al. Modeling of a pilot-scale fixed-bed reactor for iron-based Fischer-Tropsch synthesis: Two-dimensional approach for optimal tube diameter. Fuel, 2014, 122: 229-235

179 Moazami N, Wyszynski M L, Rahbar K, et al. A comprehensive study of kinetics mechanism of Fischer-Tropsch synthesis over cobalt-based catalyst. Chem Eng Sci, 2017, 171: 32-60

180 Moazami N, Wyszynski M L, Rahbar K, et al. Parametric study and multiobjective optimization of fixed-bed fischer-tropsch (FT) reactor: The improvement of FT synthesis product formation and synthetic conversion. Ind Eng Chem Res, 2017, 56: 9446-9466

181 Iandoli C L, Kjelstrup S. Exergy analysis of a GTL process based on low-temperature slurry F-T reactor technology with a cobalt catalyst. Energy Fuels, 2007, 21: 2317-2324

182 Riedel T, Claeys M, Schulz H, et al. Comparative study of Fischer-Tropsch synthesis with $\mathrm{H}_{2} / \mathrm{CO}_{\text {and }} \mathrm{H}_{2} / \mathrm{CO}_{2}$ syngas using Fe- and Co-based catalysts. Appl Catal A-General, 1999, 186: 201-213

183 Wu J M, Sun Q W, Zhang Z L, et al. Thermodynamic study for ethylene oligomerization to $\alpha$-olefin (in Chinese). J Mol Catal, 2013, 27: 385391 [吴建民, 孙启文, 张宗森, 等. 乙烯齐聚制 $\alpha$-烯烃反应体系的热力学研究. 分子催化, 2013, 27: 385-391]

184 Toch K, Thybaut J W, Marin G B. Ethene oligomerization on $\mathrm{Ni}_{-} \mathrm{SiO}_{2}-\mathrm{Al}_{2} \mathrm{O}_{3}$ : Experimental investigation and single-event microkinetic modeling. Appl Catal A-General, 2015, 489: 292-304

185 Yuan M. Research on the reaction condition optimization for ethene oligomerization to synthesize gasoline components over ZSM-5 catalyst in methanol synthesis gasoline (in Chinese). Dissertation for Master's Degree. Wuhan: Wuhan Institute of Technology, 2017 [袁明. 甲醇合成汽油 工艺中ZSM-5催化乙烯齐聚关键步骤反应条件的优化研究. 硕士学位论文. 武汉: 武汉工程大学, 2017]

186 Chen L G, Feng H J, Xie Z H. Generalized thermodynamic optimization for iron and steel production processes: Theoretical exploration and application cases. Entropy, 2016, 18: 353

187 Bejan A. Constructal-theory network of conducting paths for cooling a heat generating volume. Int J Heat Mass Transfer, 1997, 40: 799-816

188 Bejan A, Lorente S. Constructal theory of generation of configuration in nature and engineering. J Appl Phys, 2006, 100: 041301

189 Bejan A, Lorente S. Design with Constructal Theory. New Jersey: Wiley, 2008

190 Chen L G. Progress in study on constructal theory and its applications (in Chinese). Sci Sin Tech, 2012, 42: 505-524 [陈林根. 构形理论及其应 用的研究进展. 中国科学: 技术科学, 2012, 42: 505-524]

191 Chen L G, Feng H J. Multi-objective Constructal Optimization for Flow and Heat and Mass Transfer Processes (in Chinese). Beijing: Science Press, 2016 [陈林根, 冯辉君. 流动和传热传质过程的多目标构形优化. 北京: 科学出版社, 2016]

192 Feng H J, Chen L G, Xie Z H. Multi-disciplinary, multi-objective and multi-scale constructal optimizations for heat and mass transfer processes performed in Naval University of Engineering, a review. Int J Heat Mass Transfer, 2017, 115: 86-98

193 Errera M R. Constructal law in light of philosophy of science. Proc Romanian Academy Ser A-Math Phys Tech Sci Inform Sci, 2018, 18(Special Issue): $111-116$

194 Chen L G, Xiao Q H, Feng H J. Constructal optimizations for heat and mass transfers based on the entransy dissipation extremum principle, performed at the Naval University of Engineering: A Review. Entropy, 2018, 20: 74

195 Wei S H, Chen L G, Xie Z H. Constructal heat conduction optimization: Progresses with entransy dissipation rate minimization. Thermal Sci Eng Prog, 2018, 7: 155-163

196 Miguel A F, Rocha L A O. Tree-Shaped Fluid Flow and Heat Transfer. New York: Springer, 2018

197 Bejan A. Constructal law, twenty years after. Proc Romanian Academy Ser A-Math Phys Tech Sci Inform Sci, 2018, 18(Special Issue): 309-311

198 Razera A L, Errera M R, dos Santos E D, et al. Constructal network of scientific publications, coauthorship and citations. Proc Romanian Academy Ser A-Math Phys Tech Sci Inform Sci, 2018, 18(Special Issue): 105-110 
199 Chen L G, Feng H J, Xie Z H, et al. Progress of constructal theory in China over the past decade. Int J Heat Mass Transfer, 2019, 130: 393-419

200 Bejan A. Freedom and Evolution: Hierarchy in Nature, Society and Science. Basel: Springer, 2020

201 Chen L G, Yang A B, Feng H J, et al. Constructal design progress for eight types of heat sinks. Sci China Tech Sci, 2020, 63: 879-911

202 Zhou S B, Chen L G, Sun F R. Constructal optimization for solid-gas reactors based on triangular element (in Chinese). Sci China Ser E: Tech Sci, 2008, 8: 764-772 [周圣兵, 陈林根, 孙丰瑞. 基于三角形单元体的气一固反应器构形优化. 中国科学 $\mathrm{E}$ 辑: 技术科学, 2008, 38: 764-772]

203 Feng H J, Chen L G, Xie Z H, et al. "Disc-point" heat and mass transfer constructal optimization for solid-gas reactors based on entropy generation minimization. Energy, 2015, 83: 431-437

204 Feng H J, Chen L G, Xie Z H, et al. Constructal entransy dissipation rate minimization for solid-gas reactors with heat and mass transfer in a disc-shaped body. Int J Heat Mass Transfer, 2015, 89: 24-32

205 Bejan A. Constructal thermodynamics. Int J Heat Tech, 2016, 34: S1-S8

$206 \mathrm{Wu}$ Z X, Feng H J, Chen L G, et al. Constructal thermodynamic optimization for ocean thermal energy conversion system with dual-pressure organic Rankine cycle. Energy Convers Manage, 2020, 210: 112727 


\title{
Progress in thermodynamic analyses and optimizations for key component units in sea-based fuel synthesis systems
}

\author{
CHEN LinGen ${ }^{1,2}$, WANG Chao ${ }^{3}$, ZHANG Lei ${ }^{4} \&$ XIA ShaoJun ${ }^{3}$ \\ ${ }^{1}$ Institute of Thermal Science and Power Engineering, Wuhan Institute of Technology, Wuhan 430205, China; \\ ${ }^{2}$ School of Mechanical \& Electrical Engineering, Wuhan Institute of Technology, Wuhan 430205, China; \\ ${ }^{3}$ College of Power Engineering, Naval University of Engineering, Wuhan 430033, China; \\ ${ }^{4}$ The 91388 Troops, Zhanjiang 524022, China
}

This paper provides a brief introduction to the finite-time thermodynamic studies performed for chemical reaction processes. The research progress in the thermodynamic analyses and optimizations of the key component units in the two subsystems of the seabased fuel synthesis system are described. This paper describes the component units in the carbon- and hydrogen-capture subsystems (i.e., the modules on the electrochemical acidification of seawater, extraction of $\mathrm{CO}_{2}$ in the acidic seawater, and production of hydrogen). This paper also describes the component units in the catalytic synthesis subsystems, which include the reverse water gas shift unit reactor and the Fischer-Tropsch synthesis unit reactor in the fuel synthesis technological pathway of long-chain hydrocarbon cracking; the subsystem also includes the $\mathrm{CO}_{2}$ hydrogenation of light olefins unit reactor and the olefins oligomerization unit reactor in the fuel synthesis technological pathway of short-chain hydrocarbon polymerization. Modeling and performance optimizations were performed, and the thermal design and optimization for the key component units of the sea-based fuel synthesis system were explored by combining the thermodynamics, heat transfer, fluid dynamics, chemical reaction kinetics, optimal control theory, and multiple-objective optimization methods. From shallow to deep, a one-dimensional plug-flow reactor model (with a completely temperature-controlled heat reservoir) and a two-dimensional pseudo-homogeneous reactor model (with a real heat reservoir) were established; high-temperature helium was employed as the heat carrier. From the reversible to irreversible models, the classical equilibrium thermodynamic model and finite-time thermodynamic model that considers various irreversible factors were established. From a single objective to multiple-objective optimizations, the optimizations were performed for single objectives, including the minimum entropy generation rate and minimum specific entropy generation rate (i.e., the entropy generation rate averaged by the production rate of target products), and multiple-objectives by comprehensively considering the production rate of the target products' maximization and entropy generation rate minimization. The outlet mean conversion rate maximization and maximum radial temperature difference minimization were performed. Some results with important theoretical significances and application values were obtained, which can provide the scientific bases and theoretical guidelines for the design and optimization for the sea-based fuel synthesis systems. One of the important developmental trends was the constructal thermodynamic optimization for the two subsystems and the integration of the full sea-based fuel synthesis system with the component units.

finite time thermodynamics, generalized thermodynamic optimization, optimal control, sea-based fuel synthesis system, chemical reaction process, entropy generation rate, production rate, multi-objective optimization

doi: 10.1360/SST-2020-0067 